\author{
Universidade de São Paulo \\ Instituto de Física
}

\title{
Azopolímeros e Aplicações em Efeitos de Orientação de Cristais Líquidos
}

\author{
Bruno Silveira de Lima Honda
}

Tese de doutorado apresentada ao Instituto de Física para a obtenção do título de Doutor em Ciências

Banca Examinadora:

Proff. $^{\mathrm{a}}$. Dr ${ }^{\mathrm{a}}$. Elisabeth Andreoli de Oliveira (orientadora) - IFUSP

Prof. Dr. Jean Jacques Bonvent - UMC

Prof ${ }^{\mathrm{a}}$. Dr ${ }^{\mathrm{a}}$. Karin do Amaral Riske - UNIFESP

Prof $^{\mathrm{a}}$. Dr ${ }^{\mathrm{a}}$. Márcia Carvalho de Abreu Fantini - IFUSP

Prof. Dr. Mikiya Muramatsu - IFUSP

São Paulo 
“- But what good did it do?” asked the raven.

“- Good?” asked the King of All Night’s Dreaming.

“- Yes”, said the raven.

"- The monk was to die, and he died. The fox who tried to help him failed to help him. The onmyoji lost everything. What good did it do, your granting her wish?”

The king stared away at the horizon. In his eyes a single star glinted and was gone.

“- Lessons were learned”, said the pale king.

“- Events occurred as it was proper for them to do. I do not perceive that my attention was wasted".

Neil Gaiman - extraído do livro “Dream Hunters”

À minha esposa Maria Cristina, por seu companheirismo, e à minha filha Estela, por me ensinar... 


\section{Agradecimentos}

À prof ${ }^{a}$ Elisabeth Andreoli de Oliveira, pela orientação, paciência e incentivo, acima de tudo;

Ao prof. Ivan H. Bechtold, pela oportunidade de trabalho em conjunto, e pela amizade nesses anos;

Ao professores do Grupo de Fluidos Complexos do IFUSP, prof. Antônio M. Figueiredo Neto e prof ${ }^{a}$ Suhaila M Shibli, por todos esses anos de aprendizado;

Aos colegas de grupo, que são muitos, e que sem o apoio nada disso teria sido possível. São muitos nomes, e muitos feitos, só tenho a agradecer pela amizade que construí aqui dentro;

Ao prof. Dr. Antônio Domingues dos Santos do Laboratório de Materiais Magnéticos do IFUSP, pela presteza e assistência, e aos seus alunos Mariana Pojar e Gilderlon Fernandes, pela ajuda com medidas de SNOM e AFM;

Aos professores, amigos, funcionários e todos que de alguma forma fazem parte do meu dia-a-dia do IFUSP, por mais de uma década de amizade e companheirismo;

À minha família, por me suportar mesmo nos momentos mais insuportáveis, em especial aos meus pais pelo suporte e conforto;

À CAPES, CNPq, FAPESP, IMMP e CPG-IFUSP pelo auxílio financeiro;

E a todos que torceram por mim, meu muito obrigado, keep rockin'! 


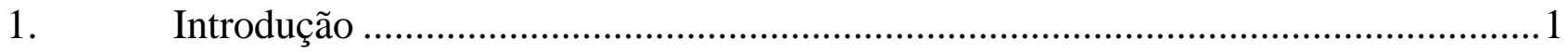

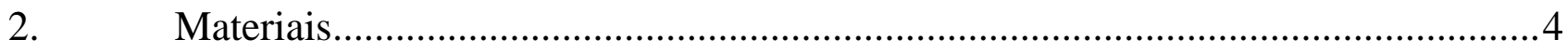

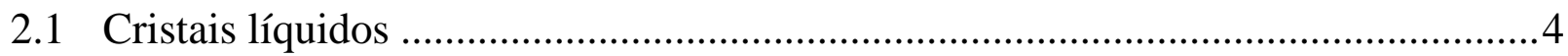

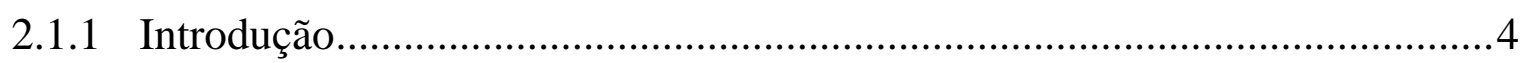

2.1.2 Mesofases e caracterização por microscopia de luz polarizada .......................5

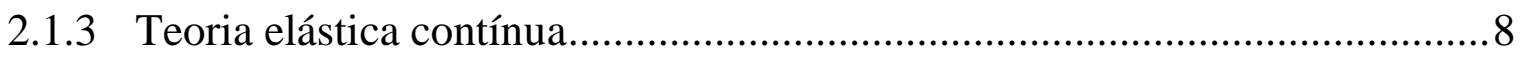

2.1.4 Efeitos de superfície no alinhamento de cristais líquidos .............................10

2.1.5 Determinação da intensidade de ancoramento azimutal ................................14

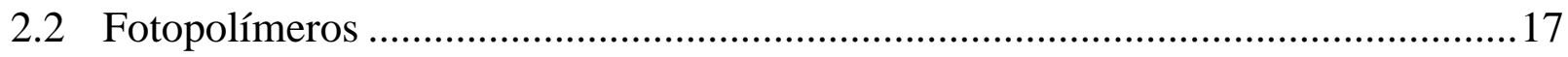

2.2.1 Introdução..............................................................................................17

2.2.2 Considerações teóricas: dinâmica de fotoalinhamento ...................................20

2.2.3 Grades de relevo ......................................................................................22

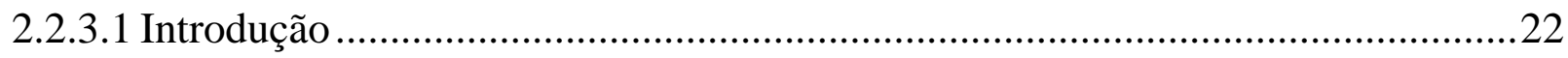

2.2.3.2 Ancoramento devido a efeitos topográficos .........................................................24

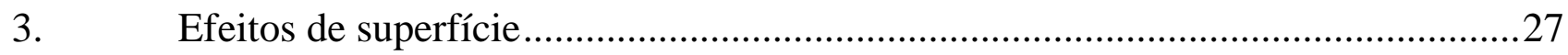

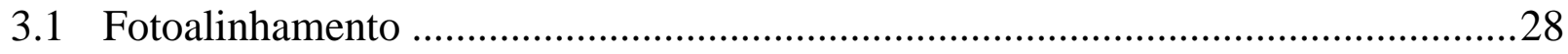

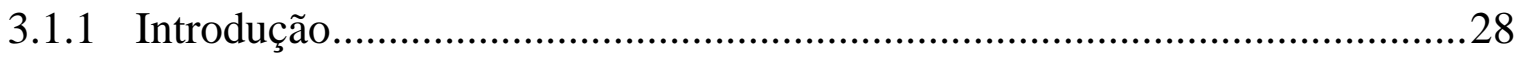

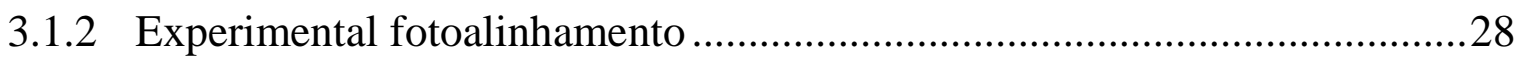

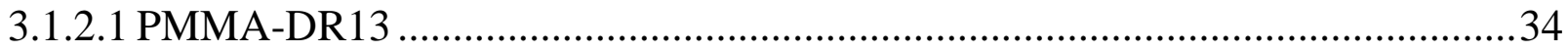

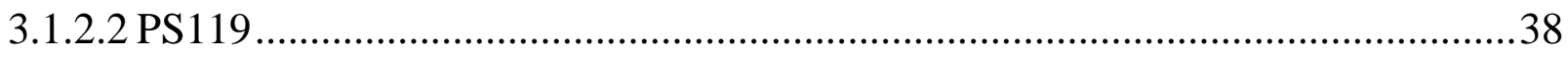

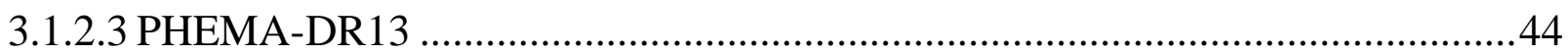

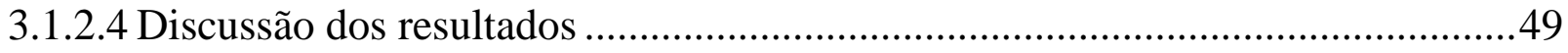

3.1.3 Determinação da intensidade de ancoramento de fotoalinhamento ..............52

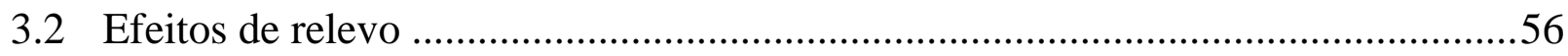

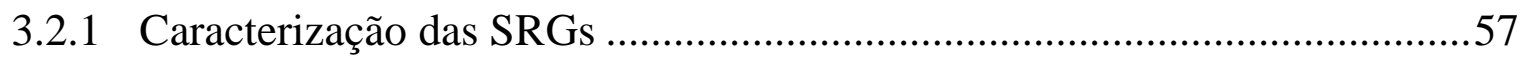

3.2.2 Estudo da topologia da superfície ..............................................................58

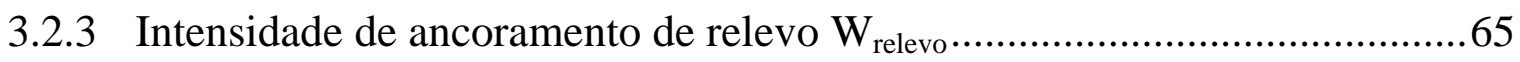

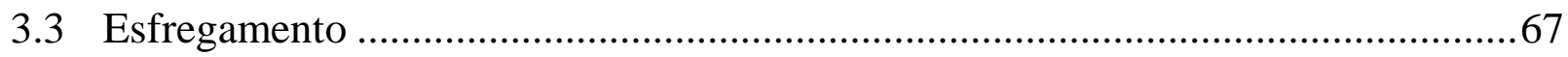




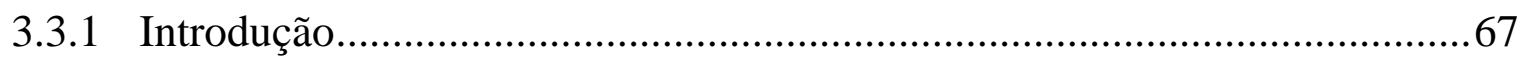

3.3.2 Procedimento experimental.......................................................................68

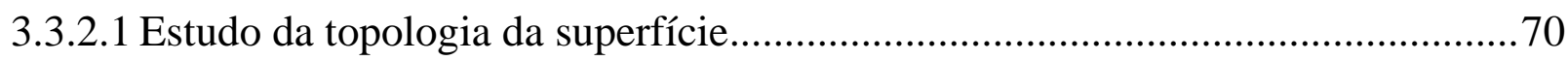

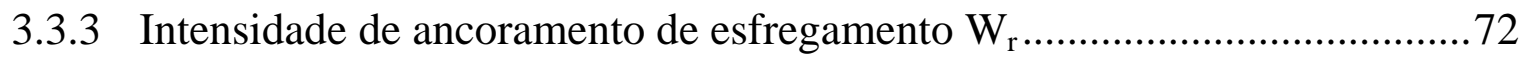

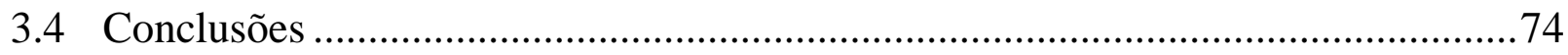

4. Competição de orientação: substrato com microtextura..........................................76

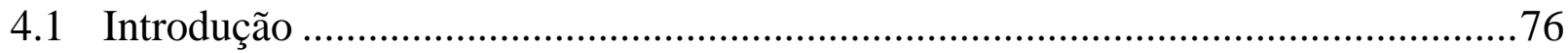

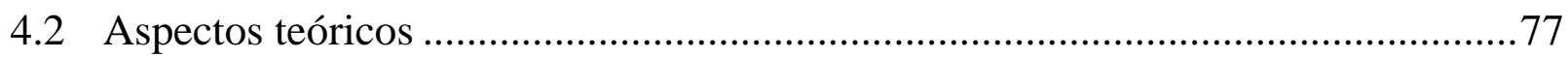

4.3 Resultados experimentais: Transições de orientação.................................................80

4.3.1 Caracterização ótica e morfológica (SNOM).................................................80

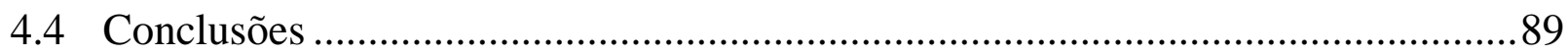

5. $\quad$ Competição de orientação: topografia versus fotoalinhamento................................91

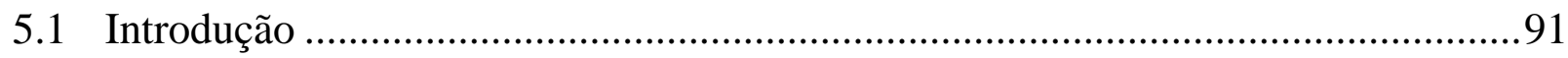

5.2 Considerações teóricas............................................................................................92

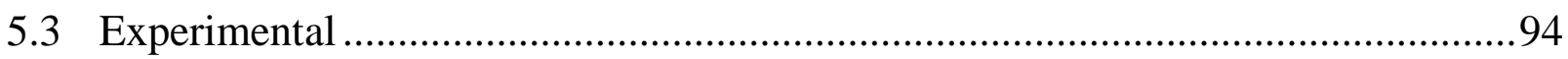

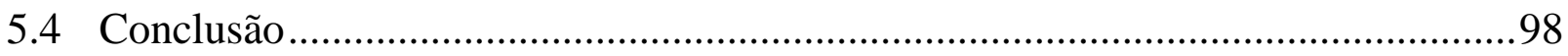

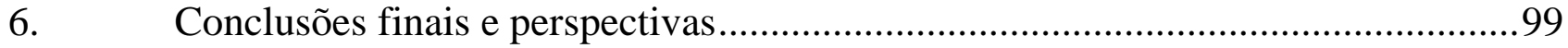

7. Apêndice A - Modelo para descrição da birref. induzida em fotopolímeros.........102

8. $\quad$ Apêndice B - Publicação ...................................................................................107

9. Apêndice C - Modelo para a formação de SRGs em materiais azocorantes.........114

10. Apêndice D - Modelo de Berrreman ..................................................................117

11. Apêndice E: Modos de operação de um microscópio de Força Atômica...............119

12. Apêndice F: Nanolitografia em azopolímeros ..................................................129

13. Referências.......................................................................................................... 135 


\section{Glossário}

5CB:4-pentil-4'-cianobifenil;

AFM: Atomic Force Microscopy;

Ar: Argônio (gás);

Aldrich (Sigma Aldrich Co.) - empresa comercial;

azo dyes: azocorantes, moléculas que à partir da absorção de um fóton podem mudar de conformação trans-cis;

birrefringência: anisotropia ótica, caracterizada por dois índices de refração distintos, que dependem da direção em que a medida é realizada (chamados índices de refração ordinário e extra-ordinário);

Cantilever: conjunto diapasão+ponta em um AFM;

Casting: técnica de deposição de filmes;

Chopper: modulador mecânico de freqüências;

CL (CLs): Cristais Líquidos;

Coherent (Coherent, Inc.) - empresa comercial;

Digital Instruments (Veeco)- empresa comercial;

Diretor (n): vetor unitário que caracteriza a direção média de alinhamento das moléculas do CL ( $\boldsymbol{n}$ e $-\boldsymbol{n}$ são indistinguíveis);

Display: monitor, mostrador de cristal líquido; 
Eixo fácil: direção preferencial de alinhamento das moléculas de cristal líquido em uma superfície. Essa direção pode ser imposta por tratamentos de superfície, mecânicos ou químicos;

Energia de ancoramento, intensidade de ancoramento: valor cuja intensidade diz o quão forte se dá a orientação das moléculas do CL na direção do eixo fácil; espelho de Loyd - aparato para se realizar o fenômeno de interferência utilizando-se um feixe monocromático simples de luz;

Feedback - corrente de retroalimentação;

full resolution - resolução máxima;

GPIB: General Purpose Interface Bus;

$K_{11}, K_{22}$ e $K_{33}$ : constantes elásticas relacionada às deformações de splay, twist e bend, respectivamente;

LCD: Liquid Crystal Display;

Lock-in: amplificador de sinais;

Merck (Merck \& Co., Inc., no Brasil Merck Sharp \& Dohme)- empresa comercial;

MOLP: microscopia ótica de luz polarizada;

Mylar: espaçador;

Nanoscope III - AFM comercial;

$\mathrm{Nd}: \mathrm{YVO}_{4}$ : cristal utilizado no laser de diodo semicondutor (ortovanadato de ítrio dopado com neodímio);

Nemático, fase nemática: mesofase exibida por materiais constituídos por moléculas (ou agregados de moléculas) com anisotropia de forma. Essa mesofase é caracterizada por apresentar ordem orientacional de longo alcance; 
PHEMA-DR13: poli(metacrilato de 2-hidroxietila-co-4'(metacriloiloxi-etil,etilamino)-4nitroazobenzeno);

PMMA-DR13: polimetilmetacrilato;

PVA: Poli (álcool vinílico);

Quimis - empresa comercial;

Rms: root mean square;

Rubbing: método mecânico de tratamento de superfície (esfregamento);

sensivity : parâmetro de operação do amplificador de sinais;

Set point: variável de operação do microscópio um AFM;

SHG - Second Harmonic Generation;

Shutter: obturador mecânico;

$\mathrm{SiO}_{\mathrm{x}}$ : óxido de silício;

Slim: refere-se a monitores finos, sem tubo catódico;

SNOM: Scan Near-field Optical Microscope;

Software: programa, executável;

Spécimen - amostra;

Spin coating: técnica de deposição de filmes;

Splay, Twist, Bend: constantes elásticas na teoria elástica contínua;

SPM: Scanning Probe Microscopy;

SRG (SRGs): Surface Relief Grating;

Tapping Mode: modo de operação de um microscópio de força atômica;

time constant: parâmetro de operação do amplificador de sinais;

Trans-cis/ cis-trans: transição/relaxação conformacional do grupo azobenzeno; 
Twist: distorção no alinhamento das moléculas de cristal líquido que correspondem à uma torção na direção de orientação, resultante das condições de contorno impostas pelas superfícies ou por efeitos de competição de alinhamento impostas pela superfície de contorno e campos externos;

VERDI, INNOVA :modelos dos equipamentos laser utilizados (Coherent)

Z-Scan - técnica experimental; 


\section{$\underline{\text { Relação de figuras }}$}

Figura 2.1: Representação de um cristal líquido na fase nemática: moléculas alongadas alinhadas numa direção preferencial, embora sem nenhum ordenamento posicional.

Figura 2.2: Representação molecular do cristal líquido termotrópico 5CB.

Figura 2.3: Representação visual para as três constantes elásticas, e suas respectivas deformações.

Figura 2.4: Tipos de ancoramentos possíveis num substrato tratado com diferentes técnicas.

Figura 2.5: Direções do diretor e do eixo fácil na superfície de contorno.

Figura 2.6: Visualização de uma cela híbrida na configuração de twist (a) vista em perspectiva e (b) vista lateral.

Figura 2.7: (a) molécula de PMMA-DR13 e (b) seu espectro de absorção de luz na região visível.

Figura 2.8: Representação das transições entre os estados cis e trans dos azocorantes.

Figura 2.9: Representação de um perfil topográfico senoidal com as moléculas alongadas se alinhando na direção dos canais.

Figura 2.10: Representação bidimensional do relevo senoidal (período p e amplitude $\boldsymbol{A}$ ) da superfície tratada. 
Figura 3.1: (a) arranjo experimental utilizado para o processo de fotoalinhamento, (b) porta-amostra posicionado sobre um goniômetro graduado.

Figura 3.2: Curva típica de transmitância em função do tempo de irradiação, mostrando a excitação e a relaxação para um filme de PMMA-DR13 com 50\% em massa de corante, excitado com intensidade $\mathrm{I}=40,0 \mathrm{~mW} / \mathrm{cm}^{2}$. Após atingir um limite de saturação, o laser de excitação foi desligado ( 300 s).

Figura 3.3: (a) fotografia com escala do filme de PMMA depositado via spin coating sobre uma lâmina de vidro, e (b) representação da molécula de PMMA-DR13.

Figura 3.4: Comportamento do processo de fotoalinhamento e da relaxação (aumento da birrefringência induzida) para o filme de PMMA-DR13 com 50\% de concentração de cromóforos (em massa), para diferentes intensidades de luz incidente. Ao se atingir a saturação, o laser de excitação é desligado e observa-se a relaxação da birrefringência induzida.

Figura 3.5: Comportamento do processo de fotoalinhamento (aumento da birrefringência induzida) para o filme de PMMA-DR13, com ajuste bi-exponencial mostrando os tempos característicos do processo.

Figura 3.6: Comportamento do processo de relaxação da birrefringência induzida para o filme de PMMA-DR13, com ajuste bi-exponencial mostrando os tempos característicos do processo.

Figura 3.7 Fotografia com escala do filme de PS119 depositado via casting sob uma lâmina de vidro. 
Figura 3.8: Curva típica de transmitância em função do tempo de irradiação, mostrando a excitação e a relaxação. Esta curva é para um filme de PS119, excitado com intensidade I $=170,0 \mathrm{~mW} / \mathrm{cm}^{2}$.

Figura 3.9: Comportamento do processo de fotoalinhamento e relaxação da birrefringência induzida para o filme de PS119, para diferentes intensidades de luz incidente.

Figura 3.10: Comportamento do processo de fotoalinhamento e relaxação da birrefringência induzida para o filme de PS119, para diferentes intensidades de luz incidente.

Figura 3.11: Comportamento do processo de fotoalinhamento e relaxação da birrefringência induzida para o filme de PS119, para diferentes intensidades de luz incidente - em escala, a birrefringência remanescente para potências baixas é praticamente nula em relação a potências elevadas.

Figura 3.12: Comportamento do processo de fotoalinhamento para o filme de PS119, com ajuste bi-exponencial mostrando os tempos característicos do processo.

Figura 3.13: Comportamento do processo de fotoalinhamento (decréscimo da birrefringência induzida) para o filme de PS119, com ajuste bi-exponencial mostrando os tempos característicos do processo.

Figura 3.14: (a) fotografia com escala do filme de PHEMA-DR13 depositado via casting sobre uma lâmina de vidro, e (b) representação da molécula de PHEMA-DR13.

Figura 3.15: Comportamento de fotoalinhamento em função da potência incidente para o PHEMA-DR13 com 15\% de concentração em massa. 
Figura 3.16: Comportamento do processo de fotoalinhamento e relaxação da birrefringência induzida para o filme de PHEMA-DR13 com 15\% de cromóforos em massa, com ajuste bi-exponencial mostrando os tempos característicos do processo.

Figura 3.17: Comportamento do processo de fotoalinhamento e relaxação da birrefringência induzida para o filme de PHEMA-DR13 com 15\% de cromóforos em massa, com ajuste bi-exponencial mostrando os tempos característicos do processo.

Figura 3.18 - Visualização do processo de fabricação de uma cela híbrida (a) vista em perspectiva e (b) vista lateral - a cela é fixada de tal forma que a distância $\boldsymbol{d}$ é a própria espessura do espaçador.

Figura 3.19: Valores de ângulo de twist para a configuração de cela híbrida usando PVA esfregado e PHEMA-DR13 tratado com fotoalinhamento para três concentrações de cromóforos.

Figura 3.20: Valores da intensidade de energia de ancoramento devido ao fotoalinhamento em função da energia de luz incidente para o PHEMA-DR13 para as três concentrações de cromóforos.

Figura 3.21: Esquema da montagem experimental usada para a formação de SRGs através de interferência de luz em um fotopolímero.

Figura 3.22: Curva típica da formação de SGR através do aumento da intensidade no primeiro máximo de difração para o PMMA-DR13.

Figura 3.23: Imagem topográfica obtida pela técnica de AFM para o PHEMA-DR13 com concentração de 15\% com 5 min. de exposição. 
Figura 3.24 Medida de AFM para a concentração de 15\% com 5 min. de exposição: perfil em 2-D; o valor de profundidade média encontrado para esta amostra foi de $18,50(0,56) \mathrm{nm}$.

Figura 3.25: Imagem topográfica medida por AFM para a concentração de 15\% com 2 min. de exposição.

Figura 3.26: Medida de AFM para a concentração de 15\% com 2 min. de exposição: perfil em 2-D; a profundidade média obtida foi de 29,86(37) $\mathrm{nm}$.

Figura 3.27: Imagem de pequenos defeitos encontrados no filme, onde inicialmente deveria haver apenas SRGs gravadas.

Figura 3.28: Valores calculados do modelo de Berreman da intensidade de energia de ancoramento devido às SRGs em função da profundidade das mesmas - a linha tracejada é meramente um guia para os olhos.

Figura 3.29: Esquema experimental da montagem utilizada para a realização de esfregamento no material (a) vista em perspectiva, e (b) vista lateral.

Figura 3.30: Imagem topográfica obtida pela técnica de AFM para o PHEMA-DR13 tratado através do esfregamento da superfície para uma amostra com $28 \%$ de concentração esfregada uma vez (a) e (b), duas vezes (c) e com esfregamento extremo (d).

Figura 3.31: Intensidade de energia de ancoramento obtida através do método de cela híbrida para processo de esfregamento para o PHEMA-DR13 - a linha tracejada serve apenas de guia para os olhos. 
Figura 4.1. Desenho esquemático da textura superficial investigada teoricamente.

Figura 4.2: Estados orientacionais esperados para a amostra de cristal líquido. $\phi_{0}=0 \rightarrow$ Estado I e $\phi_{0}=\pi / 2 \rightarrow$ Estado II.

Figura 4.3: Desenho esquemático do SNOM.

Figura 4.4: Imagem ótica de uma textura com período de $15 \mu \mathrm{m}$, as linhas desenhadas indicam as direções de alinhamento dos cromóforos nas linhas individuais.

Figura 4.5: Imagens obtidas com o SNOM para período de 3,0 $\mu m$. (a) topográfica em 3D e (b) ótica.

Figura 4.6: Imagens obtidas com o SNOM para período de 1,6 $\mu \mathrm{m}$. (a) topográfica e (b) ótica.

Figura 4.7 Imagens obtidas com o SNOM para período de 0,6 $\mu \mathrm{m}$. (a) topográfica e (b) óptica.

Figura 4.8: Imagem ótica de uma textura com $\alpha=+60^{\circ}$ e $-60^{\circ}$ e período de $15 \mu \mathrm{m}$.

Figura 4.9: Imagem ótica na interface do alinhamento do fundo e de uma textura com $\alpha$ $=+60^{\circ}$ e $-60^{\circ}$ e com período de 0,6 $\mu \mathrm{m}$. A primeira linha mostra apenas o filme de azopolímero, e a segunda linha mostra a cela com cristal líquido. As colunas B, C e D representam diferentes posições relativas com a direção do polarizador e analisador.

Figura 4.10: Imagem ótica na interface do alinhamento do fundo e de uma textura com $\alpha$ $=+60^{\circ}$ e $-60^{\circ} \quad$ e com período de $1,0 \mu \mathrm{m}$. Na primeira linha apenas do filme e na 
segunda linha da cela com cristal líquido. As colunas B e D representam diferentes posições relativas com a direção do polarizador e analisador.

Figura 4.11: Dados experimentais da transição orientacional no plano do substrato em função do período da textura. A linha contínua representa uma simulação teórica.

Figura 5.1: Representação dos efeitos de superfícies gravados em duas direções distintas (a) vista em perspectiva, e (b) vista por cima.

Figura 5.2: Ângulo resultante mostrando o alinhamento das moléculas de CL quando em contato com uma superfície com dois tratamentos de superfície distintos (em duas direções).

Figura 5.3 - Ajustes obtidos em função dos dados obtidos experimentalmente para as concentrações de 15\% 28\% e 34\% de cromóforos (em massa) para o PHEMA-DR13.

Figura C.1: Ilustração do efeito de interferência ótica obtida pela interferência de dois feixes incidentes.

Figura C2: (a) polarizações do tipo $s$ resultam em uma força resultante nula, enquanto (b) para qualquer outra configuração sempre há uma componente da força na direção $x$;

Figura E.1 - Esquema simplificado para a técnica de AFM.

Figura E.2 - Forças entre ponta e amostra para as a técnicas distintas de AFM.

Figura E.3 - Esquema para a técnica de Tapping Mode.

Figura E.4: Fotografia do equipamento de AFM Nanoscope III utilizado. 
Figura F.1 - Calibração da força necessária para a gravação de canais no polímero.

Figura F.2: Imagem por contato intermitente a $45^{\circ}$ da varredura de gravação dos canais mostrando o efeito de nanolitografia.

Figura F.3: Medida da distância para dez períodos fornece o valor médio de 224,6nm para um período.

Figura F4: Distância vertical (altura) dos canais gravados. 


\section{Abstract}

In this work we performed a study of the orientacional effect of the liquid crystals molecules in substrates coated with azopolymers films. We studied the photoalignment induced to liquid crystals molecules to determine the behavior of the magnitude of anchoring energy as a function of incident energy and azodyes concentration in the polymer. Then we performed a competition study of the competition of photoalignment effect by recording a microtexture pattern on the azopolymer surface, with two directions of alignment. In this work, we also introduced a theoretical model to explain the orientacional transitions observed as we changed the period of the patterned microtexture. Another technique utilized was the "Surface Relief Grating” recording, by using polarized light with enough power and creating an interference pattern in the azopolymer surface, we were able to create a topological structure in the surface. The main objective of this work was supposed to investigate the competition between these two photoinduced effects, when one is caused by a photoalignment of the polymer chains, and the other is due to topological issues. We concluded that it was not possible to have competition between these two effects, mainly because the magnitude of the anchoring energy induced by SRG was found to be a hundred times smaller than the photoinduced one. As an alternative to this approach, we studied, then, the competition between the rubbing process and the photoalignment effect, as the magnitude of these two effects was found to be compatible. 


\section{Resumo}

Neste trabalho foi feito o estudo do efeito de orientação de moléculas de cristal líquido (5CB) em superfícies recobertas com fotopolímeros. Estudamos o processo de alinhamento fotoinduzido às moléculas de cristal líquido, de forma a caracterizar a intensidade de energia de ancoramento em função da energia de luz incidente e da concentração de cromóforos nos fotopolímeros. Foi realizado um estudo do efeito de competição entre duas direções distintas induzidas por fotoalinhamento, através da gravação de microtexturas periódicas. Neste trabalho, foi utilizado um modelo teórico para explicar como se dá a transição orientacional conforme se muda o período da textura periódica gravada. Foi feito também a gravação de grades de relevo nesses materiais, utilizando luz polarizada com alta potência incidente através da técnica de interferência de luz. O objetivo principal deste trabalho seria uma tentativa de se realizar o efeito de competição de alinhamento entre os processos fotoinduzidos: um efeito de fotoalinhamento, levando em conta a orientação das cadeias poliméricas, e outro de relevo, levando em conta a deformação da superfície tratada. Um resultado obtido foi a impossibilidade de se realizar este estudo, pois as intensidades de energia de ancoramento induzidas envolvidas diferem entre si de um fator de duas ordens de grandeza, mostrando que a direção de fotoalinhamento sempre acaba prevalecendo. Para contornar este problema, foi estudada a competição de fotoalinhamento com a técnica de rubbing, tendo em vista que as intensidades de energia de ancoramento estudadas eram compatíveis entre si. 


\section{Introdução}

Cristal líquido [P.G. de Gennes, 1993] é um termo bastante difundido na sociedade atual, graças às suas propriedades especiais que permitiram sua ampla utilização no mercado tecnológico. De fato, desde mostradores de calculadoras, relógios digitais, monitores e televisores slim até cortinas óticas [P. J. Collings et. al., 1997], os cristais líquidos (CLs) estão presentes no cotidiano de grande parte da população mundial. Uma das propriedades mais interessantes dos CLs é a possibilidade de alinhamento de seus constituintes devido a interações com superfícies previamente tratadas [J. Cognard, 1982]. Existem atualmente vários métodos de tratamento de superfície que visam ter controle sobre o alinhamento do CL, entre eles os processos de rubbing (esfregamento) e evaporação oblíqua [B. J. Israelachvili, 1991]. O objetivo principal deste trabalho é o estudo de efeitos de competição de alinhamento em cristais líquidos (CL) quando em contato com dois potenciais de alinhamento distintos induzidos em uma superfície.

Nesse trabalho foram utilizados fotopolímeros contendo grupos azo-corantes que podem ser orientados através de um processo de fotoisomerização quando iluminados com luz linearmente polarizada. A técnica conhecida como fotoisomerização vem sendo aplicada com sucesso em filmes poliméricos dopados com azocorantes, de forma a se conseguir um tratamento de superfície para alinhamento de CL [M. W. Gibbons et al., 1991]. Um estudo preliminar foi realizado nos azopolímeros, de forma a se investigar o processo de fotoisomerização

Essa linha de pesquisa é denominada fotônica, e envolve o estudo de processos envolvendo basicamente a interação da luz (fótons) com a matéria. De fato, além do tratamento de superfície, há a possibilidade da criação de dispositivos de armazenamento de dados através de armazenamento ótico de informações [M. W. 
Gibbons et al., 1995]. Esse campo é extremamente promissor nos dias atuais. Recentemente, um estudo foi publicado onde se relata a gravação de informação ótica em "cinco dimensões" (5-D que no caso significa cinco graus de liberdade - três comprimentos de onda e duas polarizações da fonte luminosa incidente gravam informações nos três eixos cartesianos, diferenciados também por mais duas polarizações da luz) na escala de terabytes $/ \mathrm{cm}^{2}$ em outros materiais [P. Zijlstra et. al., 2009]. Tecnologicamente, a etapa tratamento de superfície para alinhamento de CL é um gargalo no processo de fabricação de displays tipo $L C D$. De fato, o processo mais utilizado é o processo de esfregamento, que por se tratar de um método totalmente mecânico, é muito difícil garantir a reprodutibilidade, pois além de inevitavelmente introduzir impurezas no filme, pode também induzir cargas estáticas na superfície esfregada prejudicando o alinhamento das moléculas do CL [I. H. Bechtold et.al., 2003]. Desta forma, o processo de fotoalinhamento é altamente promissor do ponto de vista tecnológico, é considerado um processo limpo (pois não há contato mecânico com a superfície do filme), além de ser um processo reversível e reprodutível. O processo de fotoalinhamento pode ser utilizado para induzir um alinhamento quando em contato com um material líquido cristalino, e o efeito que se observa é que a interação entre os grupos azocorantes alinhados com as moléculas do CL induz uma orientação ao CL. A direção e intensidade da orientação do CL podem ser controladas através de parâmetros experimentais como: concentração de cromóforos no filme, intensidade e tempo de exposição de luz incidende etc.

Em uma primeira etapa, foi realizado o estudo do efeito de competição de orientação induzida ao CL utilizando um substrato microtexturizado, com padrão de orientação dos cromóforos no plano do filme. O substrato tratado induz uma orientação não homogênea das moléculas do CL, acumulando energia elástica no sistema; a configuração de equilíbrio é definida pela competição entre a energia elástica devida à deformação e a energia de interação com a superfície (caracterizada pela energia de ancoramento $\boldsymbol{f}_{s}$ ). Variando-se o período da textura, pode-se chegar a uma situação em que as moléculas não acompanham mais a orientação imposta, o que acarretaria em 
deformações muito grandes. Neste trabalho foi feita a investigação deste efeito teórica e experimentalmente.

A segunda parte do trabalho consistiu em estudar o efeito de competição de orientação induzida através de interações físico-químicas entre o substrato e as moléculas de CL. Para isso, foram utilizados fotopolímeros onde foi realizado o processo de esfregamento, que induz uma orientação das moléculas paralelamente à direção de esfregamento. Em seguida, os cromóforos presentes no filme são alinhados numa direção oblíqua à direção de esfregamento pelo processo de fotoisomerização, criando deste modo um efeito de competição entre dois potenciais de alinhamento distintos. O parâmetro relevante na orientação induzida por esfregamento é o número de vezes em que esse esfregamento é realizado, e pode ser controlada experimentalmente.

Neste capítulo introduzimos o estudo realizado, juntamente com os objetivos e motivações.

No capítulo 2 será feita uma apresentação dos materiais utilizados neste trabalho, os fotopolímeros e os cristais líquidos, introduzindo as propriedades relevantes de cada um desses materiais.

Os processos de tratamento de superfície em azopolímeros e a orientação induzida ao CL serão descritos no capítulo 3.

No capítulo 4 será apresentado o estudo do efeito de competição de alinhamento com microtexturas, onde diferentes direções de orientação são impostas no plano do substrato, com a mesma intensidade de ancoramento.

O capítulo 5 apresenta o estudo realizado entre efeitos de alinhamento sobrepostos, com direções e intensidades de energia de ancoramento distintos.

O capítulo 6 traz as conclusões finais e perspectivas do trabalho, e finalmente segue a sequência de apêndices, que incluem informações e detalhes que apesar de não serem imprescíndíveis para este trabalho, são bastante relevantes. 


\section{Materiais}

Neste capítulo serão apresentados os materiais utilizados neste trabalho, e será feita uma introdução teórica referente às propriedades relevantes de cada material. Primeiramente será introduzido o conceito de cristal líquido, apresentando suas propriedades básicas e uma descrição da teoria elástica contínua e efeitos de superfície. Serão mostrados também os fundamentos para se determinar a intensidade de ancoramento planar em uma superfície tratada. Em seguida, serão apresentados os materiais poliméricos dopados com azocorantes, conhecidos como fotopolímeros (ou azopolímeros). Será feita então uma descrição do fenômeno de fotoisomerização, que é o efeito que faz com que esses materiais tenham grande interesse tecnológico na área de tratamento de superfície e armazenamento ótico de informações. Por fim, será mostrada uma propriedade muito interessante dos fotopolímeros, que é o processo de gravação de superfícies de relevo (SRG) utilizando-se a técnica de interferência de luz linearmente polarizada.

\subsection{Cristais líquidos}

\subsubsection{Introdução}

Historicamente, foi no ano de 1888 em que o botânico austríaco Friedrich Reinitzer observou [F. Reinitzer, 1888] o que parecia ser uma nova estrutura da matéria. Ao estudar o ponto de fusão da substância chamada benzoato de coresterilo, Reinitzer notou a existência de uma fase intermediária ao aquecer a amostra para provocar uma liquefação do material. Esta fase intermediária era líquida, porém apresentava uma 
aparência turva ou nebulosa, bem distinta do líquido transparente formado a altas temperaturas. Na mesma época, o físico alemão Otto Lehmann observou [O. Lehmann, 1889] que substâncias como oleato de amônio fundiam, e apresentavam um estado intermediário onde o líquido se mostrava birrefringente. Por esta razão se deu o nome cristal líquido a esta fase intermediária entre o sólido cristalino e o líquido isotrópico, e tal classificação se deve a Lehmann, embora Reinitzer seja lembrado como o descobridor desta nova fase da matéria.

Esses materiais que apresentam a fase líquido cristalina possuem uma ordem orientacional de longo alcance em seus componentes, ao mesmo tempo que escoam como fluidos ordinários: estas características fazem com que os cristais líquidos sejam classificados como fluidos complexos. No entanto, o termo mesofase se aplica melhor aos cristais líquidos, pois reflete exatamente o que são: uma fase intermediária entre duas fases conhecidas [P. G. de Gennes, 1993].

As propriedades intrínsecas mais básicas dos materiais líquidos cristalinos são a anisotropia de forma de seus constituintes (moléculas ou agregados), e o fato de esses constituintes possuírem um ordenamento orientacional de longo alcance. Algumas mesofases apresentam ordem posicional de longo alcance ao longo de uma ou duas dimensões. Essas propriedades permitem então sua ampla utilização tecnológica, pois os cristais líquidos são materiais birrefringentes [P. J. Collings, 1997] (dois eixos óticos distintos, que caracterizam dois índices de refração distintos no material: o ordinário e o extraordinário).

\subsubsection{Mesofases e caracterização por microscopia de luz polarizada}

Este trabalho foi realizado exclusivamente com cristais líquidos termotrópicos, que são formados por moléculas anisométricas e cujo parâmetro relevante nas transições de fase é a temperatura (a pressão constante). São materiais bastante estáveis termodinamicamente e reproduzem bem propriedades tal qual a temperatura de transição de fase, e são os tipos mais usados na área tecnológica atualmente. A mesofase mais 
conhecida dos cristais líquidos é a fase nemática, que é caracterizada por uma ordem orientacional de longo alcance. Para este caso, isso significa uma fase onde as moléculas podem ser representadas por bastões finos e compridos (semelhante a um lápis), e estão em média orientadas em uma direção preferencial, que é representada através de um vetor unitário $\boldsymbol{n}$ (definido como vetor diretor) conforme ilustrado na figura 2.1.

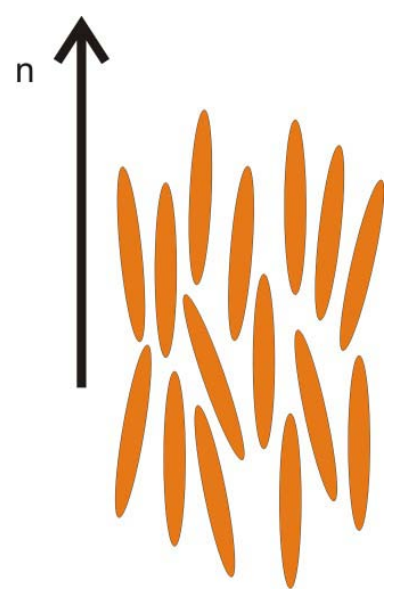

Figura 2.1: Representação de um cristal líquido na fase nemática: moléculas alongadas alinhadas numa direção preferencial, embora sem nenhum ordenamento posicional.

Uma propriedade importante do vetor diretor é a equivalência de $\boldsymbol{n}$ e $-\boldsymbol{n}$, ou seja, existe uma simetria de inversão para este parâmetro. Essa direção de $\boldsymbol{n}$ é completamente arbitrária, e pode ser fixada através de condições de contorno aplicadas, tais quais campos externos (campo elétrico ou magnético) ou tratamentos de superfície. Embora em muitos casos as moléculas não possuam polaridade elétrica, o alinhamento destas moléculas na presença de um campo elétrico ou magnético ocorre devido à anisotropia de susceptibilidade elétrica ou magnética, respectivamente. Neste trabalho foi utilizado o CL já bastante conhecido e estudado na literatura, chamado comercialmente de 5CB (4'n-pentyl-4-cyanobiphenyl) e é fornecido pela empresa Merck [http://www.merck.com/] e que se apresenta na fase nemática à temperatura ambiente. A figura 2.2 mostra a estrutura do 5CB. 


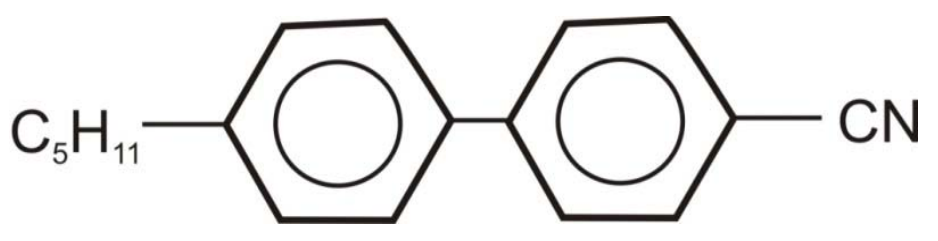

Figura 2.2: Representação molecular do cristal líquido termotrópico 5CB.

Um dos métodos mais utilizados para a observação de estruturas líquido cristalinas é a técnica de microscopia ótica de luz polarizada. Um microscópio ótico de luz polarizada possui um par de polarizadores acoplado ao microscópio ótico, sendo um polarizador situado abaixo da base onde é colocada a amostra, e outro polarizador (denominado analisador) localizado acima da lente objetiva. Quando estes estão cruzados (ou seja, posicionados com um ângulo de $90^{\circ}$ entre si) nenhuma luz é transmitida pelo microscópio a não ser que este feixe de luz passe através de um material anisotrópico colocado entre o polarizador e o analisador. Essas propriedades fazem com que a microscopia de luz polarizada seja um método bastante usado para a identificação das diferentes mesofases líquido cristalinas através da observação das chamadas "texturas".

O termo "textura” designa a imagem de uma fina camada de cristal líquido observada pelas lentes de um microscópio de luz polarizada. As características de várias texturas são causadas pela existência de diferentes tipos de defeitos que podem ser originados por vários fatores, tais como: a variação de temperatura, a aplicação de um campo magnético ou um campo elétrico, tratamento de superfície, entre outros. Neste estudo a amostra de CL se apresenta na fase nemática, e para amostras orientadas uniformemente, observa-se que ao girar a amostra com a superfície tratada entre polarizadores cruzados há a alternância entre uma imagem escura, quando a direção do diretor paralela ao analisador ou polarizador, há a extinção completa da luz e padrões claros, com máxima transmitância de luz, quando a direção de diretor forma um ângulo de $\pi / 4$ em relação ao analisador ou polarizador. Conforme será visto a seguir, esta técnica de observação nos permite obter qual o desvio da direção de alinhamento das moléculas de CL em relação a uma direção previamente imposta como condição inicial 
(essa direção é conhecida como eixo fácil), e desta forma determinar a intensidade com que as moléculas de CL se alinham numa direção imposta.

\subsubsection{Teoria elástica contínua}

Em um cristal líquido nemático as moléculas estão em média alinhadas ao longo de uma direção comum, definida pelo vetor diretor $\boldsymbol{n}$. Porém em condições reais a conformação observada não é uniforme, devido a efeitos de campos externos ou condições de contorno na superfície. Ocorrem então deformações ou distorções no alinhamento das moléculas, ou seja, a direção de $\boldsymbol{n}$ varia de um ponto para outro no volume da amostra. Nas situações mais usuais, as variações de $\boldsymbol{n}$ ocorrem em distâncias maiores que as dimensões moleculares, de modo que podemos considerar o meio como contínuo, sem descontinuidade na função $\boldsymbol{n}=\boldsymbol{n}(\boldsymbol{r})$. Isso significa que se introduzimos uma distorção em uma molécula, esta distorção se propaga a distâncias maiores que as dimensões da molécula. Tipicamente essas distorções se propagam até distâncias da ordem de $1 \mu \mathrm{m}$, e as dimensões moleculares são de $2 \mathrm{~nm}$.

Portanto podemos descrever o meio nemático como um meio contínuo, sem considerar os detalhes da estrutura na escala microscópica (molecular). Para construir uma teoria elástica, deve-se expressar uma densidade de energia livre em termos de $\boldsymbol{n}(\boldsymbol{r})$ e suas derivadas. Para escrevermos $\boldsymbol{n}=\boldsymbol{n}(\boldsymbol{r})$ em função das condições de contorno, definimos $\boldsymbol{L}$ o alcance molecular e $\boldsymbol{a}$ a dimensão molecular. Se $\boldsymbol{L}>>\boldsymbol{a}$, é possível tratar o cristal líquido nemático como um meio contínuo.

Assim, é definida uma energia de distorção por unidade de volume $\boldsymbol{f}_{\boldsymbol{d}}$, que é função das derivadas espaciais de $\boldsymbol{n}(\boldsymbol{r})$, dada por:

$$
f_{d}=f\left(\frac{\partial n_{i}}{\partial r_{i}}\right)
$$

Esta função $\boldsymbol{f}_{\boldsymbol{d}}$ vai a zero se $\nabla \boldsymbol{n}=0$, e pode ser expandida através de uma série de potências de $\nabla \boldsymbol{n}$. As seguintes condições devem ser impostas a $f_{d}$ : 
- $\boldsymbol{f}_{\boldsymbol{d}}$ deve ser uma função par em $\pm \boldsymbol{n}$, pois não devem existir termos para os quais os estados $\boldsymbol{n}$ e $-\boldsymbol{n}$ sejam distintos, uma vez que esses estados são indistinguíveis;

- não podem existir termos lineares em $\boldsymbol{f}_{\boldsymbol{d}}$, pois esses termos mudam se o sistema de coordenadas gira ao redor do diretor, se o diretor é invertido ou se o sistema de coordenadas é invertido;

- termos em $\boldsymbol{f}_{\boldsymbol{d}}$ que são da forma $\nabla . \boldsymbol{u}$ ( $\boldsymbol{u}$ um campo vetorial arbitrário) podem ser descartados. Essa é uma conseqüência da identidade:

$$
\int(\nabla \bullet \vec{u}) d \vec{r} \equiv \int d \vec{\sigma} \bullet \vec{u}
$$

onde o termo $\int d \sigma$ é uma integral de superfície na superfície do nemático e $d \sigma$ é normal à superfície em cada ponto. Essa identidade mostra que tais termos descrevem somente contribuições às energias de superfície, e para a discussão sobre propriedades no volume esses termos podem ser desconsiderados.

Levando em conta essas considerações [P. G. de Gennes, 1993], a densidade de energia de distorção pode ser escrita na forma:

$$
F=\frac{1}{2} \int_{\text {volume }}\left\{K_{11}(\vec{\nabla} \cdot \hat{n})^{2}+K_{22}[\hat{n} \cdot(\vec{\nabla} \times \hat{n})]^{2}+K_{33}[\hat{n} \times(\vec{\nabla} \times \hat{n})]^{2}\right\} \mathrm{dV}
$$

onde $K_{11}, K_{22}$ e $K_{33}$ são as constantes elásticas relacionadas às deformações de splay, twist e bend, respectivamente, mostradas na figura 2.3. As constantes elásticas $\boldsymbol{K}_{\boldsymbol{i i}}$ são positivas e tem magnitude $\boldsymbol{K}_{\boldsymbol{i i}} \approx \boldsymbol{U} / \boldsymbol{a}$, onde $\boldsymbol{U}$ é a energia de interação molecular. 


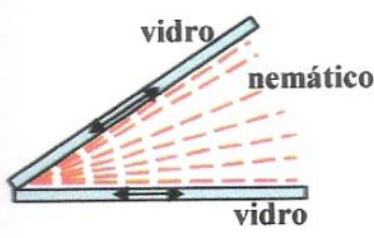

"Splay"

$\vec{\nabla} \cdot \hat{n} \neq 0$

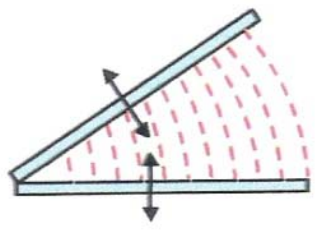

"Bend"

$(\vec{\nabla} \times \hat{n}) \perp \hat{n}$

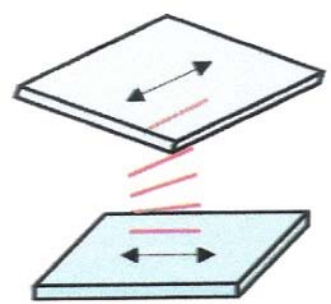

"Twist"
$(\vec{\nabla} \times \hat{n}) / / \hat{n}$

Figura 2.3: Representação visual para as três constantes elásticas, e suas respectivas deformações.

Para a determinação da configuração do diretor nos estados de equilíbrio, deve-se proceder a minimização de $\boldsymbol{f}_{\boldsymbol{d}}$ considerando as condições de contorno apropriadas. Essa minimização resulta em equações do tipo Euler-Lagrange [G. Arfken, 1985], em geral acopladas e às vezes não-lineares, e são de difícil solução. Nestes casos, uma das aproximações que podem ser realizadas é considerar que todas as constantes elásticas são iguais, o que simplifica muito a resolução das equações diferenciais envolvidas. Essa aproximação, conhecida como aproximação de constante única, embora não ofereça uma descrição exata, permite uma boa descrição qualitativa. Desta forma, tomando-se $\boldsymbol{K}_{\mathbf{1 1}}=$ $\boldsymbol{K}_{22}=\boldsymbol{K}_{33}=\boldsymbol{K}$, a equação é escrita como:

$$
f_{d}=\frac{1}{2} K\left[(\nabla \bullet \vec{n})^{2}+(\nabla \times \vec{n})^{2}\right]
$$

\subsubsection{Efeitos de superfície no alinhamento de cristais líquidos}

Os cristais líquidos são bastante sensíveis em relação às condições de contorno na superfície onde há contato, e esses efeitos de superfície induzem uma configuração à amostra como um todo uma vez que a interação do cristal líquido com a superfície induz uma orientação às moléculas que será propagada para o volume [A. A. Sonin, 1995]. A figura 2.4 mostra uma representação de três tipos básicos de alinhamentos que podem ser induzidos através de tratamento de superfícies de contorno. 


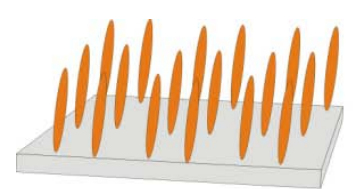

Homeotrópico

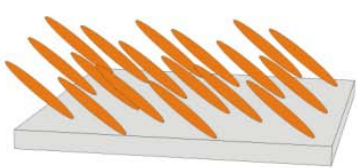

Inclinado uniforme

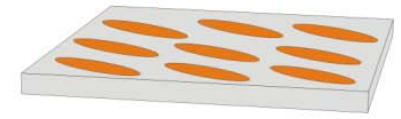

Planar uniforme

Figura 2.4: Tipos de ancoramentos possíveis num substrato tratado com diferentes técnicas.

De acordo com a figura 2.4, pode-se realizar tratamentos de superfície para induzir um ancoramento planar, para o qual as moléculas orientam-se no plano do substrato. Por outro lado, também é possível tratar a superfície de maneira a introduzir um ancoramento homeotrópico, que se dá fora do plano do substrato. A situação entre esses dois extremos é chamada inclinada uniforme onde as moléculas, apesar de se orientarem na direção do plano do substrato, também possuem uma componente fora do plano. Combinando esses três tipos de alinhamento do diretor próximo à superfície, é possível obter diversas configurações do diretor no volume da amostra. Esse efeito de superfície é conhecido como ancoramento, e será mais evidente quanto menor a dimensão do sistema. Existem duas situações possíveis para este ancoramento: quando o ancoramento é forte, o tratamento de superfície faz com que as moléculas fiquem fixas nessa superfície, e a energia de ancoramento pode ser considerada infinita. Quando o ancoramento é fraco, a orientação das moléculas em relação ao eixo da pode ser diferente daquela imposta pelo substrato devido a efeitos de volume. Existem diversos métodos de tratamento de superfícies, e a escolha destes depende principalmente do tipo de ancoramento que se deseja obter.

O método mais utilizado no tratamento de superfície para a construção de displays de CL é a técnica de esfregamento (rubbing), que é um tratamento mecânico obtido através do esfregamento da superfície, e que introduz basicamente um alinhamento planar. Para se conseguir um alinhamento homeotrópico, utiliza-se, por exemplo, a técnica de evaporação oblíqua para a deposição de $\mathrm{SiO}_{\mathrm{x}}$ no substrato [T. Ushida et.al., 1980]. Outras técnicas também se mostram bastante eficazes e reprodutíveis, como a técnica de fotoalinhamento e gravação de grades de relevo. 
Apesar de haver uma boa variedade de técnicas de tratamento de superfície, o alinhamento das moléculas de CL em contato com a superfície é interpretada como sendo um efeito de relevo (onde a própria superfície de contorno induz uma orientação às moléculas de CL), ou um efeito de interações tipo van der Waals do CL com as moléculas alinhadas da superfície do polímero [S. Kumar et al., 2005].

Em geral, as interações entre os cristais líquidos e a superfície são descritas com uma abordagem fenomenológica através de uma densidade de energia livre $f_{s}$, que é composta por uma parte isotrópica $\boldsymbol{f}_{\boldsymbol{s i}}$ (equivalente à tensão superficial nos líquidos isotrópicos) e uma parte anisotrópica (energia de ancoramento) $\boldsymbol{f}_{\mathrm{sa}}$. A energia de ancoramento é caracterizada pela intensidade de ancoramento $W$, e pela direção do eixo fácil $\boldsymbol{n}_{0}$, que corresponde à direção preferencial de orientação induzida na superfície na ausência de campos externos.

A intensidade de ancoramento pode ser separada em duas componentes, uma energia de ancoramento azimutal $\boldsymbol{W}_{\varphi}$ (relacionada ao plano da superfície), e uma componente zenital $\boldsymbol{W}_{\boldsymbol{\theta}}$ (relacionada ao plano normal à superfície). Valores típicos de intensidade de ancoramento $W$ para cristais líquidos termotrópicos são entre $10^{-6}$ e $10^{-4}$ $\mathrm{J} / \mathrm{m}^{2}$, dependendo do tratamento de superfície e do cristal líquido utilizado.

A expressão mais simples para esta densidade de energia foi proposta por Rapini e Papular [A. Rapini e M. Papoular, 1969], e é dada por:

$$
f_{s a}=-\frac{1}{2} W\left(\hat{n} \bullet \hat{n}_{0}\right)^{2}
$$

onde $\boldsymbol{n}_{0}$ é o chamado eixo fácil da superfície.

Em geral, para cristais líquidos termotrópicos a energia de interação das moléculas com o substrato é muito mais forte do que a interação entre as moléculas, e a configuração na região da superfície é fracamente afetada por campos externos. Desta forma as condições de contorno podem ser consideradas fixas e independentes da intensidade do campo externo aplicado. Isso também significa que, quando o campo externo é removido, a configuração imposta pela superfície é dominante e se propaga no volume. 
Quando a intensidade de ancoramento no processo de minimização da energia é considerada infinita, as condições de contorno são sempre satisfeitas e, portanto, basta minimizar a energia de distorção no volume. Entretanto, quando essa energia de ancoramento é finita, deve-se levar em conta a anisotropia da energia livre de superfície. A parte anisotrópica $\boldsymbol{f}_{\boldsymbol{s} a}$ da energia depende do desvio do diretor de uma posição de equilíbrio ao longo do eixo fácil do substrato [L. M. Blinov et. al., 1989]. Os ângulos azimutal e zenital $\boldsymbol{\varphi}$ e $\boldsymbol{\theta}$, respectivamente, descrevem a orientação do diretor em um sistema de coordenadas local com o eixo zenital perpendicular à superfície, conforme a figura 2.5. Os ângulos $\boldsymbol{\varphi}_{\min }$ e $\boldsymbol{\theta}_{\min }$ relacionam-se aos eixos fáceis, isto é, correspondem à direção de orientação que minimizam a energia de distorção.

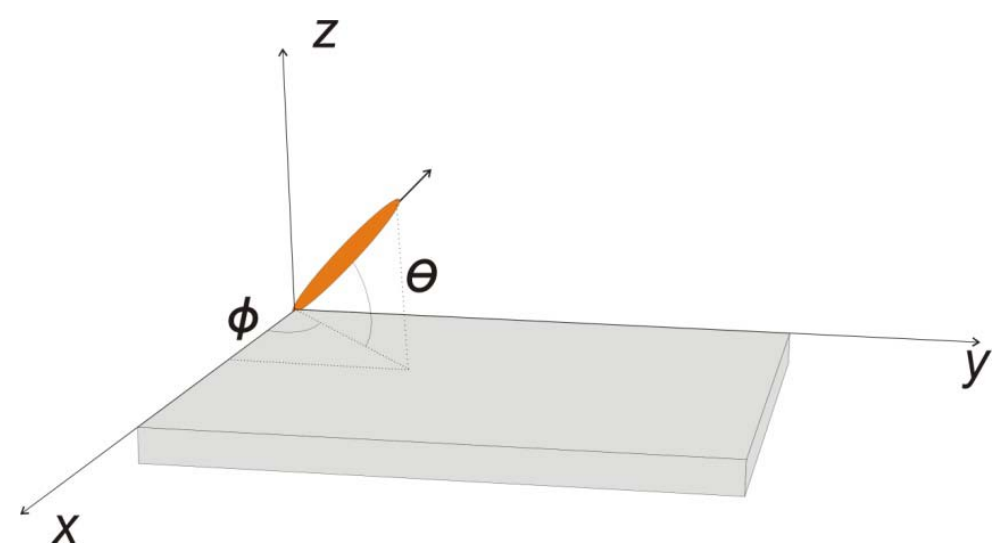

Figura 2.5: Direções do diretor e do eixo fácil na superfície de contorno.

Assim, a parte anisotrópica da energia livre de superfície pode ser escrita como duas funções independentes expandidas em séries de potência pares de $\operatorname{sen}^{2 n}(\boldsymbol{\varphi}, \boldsymbol{\theta})$ :

$$
f_{s a}(\theta)=\frac{1}{2} W_{1}^{\theta} \sin \left(\theta-\theta_{\min }\right)^{2}+\frac{1}{2} \sum_{n=2}^{\infty} W_{n}^{\theta} \sin ^{2 n}\left(\theta-\theta_{\min }\right)
$$

e

$$
f_{s a}(\varphi)=\frac{1}{2} W_{1}^{\varphi} \sin \left(\varphi-\varphi_{\min }\right)^{2}+\frac{1}{2} \sum_{n=2}^{\infty} W_{n}^{\varphi} \sin ^{2 n}\left(\varphi-\varphi_{\min }\right)
$$


onde $\boldsymbol{W} \boldsymbol{\varphi}$ e $\boldsymbol{W}_{\boldsymbol{\theta}}$ são as intensidades de ancoramento azimutal e zenital respectivamente. Em primeira aproximação, usualmente é considerado apenas o primeiro termo de cada equação mostrada anteriormente.

Deste modo, para um cristal líquido nemático em contato com uma superfície, ou sob a ação de algum campo externo, a energia livre é dada [V. P. Vorflusev et al., 1995] pela soma das contribuições no volume e das contribuições de superfície:

$$
\begin{aligned}
& F=\frac{1}{2} \int_{\text {volume }}\left\{K_{11}(\vec{\nabla} \cdot \hat{n})^{2}+K_{22}[\hat{n} \cdot(\vec{\nabla} \times \hat{n})]^{2}+K_{33}[\hat{n} \times(\vec{\nabla} \times \hat{n})]^{2}\right\} \mathrm{dV} \\
& -\frac{1}{2} \int_{\text {superfície }}\left[W_{\theta} \sin ^{2}\left(\theta-\theta_{\min }\right)+W_{\varphi} \sin ^{2}\left(\varphi-\varphi_{\min }\right)\right] \mathrm{dA}
\end{aligned}
$$

onde os três termos na integral de volumes estão relacionados às energias de deformações splay, twist e bend do vetor diretor, respectivamente, e a integral de superfície descreve o ancoramento no substrato que limita o CL. A minimização da equação da energia livre, levando em conta as condições de contorno apropriadas, leva à determinação da configuração de equilíbrio do diretor na cela.

Neste trabalho as superfícies de contorno serão tratadas com fotopolímeros, e a direção preferencial de alinhamento, assim como a intensidade de ancoramento, serão controladas através do processo de fotoalinhamento. Conforme foi mostrado em um estudo realizado anteriormente no GFCx-IFUSP [L. T. Thiegui, 2004], a energia de ancoramento zenital é muito pequena quando comparada à intensidade de ancoramento azimutal para este processo.

\subsubsection{Determinação da intensidade de ancoramento azimutal}

Uma maneira de se determinar as energias de ancoramento zenital e azimutal é a construção das chamadas celas híbridas (também conhecidas como cela nemática torcida) preenchidas com cristal líquido. Para tanto, devem-se fixar as condições de contorno numa superfície e deixar a outra superfície com o material a ser estudado. A 
seguir será descrito o método para determinação experimental de $\boldsymbol{W} \boldsymbol{\varphi}$, que caracteriza a interação do substrato com o CL.

Vamos considerar uma cela plana, paralela ao eixo $\boldsymbol{x}$-y em um sistema de referência conforme mostrado na figura 2.6. A superfície 1 recebe um tratamento de forma a criar um eixo fácil na direção $\boldsymbol{x}$ com ancoramento forte, que pode ser obtido através de inúmeros métodos. A superfície 2, ao contrário, recebe outro tipo de tratamento só que na direção $y$. Esta diferença de orientação do eixo fácil das duas superfícies resulta numa torção (twist) das moléculas de cristal líquido na amostra ao longo do eixo $\mathbf{z}$, conforme a figura. Deste modo, as deformações splay e bend não estão presentes, e os termos relacionados a ela podem ser desconsiderados na expressão da energia livre do sistema (eq. 7).

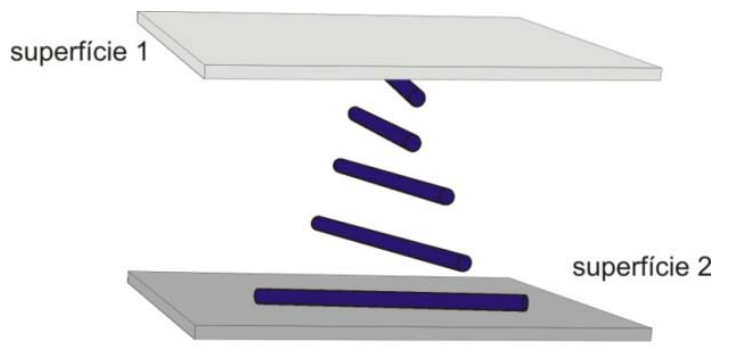

(a)

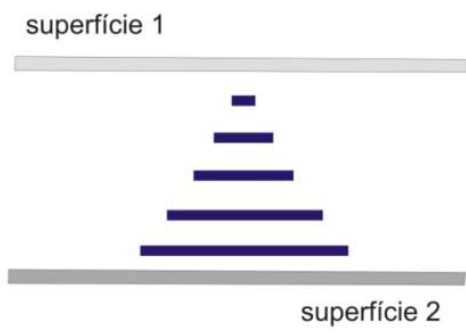

(b)

Figura 2.6: Visualização de uma cela híbrida na configuração de twist (a) vista em perspectiva e (b) vista lateral. 
Considerando um ancoramento planar bastante forte na superfície 1, assume-se que as condições de contorno $\varphi_{\min 1}=\varphi_{1}=0, \theta_{\min 1}=\theta_{1}=0$, são satisfeitas, $W \varphi_{1}$ é considerada infinita; as condições de contorno na superfície 2 são $\varphi_{2}>0, \varphi_{\min 2}=\Phi, \boldsymbol{\theta}_{\text {min2 }}$ $=0$ e $\boldsymbol{W} \varphi_{2}$ finita.

Considerando que as condições de contorno na superfície 1 são sempre satisfeitas, a orientação na amostra deverá ser obtida a partir da minimização da energia livre:

$$
\frac{F}{A}=\frac{1}{2} \int_{0}^{d}\left[K_{22} \frac{\varphi_{2}^{2}}{d}-\frac{1}{2} W_{\varphi 2} \sin ^{2}\left(\varphi_{2}-\Phi\right)\right],
$$

onde $\boldsymbol{d}$ é a espessura da cela.

Realizando a minimização da energia livre, obtemos:

$$
\frac{d^{2} \varphi}{d z^{2}}=0
$$

Assim, a equação 8 pode ser reescrita como

$$
\frac{F}{A}=\frac{1}{2} K_{22} \frac{\varphi_{2}^{2}}{d}-\frac{1}{2} W_{\varphi 2} \sin ^{2}\left(\varphi_{2}-\Phi\right) .
$$

A condição para energia mínima em relação à direção de ancoramento, $\varphi_{2}$, é obtida através do equilíbrio entre o torque elástico (proveniente da distorção no volume) e o torque na superfície:

$$
K_{22} \frac{\varphi_{2}^{2}}{d}-W_{\varphi 2} \sin \left(\varphi_{2}-\Phi\right) \cos \left(\varphi_{2}-\Phi\right)=0
$$

que leva a uma relação entre a espessura $\boldsymbol{d}$, o ângulo de twist em relação à superfície 2 , $\boldsymbol{\varphi}_{2}$, e a intensidade de ancoramento azimutal, $\boldsymbol{W} \boldsymbol{\varphi}_{2}$, dada por:

$$
W_{\varphi_{2}}=\frac{2 K_{22} \varphi_{2}}{d \sin \left[2\left(\varphi_{2}-\Phi\right)\right]}
$$




\subsection{Fotopolímeros}

\subsubsection{Introdução}

Os polímeros que contêm algum grupo funcional azobenzeno na sua estrutura são excelentes candidatos à construção de dispositivos óticos baseados em moléculas, explorando convenientemente suas propriedades físico-químicas. Uma das propriedades explorada é a isomerização (transição conformacional) trans-cis/cis-trans fotoinduzida e reversível do grupo azobenzeno. Um exemplo de um material contendo grupo azobenzeno é a classe de materiais chamados azo dyes, que são corantes que possuem o grupo azo (- $\mathbf{N}=\mathbf{N}-$ ) como cromóforo na sua estrutura molecular aromática, e podem ser introduzidos em uma estrutura polimérica formando um fotopolímero com propriedades especiais A figura 2.7 mostra um desenho estrutural de uma molécula deste tipo, juntamente com seu espectro de absorção na região da luz visível:

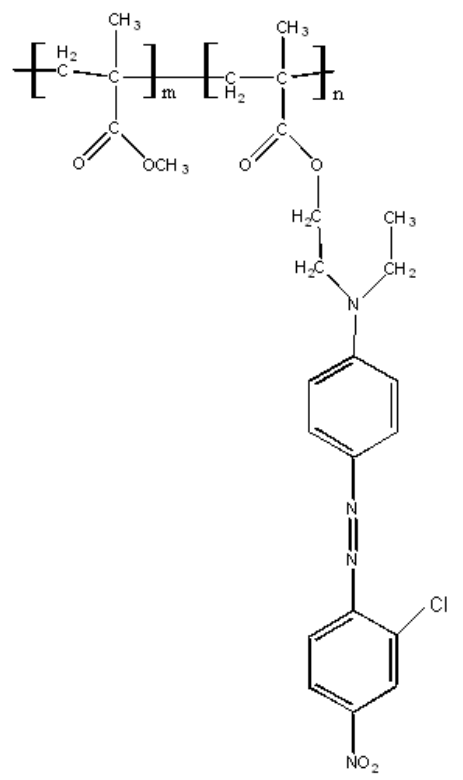

(a)

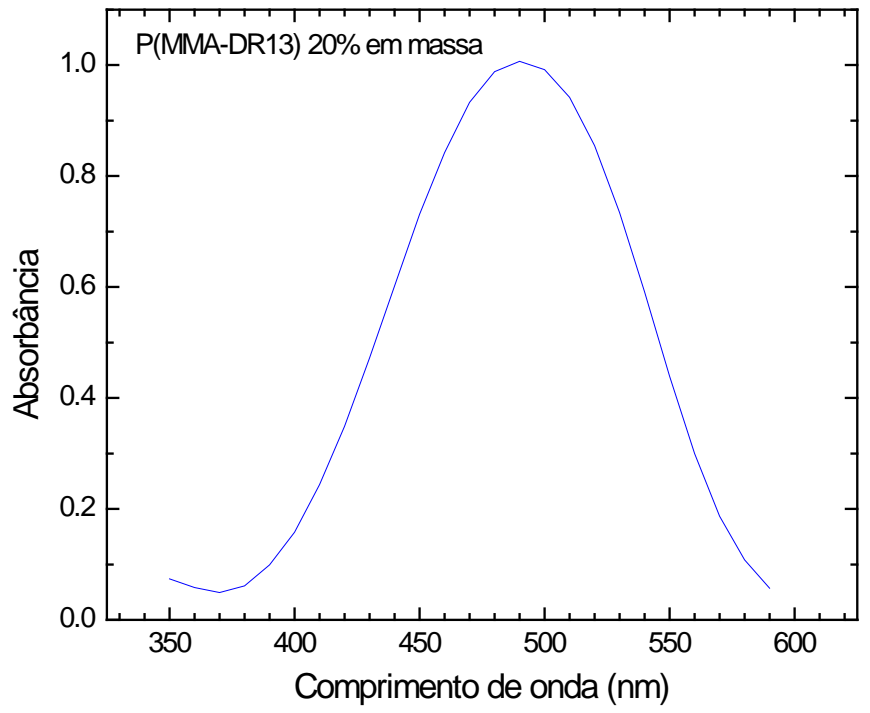

(b)

Figura 2.7: (a) molécula de PMMA-DR13 e (b) seu espectro de absorção de luz na região visível. 
As duas configurações geométricas estáveis para o grupo azobenzeno são conhecidas como cis e trans, e a diferença energética entre elas é cerca de $50 \mathrm{~kJ} / \mathrm{mol}$ (no caso do azobenzeno). Esses dois isômeros podem ser separados [G. S. Hartley, 1937] através de exposição à luz com comprimento de luz adequado (h.v) ou através de processos térmicos $(\Delta \mathbf{T})$. Como a forma trans é geralmente mais estável à temperatura e iluminação ambiente, a isomeração térmica é na direção cis para trans, enquanto que a luz induz transições em ambas as direções conforme ilustra a figura 2.8:

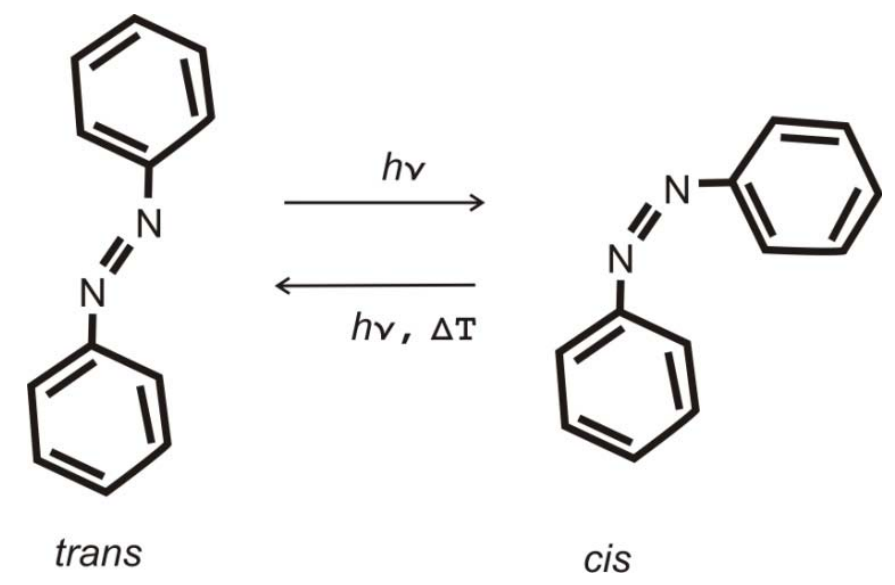

Figura 2.8: Representação das transições entre os estados cis e trans dos azocorantes.

Deste modo, quando ocorre a irradiação de um filme azobenzeno inicialmente isotrópico com luz linearmente polarizada, provocamos a mudança do estado trans para o estado cis das moléculas que possuem seus momentos de dipolo na direção paralela à direção de polarização $\boldsymbol{P}$ da luz. A probabilidade de uma molécula de absorver um fóton incidente depende diretamente do ângulo $\boldsymbol{\alpha}$ formado entre o dipolo da molécula e a direção de polarização da luz, e essa probabilidade de absorção é proporcional a $\cos (\alpha)$. Em outras palavras, a probabilidade da transição trans-cis é máxima quando as direções do dipolo da molécula e da direção de polarização da luz são paralelas, e mínima quando são perpendiculares entre si. Deste modo, as moléculas que estiverem no estado trans (mais estável à temperatura ambiente) e com momento de dipolo numa direção paralela à polarização da luz têm probabilidade máxima de absorver um fóton, e então mudar de 
conformação. O estado cis por outro lado não é estável, e após um intervalo de tempo as moléculas relaxam para o estado trans através de um processo térmico. Ao retornar a este estado as moléculas o fazem numa direção aleatória em relação à sua direção inicial; eventualmente essa direção pode vir a ser perpendicular à direção $\boldsymbol{P}$. Uma outra molécula que sofra este processo de absorção do fóton e retorne ao estado trans em uma orientação espacial diferente, terá a probabilidde de em algum instante absorver outro fóton e repetir o processo. Após um tempo de exposição à luz linearmente polarizada em uma direção $\boldsymbol{P}$, espera-se portanto o aumento da densidade populacional no estado trans que estão alinhados numa direção perpendicular à $\boldsymbol{P}$. Um dos efeitos observáveis durante este processo é o aumento da birrefringência do material, relacionado diretamente com o alinhamento dos grupos azocorantes no filme. Ao se desligar a fonte de excitação, observa-se um processo de relaxação, e eventualmente haverá uma birrefringência remanescente no material que inicialmente se apresentava isotrópico. Da mesma maneira, ao se utilizar de uma luz circularmente polarizada, o efeito que se observa é a perda de qualquer alinhamento gravado anteriormente, fazendo com que as moléculas se reorientem de forma aleatória na superfície do substrato, apagando qualquer informação anterior - ou seja, destruindo a birrefringência induzida e tornando o meio novamente isotrópico (esse mesmo efeito pode ser conseguido aquecendo o material em uma estufa adequada, onde o efeito térmico rearranja as moléculas sem uma direção preferencial). Estas propriedades tornam estes materiais bastante interessantes no campo da fotônica, principalmente por este material ser bastante adequado para gravação de informações óticas - e ainda mais, de maneira reversível [A. Natansohn et al, 2002; A. Natansohn et $a l, 2002]$. 


\subsubsection{Considerações teóricas: dinâmica de fotoalinhamento}

Um modelo teórico foi desenvolvido por Sekkat e colaboradores, para explicar o processo de reorientação fotoinduzida de azobenzenos em meio viscoso [Sekkat et al., 1995] que se aplica satisfatoriamente a filmes bem organizados, tais como filmes Langmuir-Blodget (LB) contendo grupos azocorantes. No entanto, existem alguns aspectos relacionados ao processo de fotoisomerização que não são contemplados nesse modelo, como por exemplo, o volume livre (ou vacância) necessário para que possa ocorrer uma reorientação (que depende da forma como o grupo azo-corante está ligado ao polímero, e da quantidade desses grupos). Foi observado experimentalmente que para filmes de LB, com grupos azocorantes na cadeia principal, existe uma intensidade mínima de irradiação para que o filme desenvolva uma anisotropia ótica [M. Schönhoff et al., 1996], isto é, há uma taxa mínima de fotoisomerização e esse é um resultado experimental importante que não pode ser explicado pelo modelo de Sekkat. Além disso, esse modelo introduz várias variáveis, tornando cada vez mais difícil a obtenção de uma solução analítica. $\mathrm{O}$ modelo de Sekkat será discutido no Apêndice A. Experimentalmente, tanto o processo de formação quanto o decaimento da birrefringência devem ser compreendidos pelo modelo escolhido, e empiricamente um ajuste do tipo exponencial é uma excelente escolha em uma primeira aproximação.

A equação de Debye [A. R. Blyte, 1971] descreve como se dá a evolução temporal dos processos de formação e decaimento da birrefringência induzida como um simples função exponencial para cada caso. Para o aumento da birrefringência,

$$
y(t)=C\left[1-e^{\left(\frac{t}{\tau_{C}}\right)}\right],
$$

e da mesma forma para o decaimento temos:

$$
y(t)=D\left[1-e^{-\left(\frac{t}{\tau_{D}}\right)}\right]
$$

onde $\boldsymbol{y}(\boldsymbol{t})$ é a intensidade (sinal) da birrefringência, $\boldsymbol{C}$ e $\boldsymbol{D}$ são a amplitude de intensidade do sinal da birrefringência, $\boldsymbol{R}$ é o valor de sinal residual (birrefringência final), e as 
constantes de tempo $\tau_{C}$ e $\tau_{\boldsymbol{D}}$. Essas constantes de tempo são os únicos parâmetros que descrevem os processos de crescimento e decaimento da birrefringência, e considera que todos os elementos se formam e relaxam de forma idêntica.

Entretanto, os resultados experimentais não são bem ajustados por uma função exponencial simples. De fato, devido às interações entre as cadeias poliméricas, é comum considerar que esse processo de relaxação na verdade seja uma superposição de processos tipo Debye, com diferentes tempos de relaxação e amplitude. Na literatura em geral tem sido usada uma função bi-exponencial, com uma interpretação onde as constantes de tempo obtidas com o modelo são associadas com a existência de dois processos de orientação distintos, um rápido e um lento.

Para o aumento da birrefringência, a orientação rápida é geralmente associada ao ciclo de fotoisomerização trans-cis-trans, enquanto a orientação lenta é associada ao ciclo de fotoisomerização ativado termicamente e acompanhado do movimento da cadeia polimérica. No processo de decaimento da birrefringência, a desorientação rápida é associada à isomerização térmica cis-trans, e a desorientação lenta está relacionada principalmente com a difusão rotacional térmica dos grupo azo devido ao movimento das cadeias poliméricas.

A equação bi-exponencial que descreve o processo de aumento de birrefringência pode ser escreto como:

$$
y(t)=C_{1}\left[1-e^{\left(\frac{t}{\tau_{\text {rapido }}}\right)}\right]+C_{2}\left[1-e^{\left(\frac{t}{\tau_{\text {lento }}}\right)}\right]
$$

e o decaimente analogamente:

$$
y(t)=D_{1}\left[1-e^{-\left(\frac{t}{\tau_{\text {rapido }}}\right)}\right]+D_{2}\left[1-e^{-\left(\frac{t}{\tau_{\text {lento }}}\right)}\right],
$$

onde $y(t)$ é a intensidade (sinal) da birrefringência, $C_{1}, C_{2}$ e $D_{1}, D_{2}$ são as amplitudes de intensidade dos sinais da birrefringência, $\boldsymbol{R}$ é o valor de sinal residual (birrefringência final), e as constantes de tempo $\tau_{\text {rapido }}, \tau_{\text {lento }}$ são as constantes de tempo características para o crescimento e decréscimo da birrefringência induzida no material. 
Um outro modelo empírico proposto para explicar o comportamento da birrefringência fotoinduzida em alguns filmes é o modelo da exponencial estendida, que pode ser útil qundo há uma distribuição de tempos de relaxação [ref].

\subsubsection{Grades de relevo}

\subsubsection{Introdução}

Os primeiros trabalhos de inscrição de grades de relevo (SRG) foram publicados por dois grupos de pesquisa independentemente [A. P. Guwot et. al., 1986; Sionnest W. Chen et. al., 1989]. Ambos relataram a formação das SRG com grande amplitude em filmes poliméricos contendo grupos de azobenzenos ligados covalentemente à cadeia principal. A inscrição de SRGs é feita incidindo-se dois feixes laser (com um ângulo entre eles) sobre a superfície da amostra, de modo a gerar um padrão de interferência na luz sobre o filme. Esse padrão de franjas de interferência grava uma grade de relevo sobre o filme graças à propriedade de fotoisomerização dos grupos azobenzênicos. Em uma situação particular, ao se utilizar luz polarizada com a direção de polarização da luz na direção de formação das grades, há o deslocamento de massa da região iluminada para a região não iluminada. Observa-se que a profundidade dos canais gravados depende do tempo de exposição e/ou intensidade do laser, e o período dos canais pode ser controlado através da variação do ângulo entre os dois feixes incidentes. A gravação de SRGs também é um processo reversível [X. L. Jiang et al., 1998].

Existem vários mecanismos propostos na literatura para explicar o processo de formação de SGR em sistemas poliméricos [I. Drevensek Olenik et. al., 2006], sendo que o mais aceito e utilizado atualmente é o chamando modelo de gradiente de força [J. Kumar et. al., 1998; N. Inoue et. al., 2008], que será mostrado com maiores detalhes no Apêndice C. 
Neste trabalho foram utilizados polímeros com uma alta $\boldsymbol{T}_{\boldsymbol{g}}$ (temperatura abaixo da qual as cadeias poliméricas perdem sua mobilidade), e as intensidades de exposição luminosa, e foi considerado que as potêncais eram relativamente baixas (regime de pequenas variações na região de temperatura ambiente). Assim, em nossos experimentos é possível considerar que o efeito da temperatura para a formação de grades é desprezível, e considera-se que o transporte de massa de uma região para outra é de origem fotônica. Quando são utilizadas potências muito elevadas, onde os efeitos térmicos resultantes são realmente relevantes, observa-se visualmente a degradação do filme.

No processo puramente fotônico, é assumido que as moléculas do polímero movem-se das regiões iluminadas para as não iluminadas do padrão de interferência criado. Esses padrões podem ser apagados termicamente, ou com a ação de luz polarizada convenientemente. A dependência com a polarização é extremamente importante [S. G. Grubb et. al., 1988], pois o transporte de massa ocorre apenas em materiais contendo grupos azobenzenos e na direção do campo elétrico, ou seja, o processo de fotoisomerização trans-cis-trans é pré-requisito essencial para dar mobilidade aos grupos azocorantes [M. Sheik-bahae et. al., 1991]. O modelo do gradiente do campo elétrico é um dos modelos teóricos mais aceitos para explicar a formação de SGR em filmes com alta $\boldsymbol{T}_{\boldsymbol{g}}$ (onde efeitos térmicos podem ser desprezados). Essa teoria é baseada na força originada pelo gradiente de campo elétrico opticamente induzido pelo padrão de interferência gerado sobre o filme [R. K. Meyer et. al., 1994], e mostra que o deslocamento dos grupos azocorantes se dá sempre quando a direção do gradiente de campo elétrico está na direção de polarização da luz. 


\subsubsection{Ancoramento devido à efeitos topográficos}

O problema da orientação de um CL em contato com uma superfície ondulada foi analisado originalmente por D. Berreman [D. W. Berreman, 1972], considerando uma energia de distorção introduzida pela presença de um relevo senoidal na superfície. Tomando uma superfície com uma ondulação unidimensional, por exemplo, na direção do eixo $x$ com um período espacial $P$, o perfil da superfície pode ser escrito na sua forma mais simples como uma onda senoidal definindo um período e a amplitude da ondulação (profundidade do canal). Segundo D. Berreman, o modelo tem validade para valores de $2 \pi \boldsymbol{A} / \boldsymbol{p}$ pequenos. Conforme mostrado na figura 2.9 , a condição de minimização de energia se dá quando as moléculas de CL se alinham na mesma direção dos canais:

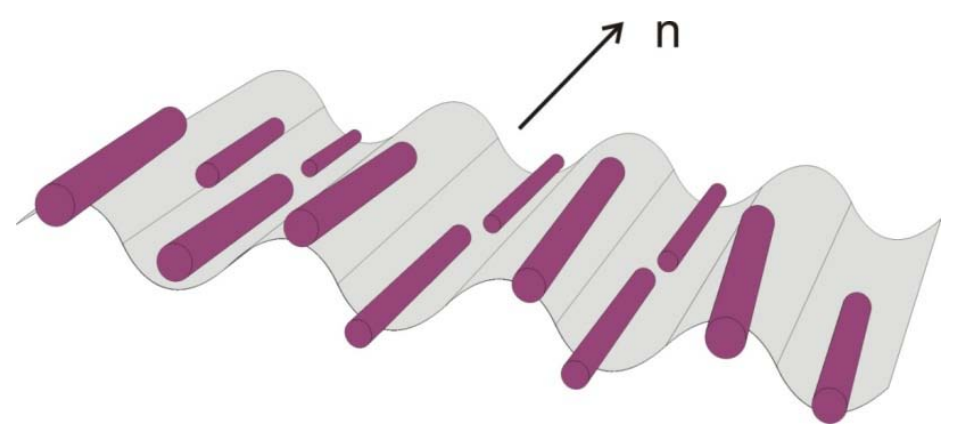

Figura 2.9: Representação de um perfil topográfico senoidal com as moléculas alongadas se alinhando na direção dos canais.

Para se determinar a configuração do vetor diretor no estado de equilíbrio, devese primeiramente escrever a densidade de energia livre do sistema conforme discutido anteriormente. Para calcular a intensidade de energia de ancoramento, considera-se o custo energético para se trazer uma molécula da posição de mínima energia $(\varphi=0)$ para uma posição perpendicular à superfície dos canais $(\varphi=\pi / 2)$ conforme ilustrado na figura 2.10 . 


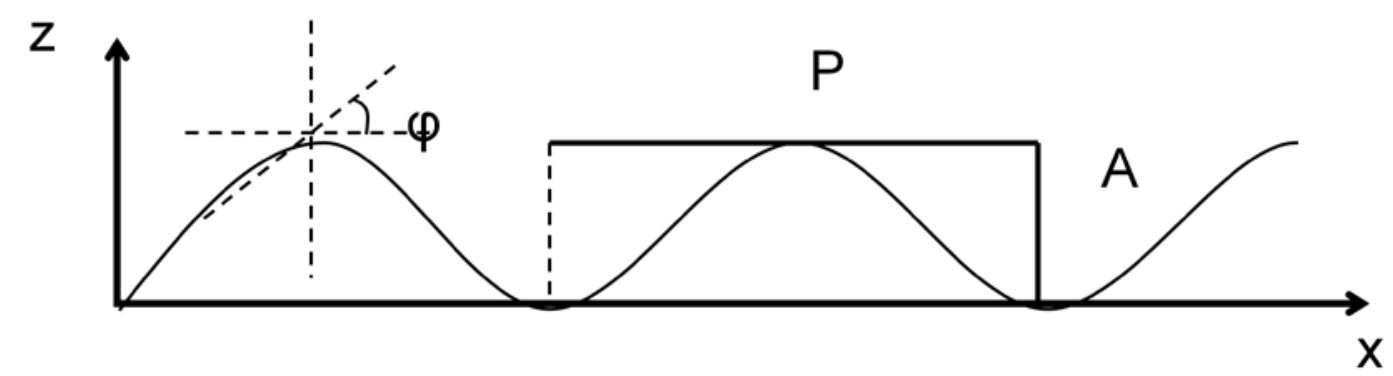

Figura 2.10: Representação bidimensional do relevo senoidal (período p e amplitude $\boldsymbol{A}$ ) da superfície tratada.

Dessa forma, escreve-se o vetor diretor como:

$$
\vec{n}=(\sin \varphi, 0, \cos \varphi)
$$

e os termos da energia livre de Frank (equação 8) são calculados a partir da teoria elástica contínua [apêndice D]. Fazendo-se a chamada aproximação de constante única $\left(K_{1}=K_{22}=K_{33}=k\right)$ calcula-se a energia livre associada à distorção do diretor, dada por:

$$
F=\frac{1}{2} k \int_{V}\left[\left(\frac{\partial \varphi}{\partial x}\right)^{2}+\left(\frac{\partial \varphi}{\partial z}\right)^{2}\right] d V,
$$

onde $k$ é a constante elástica e $\varphi$ o ângulo azimutal. Procedendo a minimização da energia livre obtem-se a equação diferencial para $\varphi(x, z)$ :

$$
\frac{\partial^{2} \varphi}{\partial x^{2}}+\frac{\partial^{2} \varphi}{\partial z^{2}}=0
$$

Através do método de separação de variáveis, escreve-se a solução na forma:

$$
\varphi(x, z) \equiv X(x) Z(z)
$$

e reescrevendo a equação de Laplace [G. Arfken, 1985], obtém-se:

$$
\begin{gathered}
X^{\prime \prime} Z+Z^{\prime \prime} X=0 \rightarrow-\frac{X^{\prime \prime}}{X}=\frac{Z^{\prime \prime}}{Z}=C \\
\left\{\begin{array}{l}
X^{\prime \prime}+X=0 \rightarrow Z=D e^{q z}+E e^{-q z} \\
Z^{\prime \prime}-Z=0 \rightarrow X=B \sin (q x)+C \cos (q x)
\end{array}\right.
\end{gathered}
$$


O perfil de orientação do diretor é dado por:

$$
\varphi(x, y)=A q \cos (q x) e^{-q z}
$$

Substituindo o valor de $\varphi$ calculado na expressão 20, obtém-se a densidade de energia dada por:

$$
\rho=\int_{0}^{\infty} f(z) d z=\frac{1}{2} k A^{2} q^{4} \int_{0}^{\infty} e^{-2 q z} d z=\frac{1}{4} k_{e}(A q)^{2} q
$$

onde $\boldsymbol{p}=2 \pi / \boldsymbol{q}$, e esse valor pode ser interpretado como energia de ancoramento topográfica e depende do período e da amplitude do padrão de relevo criado na superfície. Portanto, pode-se caracterizar o ordenamento induzido às moléculas do CL pelo relevo do substrato por meio da intensidade de ancoramento topográfica $\boldsymbol{W}_{T \boldsymbol{P}}$ dada por:

$$
W_{T P}=\frac{1}{4} k(A q)^{2} q
$$




\section{Efeitos de superfície}

Neste capítulo serão apresentados os resultados obtidos relativos à caracterização da intensidade de ancoramento induzida em fotopolímeros através de três técnicas distintas, de forma a se conseguir uma variação na na magnitude de intensidade de ancoramento acessíveis experimentalmente, variando-se os parâmetros relevantes para cada técnica específica. O primeiro tratamento de superfície abordado é a técnica de fotoalinhamento, onde foi realizado um estudo preliminar do efeito de fotoalinhamento, sem CL, estudando a dinâmica de orientação dos grupos azocorantes em função da energia de luz incidente e da concentração de cromóforos dispersos na matriz polimérica. Em seguida, foi feita a investigação do efeito de formação de SRGs em azopolímeros, onde o efeito de orientação do CL neste caso é devido ao relevo da superfície. A intensidade de ancoramento induzida às moléculas do CL depende de fatores geométricos, tais como a amplitude e período do relevo gravado no substrato (eq. 7). Por fim será mostrado o estudo realizado com a técnica de esfregamento.

Para cada técnica de tratamento de superfície, foi realizada a determinação da intensidade de ancoramento, que trará informações sobre quão forte se dá o alinhamento do CL em uma direção pré-definida pelo tratamento de superfície (eixo fácil). 


\subsection{Fotoalinhamento}

\subsubsection{Introdução}

O estudo do fenômeno de fotoalinhamento pode ser feito através do monitoramento da birrefringência induzida ao filme de azopolímero, causada pelo alinhamento dos grupos azocorantes (grupos laterais) dispersos na matriz polimérica. Para este estudo, foram utilizados três materiais distintos. Foi feita a caracterização individualmente para cada fotopolímero variando a energia de luz incidente, e quando possível, a concentração dos grupos azobenzeno. Dessa forma, pode-se controlar a intensidade de energia de ancoramento através da potência de luz incidente, do tempo de exposição à luz e também da concentração de cromóforos. O interesse principal dessas medidas é saber qual a faixa de potência ideal para cada fotopolímero, determinando, por exemplo, se há algum valor mínimo de potência para que o fenômeno ocorra e também qual a potência máxima que se pode trabalhar sem que efeitos térmicos e nãolineares comecem a aparecer ou degradar o filme. A fonte utilizada para excitação foi um laser de Argônio da marca Coherent INNOVA do laboratório do GFCx-IFUSP.

\subsubsection{Experimental fotoalinhamento}

Nesta seção, serão mostrados os resultados obtidos para a determinação da energia de ancoramento induzida pelo efeito de fotoalinhamento no filme de azopolímero para os três polímeros estudados. Para este estudo, o parâmetro relevante e acessível experimentalmente é a energia luminosa que incide sobre a amostra, ou seja, consegue-se controlar a potência de luz incidente por unidade de área e o tempo de exposição à fonte luminosa. Foram feitos testes de potência para todas as amostras, pois se deseja trabalhar numa faixa de potência onde o efeito de fotoalinhamento ocorra sem haver degradação do filme, sem qualquer outro tipo de efeitos térmicos ou não lineares. 
Para potências elevadas observou-se que o comportamento da transmitância de luz é irregular, e os efeitos não são reprodutíveis. Em casos extremos, o filme começa a se deteriorar, ficando quebradiço e perdendo aderência com o substrato de vidro. Em particular, este estudo foi feito visando estudar o fenômeno de fotoalinhamento em uma faixa de baixas potências de luz incidente, para evitar efeitos não lineares e deslocamento de massa que pode dar origem a defeitos na superfície [S. Bian et. al., 1998]. No processo de alinhamento, utiliza-se uma fonte de luz polarizada e incide-se a luz numa direção perpendicular à superfície do filme. A princípio, o material se encontra com os grupos azobenzenos distribuídos com ordenação aleatória na superfície do filme. Conforme o tempo de exposição vai aumentando, maior é o número de moléculas com direção perpendicular à polarização de luz incidente, e maior é a birrefringência $\Delta \mathbf{n}$ induzida no filme. Essa birrefringência pode ser verificada por meio da medida da intensidade de luz transmitida pelo filme (transmitância) entre polarizadores cruzados ao ser iluminado pr um feixe de prova. O esquema da montagem utilizada está detalhado na figura (3.1-a). A amostra era posicionada em um porta-amostras acoplado a um goniômetro que podia girar livremente mantendo o plano do substrato perpendicular à luz incidente, conforme ilustrado na figura (3.1b). 


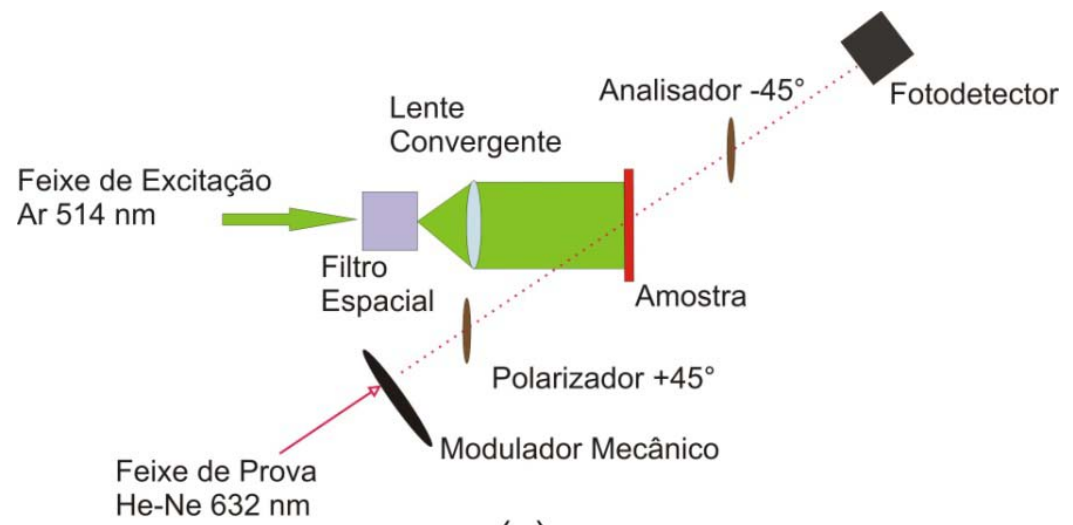

(a)
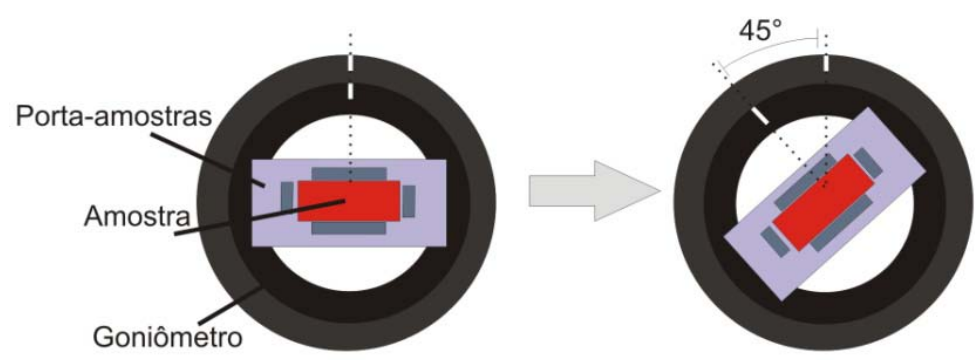

(b)

Figura 3.1: (a) arranjo experimental utilizado para o processo de fotoalinhamento, (b) portaamostra posicionado sobre um goniômetro graduado.

Neste arranjo, o laser de Ar Coherent INNOVA [http://www.coherent.com] (operando com comprimento de onda $\lambda=514 \mathrm{~nm}$ ) é a fonte excitadora, e é ligado através do acionamento de um obturador mecânico (shutter). Ao incidir sobre a amostra, o feixe de excitação dá início ao processo de fotoalinhamento na superfície do filme, induzindo uma birrefringência no material. Um feixe luminoso de baixa intensidade de He-Ne atua como feixe de prova, monitorando a birrefringência no material através da medida de transmitância do filme do filme de azopolímero entre polarizadores crruzados. Conforme o tempo de exposição aumenta, há o aumento da birrefringência induzida e consequentemente será medido um aumento na transmitância de luz; ao se desligar a fonte excitadora, o que se observa é a relaxação da birrefringência foto-induzida e será medido um decréscimo do sinal de transmitância de luz. Todo o sistema de aquisição do sinal de intensidade de luz é controlado através de um amplificador do tipo lock-in, e os 
dados obtidos são enviados através de uma interface GPIB acoplada em um microcomputador PC. Como a ordem de magnitude luminosa do sinal é relativamente baixa (consequentemente a variação de intensidade também será baixa), foi instalado um modulador mecânico de frequências (chopper) que modula o sinal do feixe de prova antes deste atingir o fotodetector. Desta forma, seleciona-se o tempo de aquisição do lock-in para que o mesmo esteja em sincronia com a frequência do sinal modulado incidente, de tal forma a não registrar um sinal contínuo, mas sim uma espécie de “média de sinais” incidentes para que deste modo haja uma melhor acurácia no valor medido. Deste modo, é possível a medida de sinais com intensidades relativamente baixas e com variações na mesma ordem de grandeza. Outro cuidado adotado é a divisão do feixe antes de passar pelos polarizadores de modo a se obter um feixe de referência, utilizando um outro detector (de referência) de modo a ser possível minimizar a flutuação de intensidade do laser de prova, caso esta ocorra. Essas pequenas flutuações de intensidade que se observam em lasers a gás podem levar a conclusões errôneas. Com este método de se comparar os dois sinais este problema é minimizado. $\mathrm{O}$ amplificador lock-in é configurado de tal forma que o sinal resultante é uma razão entre o sinal de prova e o sinal de referência sincronizado com a frequência do modulador, e deste modo qualquer flutuação de intensidade que o sinal venha a sofrer é eliminado.

Desta forma, controla-se a aquisição através de um software simples, e obtém-se tanto uma imagem visual (extensão .eps) quanto um arquivo de dados (extensão .dat). O software foi desenvolvido no próprio GFCx-IFUSP, e o único parâmetro relevante é o número de pontos a serem adquiridos (a saber, obtém-se o valor médio do amplificador lock in a cada 0,5 s). Através do amplificador lock in pode-se também configurar qual a amplitude da escala de medida (sensibilidade medida em $m V$ do sinal obtido do fotodetector) e o valor time constant, que regula a periodicidade com a qual os dados são adquiridos. O procedimento padrão utilizado é primeiramente ligar o feixe de prova e inicializar o sofware, alinhando os polarizadores e deixando o polarizador e analisador cruzados entre si. Inicialmente, o valor da transmitância é nulo (ou quase nulo, se houver uma pequena birrefringência inicial), e então é iniciada a aquisição via software com a 
fonte de excitação ainda desligada. Após cerca de 10 s liga-se o laser de excitação, e o programa executa a aquisição até que sejam atingidos o números de pontos prédeterminados.

Observa-se que o valor de transmitância atinge um valor máximo após certo tempo de irradiação, conhecido como valor de saturação da transmitância. Esse valor de saturação depende principalmente da quantidade de cromóforos presentes no filme, da intensidade e do tempo de exposição à fonte luminosa, e é maior conforme aumentamos as quantidades acima. Após desligarmos a fonte luminosa, observa-se um fenômeno de relaxação dos cromóforos, caracterizado pela diminuição da transmitância medida. Além disso, existe também uma birrefringência remanescente induzida no material, pois o valor da transmitância após o processo de relaxação ter acabado ainda permanece acima do valor inicial, ou seja, há o registro de informação ótica neste processo. A figura 3.2 ilustra o comportamento padrão para o efeito de fotoalinhamento para o filme de PMMA -DR13, ligando-se a fonte luminosa no instante inicial e desligando-a em 200 segundos. 


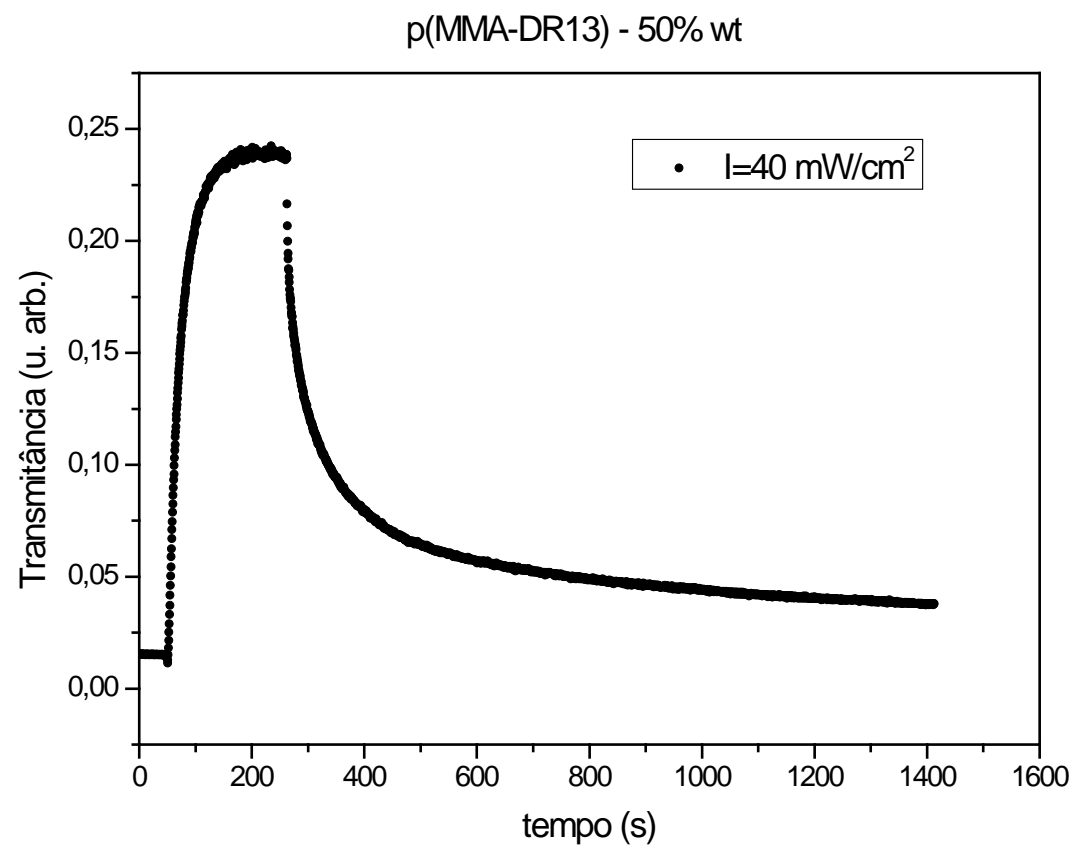

Figura 3.2: Curva típica de transmitância em função do tempo de irradiação, mostrando a excitação e a relaxação para um filme de PMMA-DR13 com 50\% em massa de corante, excitado com intensidade I = 40,0 mW/ $\mathrm{cm}^{2}$. Após atingir um limite de saturação, o laser de excitação foi desligado ( 300 s).

O procedimento adotado para todos os azopolímeros foi realizar um teste preliminar para determinar quais valores de energia incidente seriam possíveis de se trabalhar, mantendo a reprodutibilidade do efeito. Para isto, foram feitas diversas medidas que tinham como finalidade verificar qual o comportamento do fenômeno de fotoalinhamento em função da energia luminosa incidente. A energia total que incide sobre o material é o produto entre a potência de luz incidente e o tempo de exposição a esta fonte luminosa, e para este material foi adotado um tempo de exposição fixo e igual a 15 minutos, de forma que a energia luminosa é alterada mudando-se a potência do laser de excitação. 


\subsubsection{PMMA-DR13}

O PMMA-DR13 é um polímero do tipo metacrilato dopado com corante DR13 (DR vem do inglês dispersed red - e de fato apresenta uma cor avermelhada) sintetizado pelo Grupo de Polímeros "Prof. Bernhard Gross" do Instituto de Física de São Carlos IFSC-USP. Este polímero é um material apresentado na forma de pó de uma cor vermelho escuro, que é solúvel em clorofórmio numa concentração entre $1 \%$ e $2 \%$ em massa. O produto diluído apresenta uma coloração também vermelho escuro, e os filmes são produzidos pela técnica de spin coating. Como o solvente é volátil à temperatura ambiente, é possível conseguir filmes bastante homogêneos e uniformes com esta técnica. Após o processo de deposição, os filmes eram postos a secar em uma estufa a $70^{\circ} \mathrm{C}$ durante uma hora. A figura 3.3 mostra (a) uma fotografia do filme já depositado através da técnica de spin coating e (b) a representação da molécula de PMMA-DR13 com o grupo azocorante ligado como uma cadeia lateral na cadeia principal.

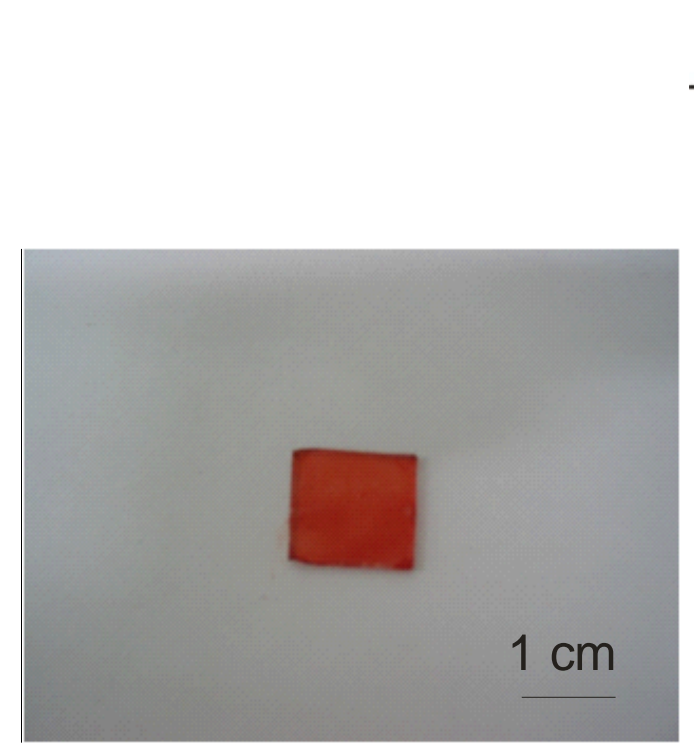

(a)

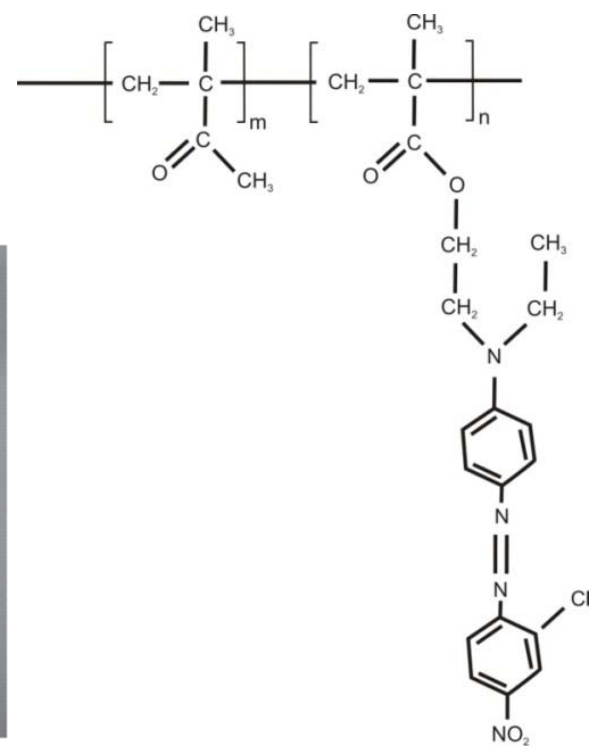

(b)

Figura 3.3: (a) fotografia com escala do filme de PMMA depositado via spin coating sobre uma lâmina de vidro, e (b) representação da molécula de PMMA-DR13. 
Foi feito então o procedimento experimental para o estudo do fenômeno de fotoalinhamento, utilizando. Para este material, a faixa de potência de luz incidente ideal fica entre $20 \mathrm{~mW} / \mathrm{cm}^{2}$ e $80 \mathrm{~mW} / \mathrm{cm}^{2}$. Acima desta potência, o filme começa a apresentar um comportamento não linear na transmitância de luz, e aumentando-se ainda mais a potência observa-se visualmente a degradação do filme, que apresenta rachaduras aparentes na superfície e por vezes perdendo adesão ao substrato de vidro. A figura 3.4 mostra o comportamento típico de aumento e diminuição da transmitância de luz (birrefringência induzida) para três potências incidentes e com diferentes tempos de irradiação.

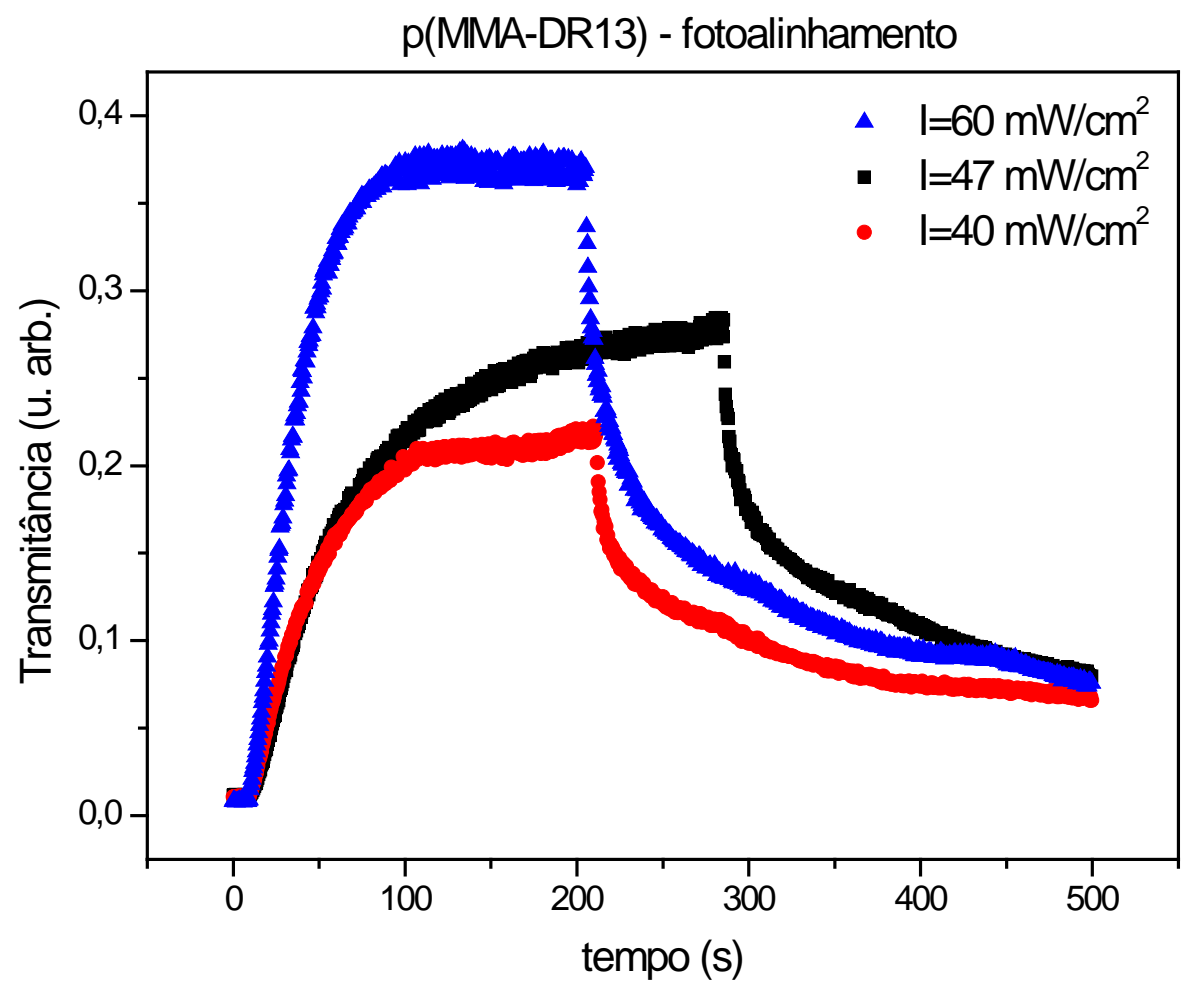

Figura 3.4: Comportamento do processo de fotoalinhamento e da relaxação (aumento da birrefringência induzida) para o filme de PMMA-DR13 com 50\% de concentração de cromóforos (em massa), para diferentes intensidades de luz incidente. Ao se atingir a saturação, o laser de excitação é desligado e observa-se a relaxação da birrefringência induzida. 
Observando a figura 3.4, podemos notar que as curvas mostram que a birrefringência induzida aumenta conforme se aumenta a potência de luz incidente, e que há uma saturação do sinal após algumas dezenas de segundos. O material apresenta um excelente comportamento de fotoalinhamento nesta faixa de potências (entre 20 e 80 $\mathrm{mW} / \mathrm{cm}^{2}$ ), apresentando curvas suaves de transmitância de luz, com resultados bastante reprodutíveis. Um fato importante a se notar na figura é que a birrefringência remanescente é praticamente a mesma, mesmo com valores distintos de energia incidente (controlada através da potência de luz incidente e tempo de exposição à luz). Nota-se também que o aumento da birrefringência induzida é mais rápido para potências de iluminação mais altas.

As curvas obtidas foram ajustadas com o modelo teórico encontrado na literatura. Foi feito um teste preliminar utilizando-se de dois ajustes: um exponencial e um biexponencial, conforme discutido na seção 2.2.2. De fato, conforme sugerido anteriormente foi verificado que o modelo mono exponencial não se ajusta bem à curva experimental, mostrando que o processo de fotoalinhamento não pode ser explicado usando-se somente um tempo característico para o fenômeno. Porém, ao se realizar o ajuste bi-exponencial observou-se um ajuste muito mais preciso, de forma a ser tomado como o ajuste padrão para este material. Desta forma, podemos interpretar o fenômeno de fotoalinhamento como sendo um processo com dois tempos característicos. As figuras 3.5 e 3.6 mostram os ajustes realizados para a formação e relaxação da birrefringência num filme de PMMA-DR13 com concentração de 50\% de cromóforos (em massa). 


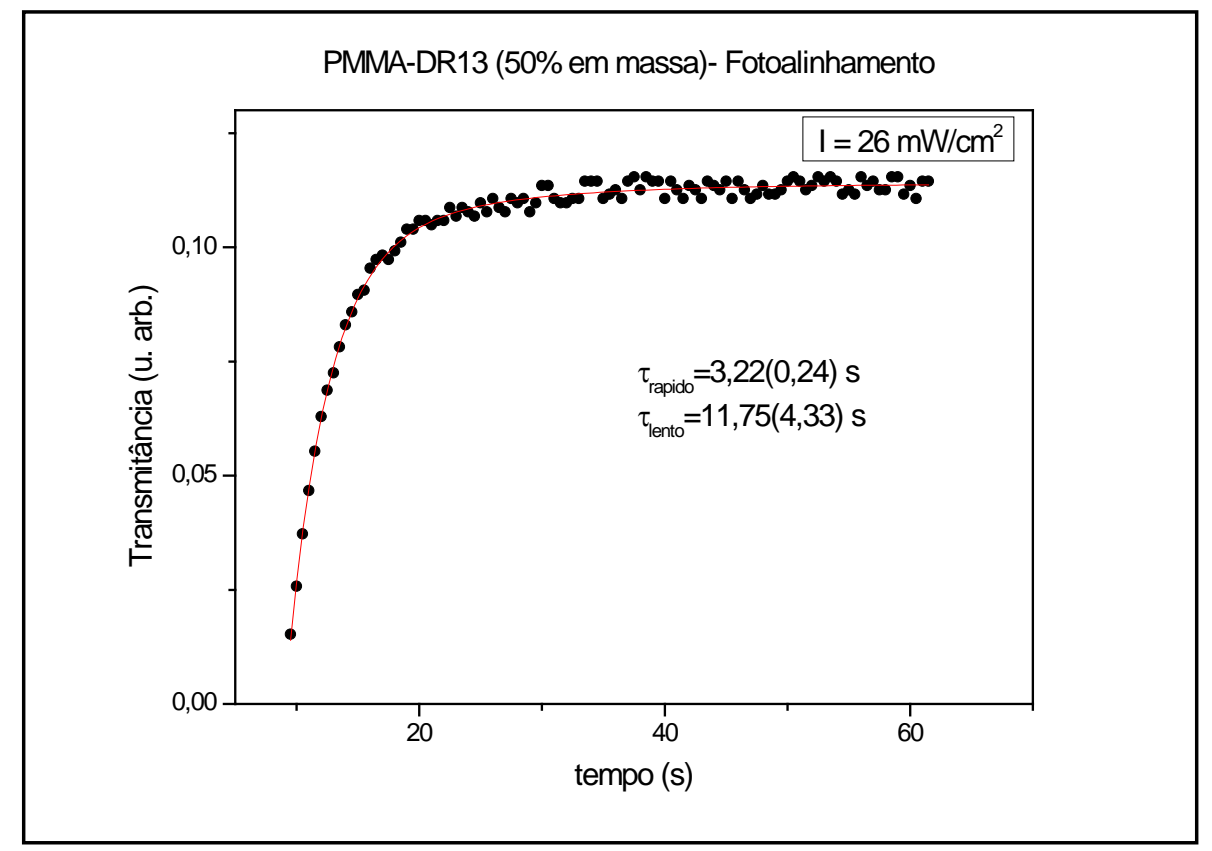

Figura 3.5: Comportamento do processo de fotoalinhamento (aumento da birrefringência induzida) para o filme de PMMA-DR13, com ajuste bi-exponencial mostrando os tempos característicos do processo.

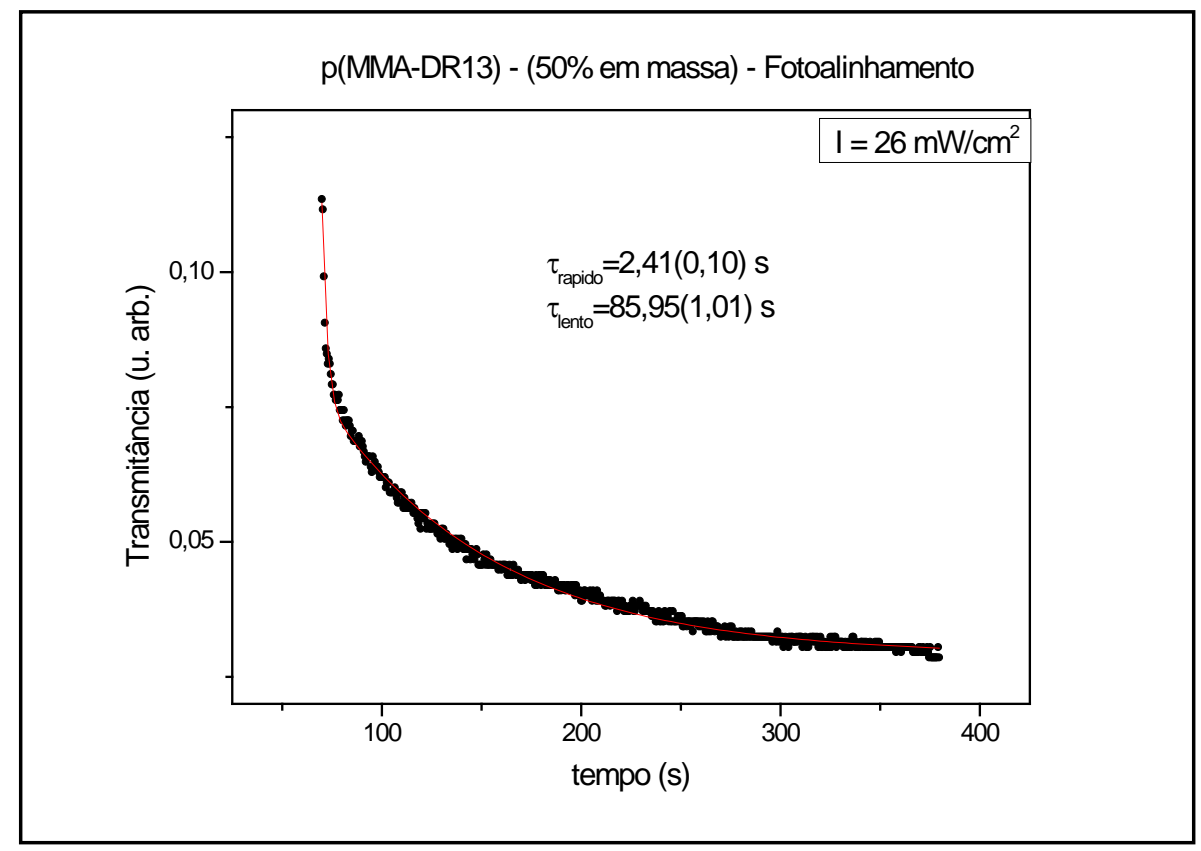

Figura 3.6: Comportamento do processo de relaxação da birrefringência induzida para o filme de PMMA-DR13, com ajuste bi-exponencial mostrando os tempos característicos do processo. 
Os filmes com maior concentração de cromóforos (50\% em massa) são mais sensíveis aos efeitos não lineares do que os filmes com menor concentração de cromóforos (15\% em massa). Para potências incidentes entre 20 e $80 \mathrm{~mW} / \mathrm{cm}^{2}$, as curvas de transmitância de luz em função do tempo são suaves e reprodutíveis para todas as concentrações de cromóforos utilizadas, e permite que o patamar de saturação seja atingido em dezenas de segundos.

\subsubsection{2 $\underline{\text { PS119 }}$}

Outro polímero estudado foi o PS119, que é um material de fácil manuseio, e por se tratar de um produto comercial não se tem acesso a quaisquers alterações em relação à composição química e estrutura molecular, nem ao tipo e concentração de azocorante presente. A única informação que temos acesso é que o azocorante também está ligado covalentemente à cadeia principal do polímero como um grupo lateral. O material em si é um pó avermelhado, que é dissolvido em água destilada (de 0,5\% a $2 \%$ em massa) formando uma solução transparente e com uma coloração alaranjada bastante intensa. O processo de deposição é simples, utizando a técnica de casting, que consiste simplesmente em depositar uma macrogota do material em uma lâmina de vidro com o auxílio de uma pipeta. Após cerca de 24h secando à temperatura ambiente o filme está pronto para ser utilizado. A figura 3.7 mostra o aspecto visual do filme depositado. 


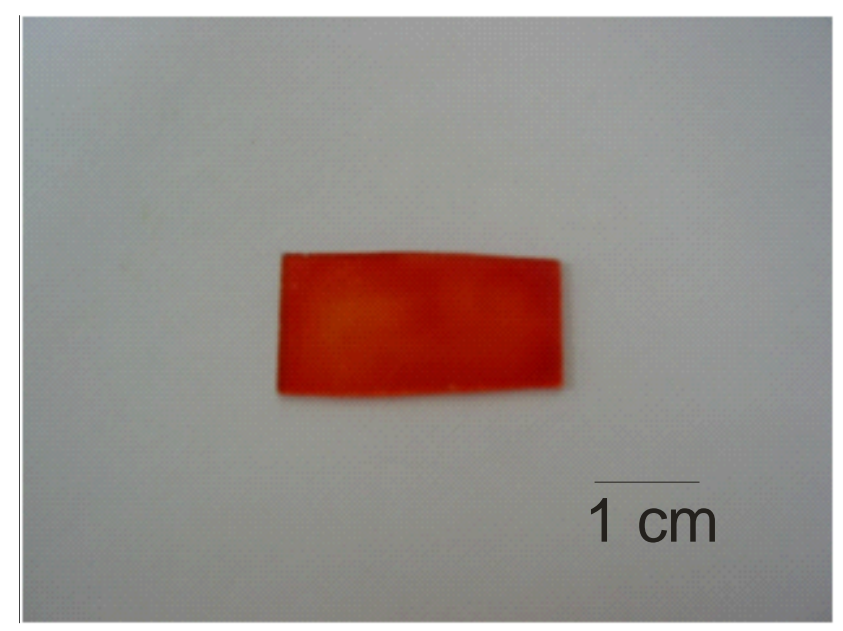

Figura 3.7 Fotografia com escala do filme de PS119 depositado via casting sob uma lâmina de vidro.

Foi feito então o procedimento de fotoalinhamento para o filme de PS119. Os testes iniciais mostraram que não se obtém um valor de saturação do efeito, mesmo ao se irradiar a amostra com $180 \mathrm{~mW} / \mathrm{cm}^{2}$ por cerca de $90 \mathrm{~min}$. Para potências acima deste valor, há o aparecimento de efeitos não lineares no comportamento da transmitância de luz, e ainda observa-se a degradação do filme, com rachaduras e perda da aderência com o substrato de vidro. A figura 3.8 ilustra o comportamento padrão para o filme de PS119, com uma alta potência de luz incidente $\left(170 \mathrm{~mW} / \mathrm{cm}^{2}\right)$. 


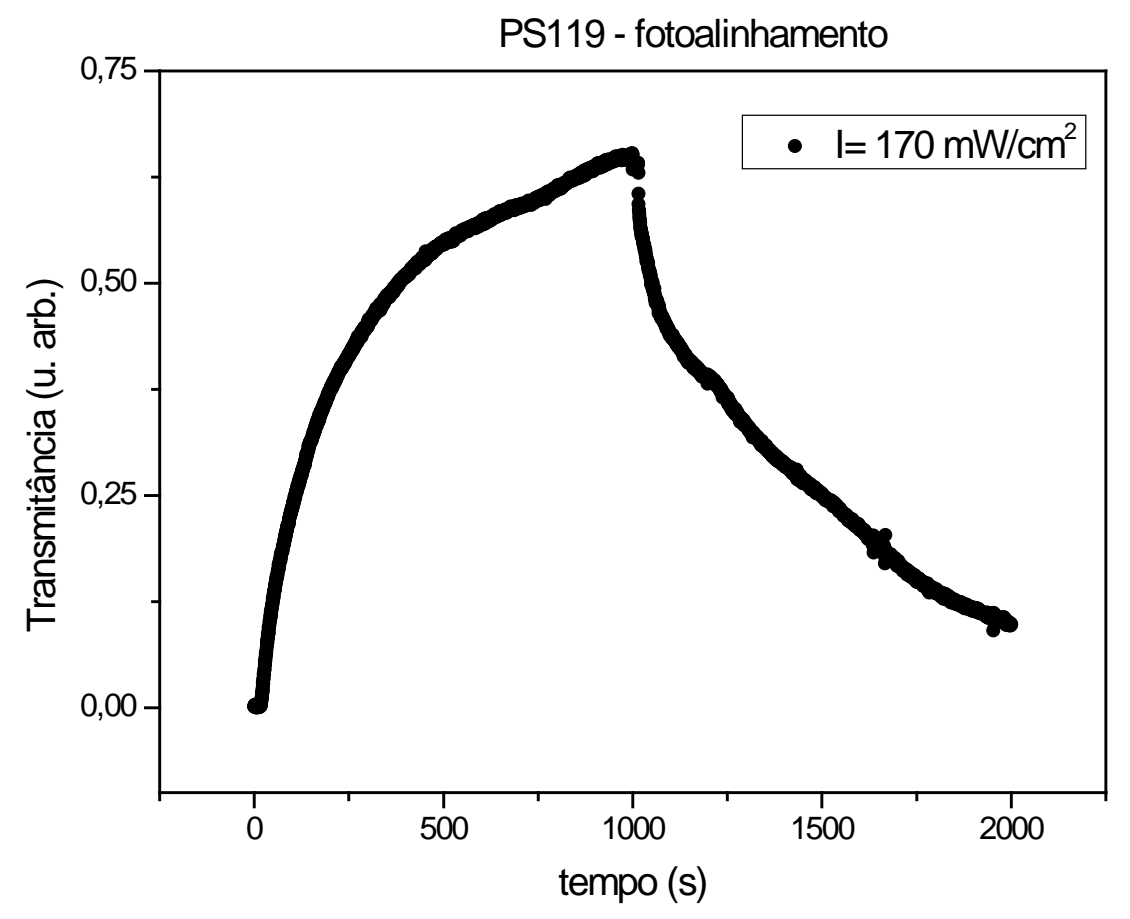

Figura 3.8: Curva típica de transmitância em função do tempo de irradiação, mostrando a excitação e a relaxação. Esta curva é para um filme de PS119, excitado com intensidade I = 170,0 $\mathrm{mW} / \mathrm{cm}^{2}$.

Foram realizadas várias medidas de fotoalinhamento, com o intuito de se determinar quais as melhores condições experimentais para realizar esse processo para o filme de PS119. As figuras 3.9 e 3.10 mostram o comportamento do fenômeno de fotoalinhamento para regime de potências baixas. Para melhor visualização em cada figura houve a normalização da intensidade de luz transmitida. 


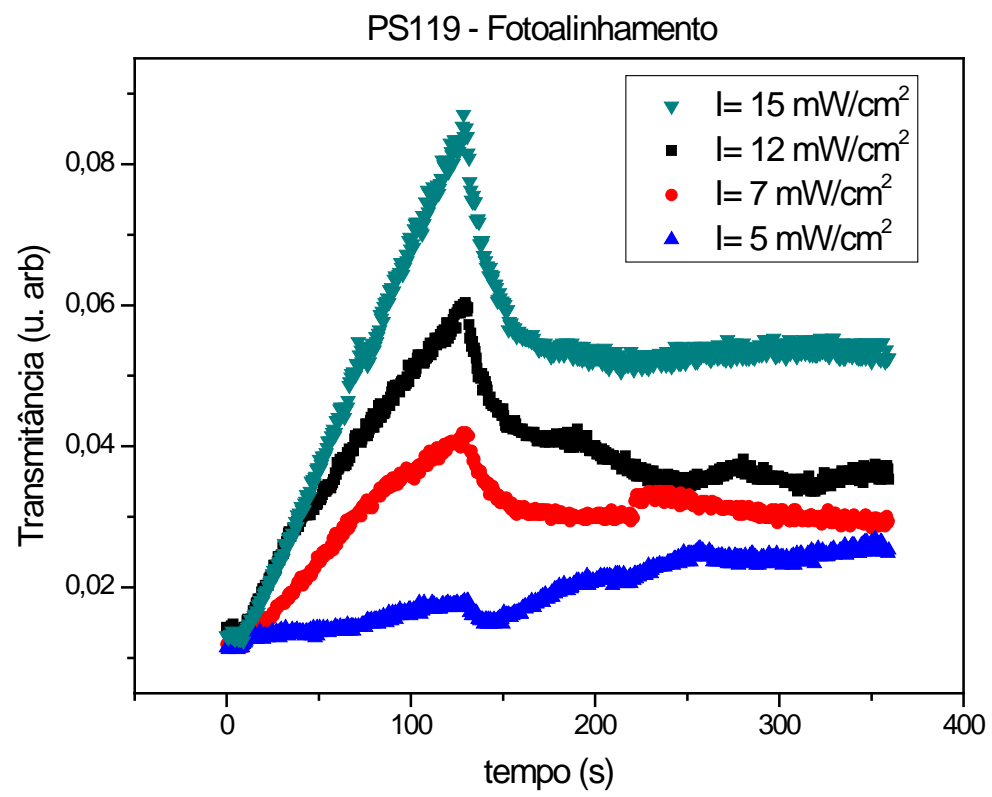

Figura 3.9: Comportamento do processo de fotoalinhamento e relaxação da birrefringência induzida para o filme de PS119, para diferentes intensidades de luz incidente.

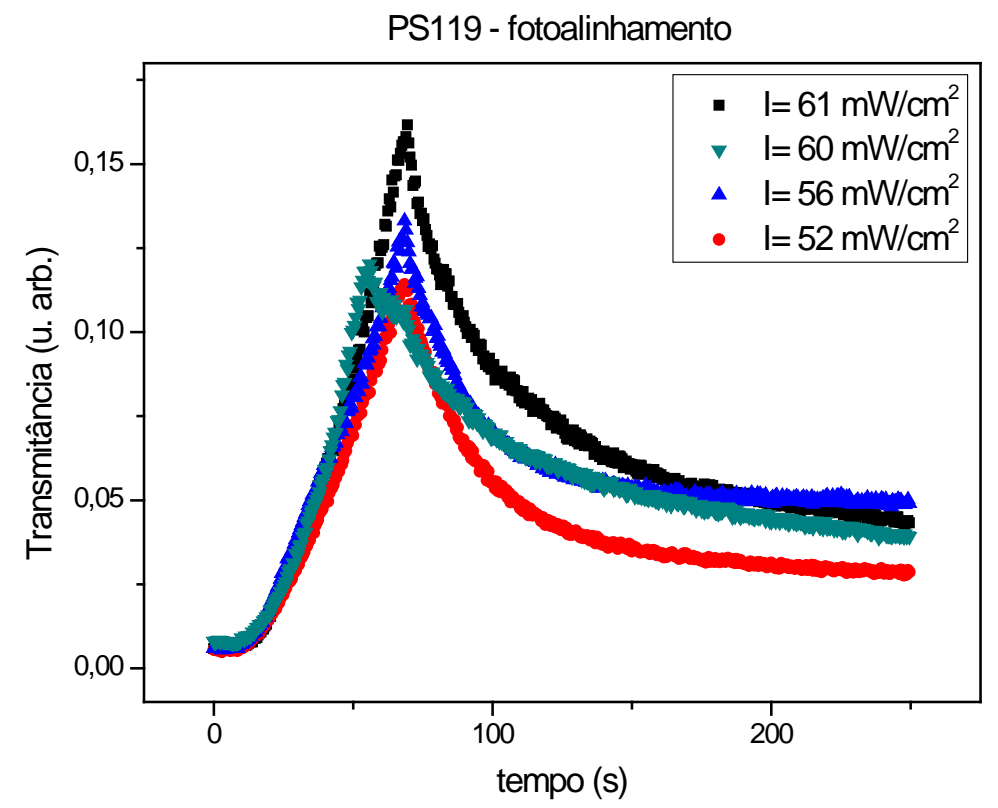

Figura 3.10: Comportamento do processo de fotoalinhamento e relaxação da birrefringência induzida para o filme de PS119, para diferentes intensidades de luz incidente. 
Na figura 3.11 vemos que para regimes de potências baixas (da ordem de dezenas de $\mathrm{mW} / \mathrm{cm}^{2}$ ), o aumento da birrefringência é praticamente linear, porém não se atinge um valor de saturação. Além disso, observa-se que a birrefringência remanescente é muito baixa comparado ao valor máximo de transmitância medido (cerca de 0,5\% deste valor) .

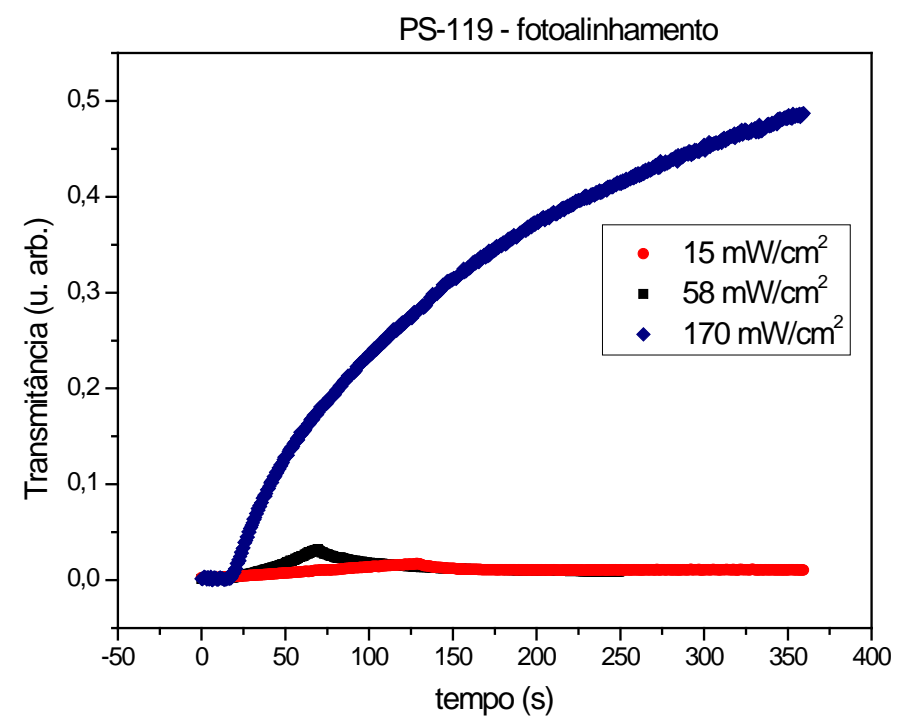

Figura 3.11: Comportamento do processo de fotoalinhamento e relaxação da birrefringência induzida para o filme de PS119, para diferentes intensidades de luz incidente - em escala, a birrefringência remanescente para potências baixas é praticamente nula em relação a potências elevadas.

Ao aumentar a potência, observa-se o comportamento característico dos fotopolímeros, apresentando uma curva que se ajusta bem a uma função bi-exponencial, tanto para o crescimento quanto para a relaxação da birrefringência induzida. Porém, mesmo com tempos altos de exposição, não foi possível determinar o limite de saturação da transmitância de luz. As figuras 3.12 e 3.13 apresentam os ajustes realizados para o crescimento e relaxação do fenômeno de fotoalinhamento para o PS119. 


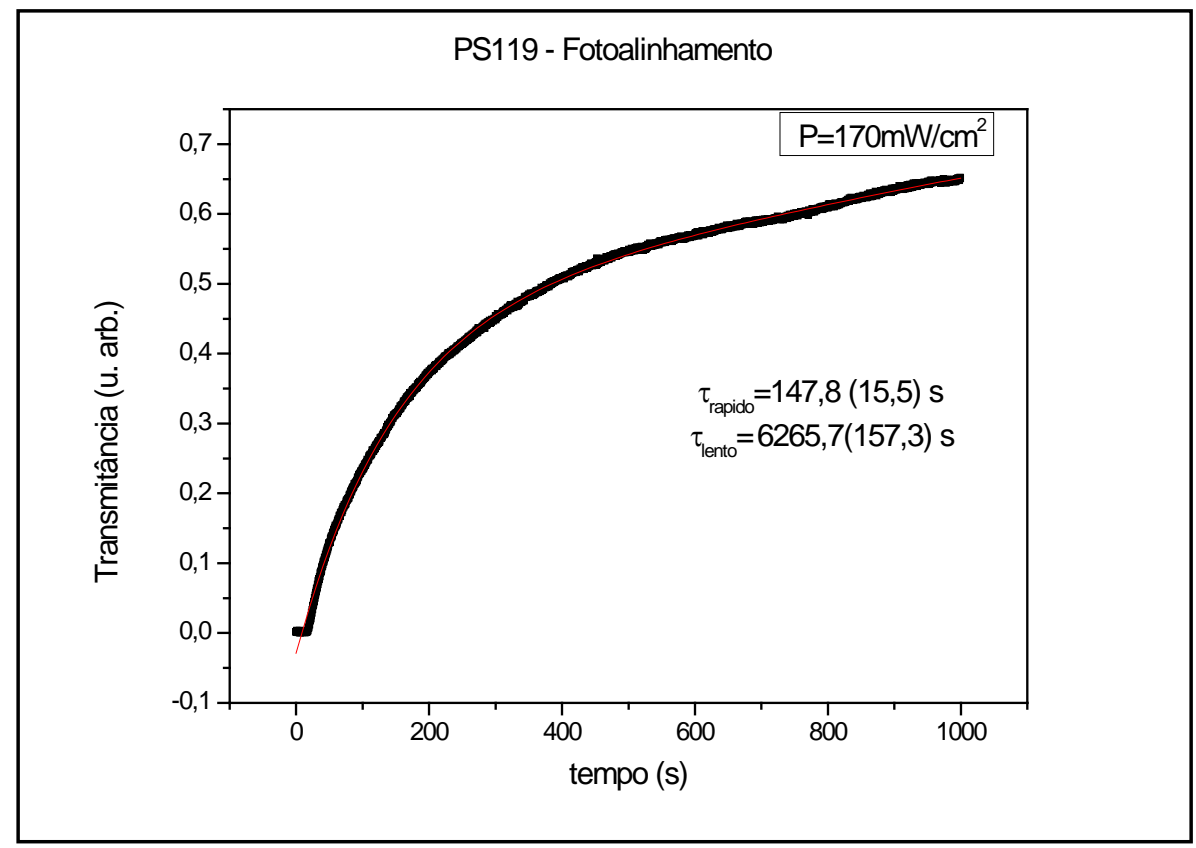

Figura 3.12: Comportamento do processo de fotoalinhamento para o filme de PS119, com ajuste bi-exponencial mostrando os tempos característicos do processo.

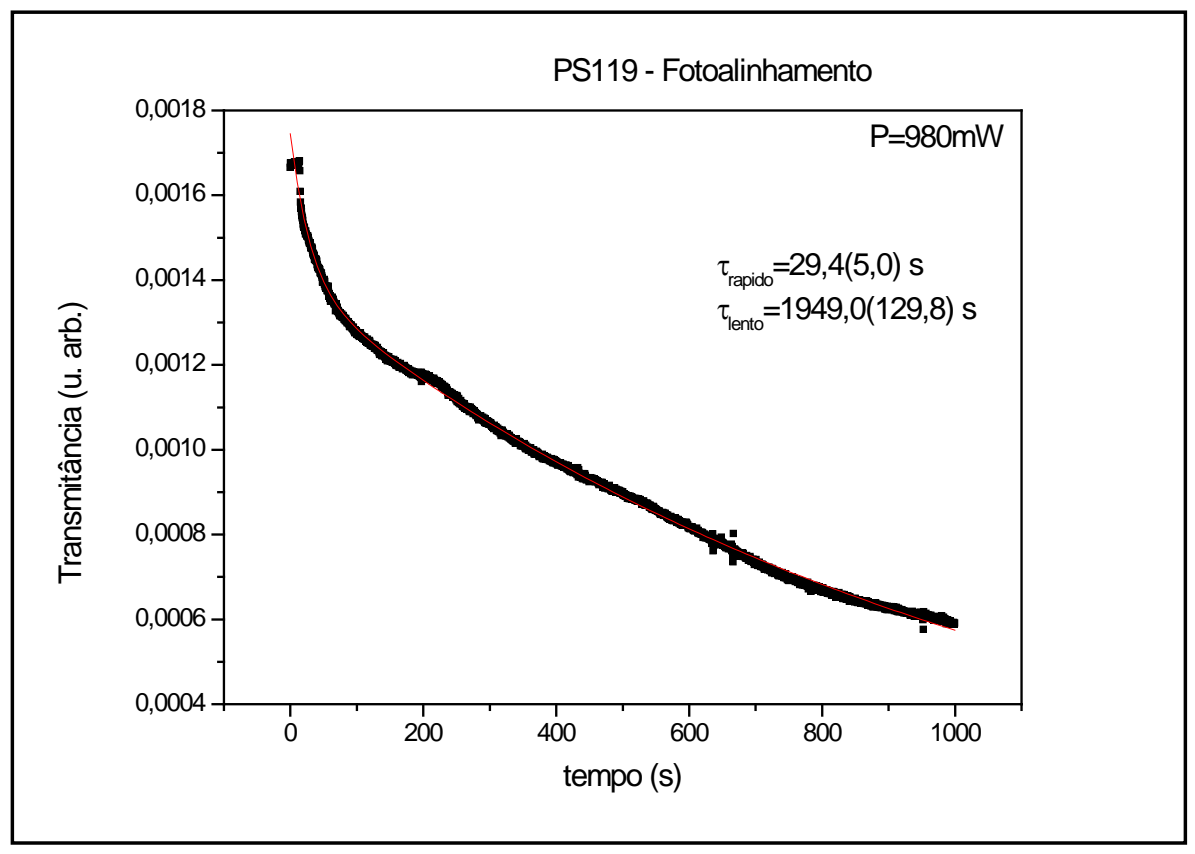

Figura 3.13: Comportamento do processo de fotoalinhamento (decréscimo da birrefringência induzida) para o filme de PS119, com ajuste bi-exponencial mostrando os tempos característicos do processo. 
Mesmo usando potências relativamente altas e tempos de exposição também altos (ao ponto de haver degradação do filme por efeitos térmicos), não foi possível atingir este patamar de saturação da birrefringência induzida. Vale lembrar que estamos interessados em regimes de baixas energias de luz incidente, de forma a evitar efeitos tal qual a movimentação ou a degradação do material polimérico. As curvas de transmitância realizadas em função da potência também mostraram que em potências baixas não há praticamente nenhuma birrefringência induzida no material após algumas dezenas de minutos depois que se desliga a fonte luminosa.

\subsubsection{PHEMA-DR13}

O outro polímero estudado foi o PHEMA dopado com o corante DR13, também sintetizado pelo Grupo de Polímeros "Prof. Bernhard Gross" do Instituto de Física de São Carlos IFSC-USP. Um diferencial deste material foi a possibilidade de se trabalhar com três concentrações distintas de cromóforos na cadeia polimérica, o que nos dá um parâmetro adicional no estudo proposto. Para o PHEMA, foram utilizadas concentrações de $15 \%$, $28 \%$ e $34 \%$ de cromóforos na cadeia polimérica. Este material foi o mais trabalhoso de se manipular, pois a reprodutibilidade no processo de deposição de filmes foi bastante árdua. O produto se apresenta como um pó com uma tonalidade de vermelho bastante escura (mais escura conforme se aumenta a concentração de cromóforos), e é solúvel tanto em dimetilformamida quanto em dimetil-pirrolidona. Escolhemos usar o dimetilformamida, por recomendação de técnicos da área química pois é um material mais inofensivo ao manuseio do que o outro solvente, tomando todos os devidos cuidados como o uso de máscara e luvas. Foram feitas várias tentativas para se obter um filme com a superfície o mais uniforme possível, e de forma a se conseguir reproduzir essa deposição para todas as concentrações disponíveis. A princípio, a técnica mais adequada é a de casting, pois consegue-se filmes com uma boa reprodutibilidade (com espessura média de $200 \mu \mathrm{m}$ ). Porém, foram encontrados diversos problemas em relação à deposição deste material, principalmente no que se refere ao processo de secagem da 
amostra devido à pouca aderência do filme ao substrato. A solução encontrada foi a utilização de uma estufa a vácuo da empresa Quimis [http://www.quimis.com.br/], que tem como característica principal diminuir a temperatura de evaporação do solvente, e também diminuir este tempo de evaporação para que a deposição do filme ocorra rapidamente. A pressão de vácuo utilizada foi a recomendada pelo fabricante, e foi verificado que a faixa de temperatura ideal entre $55^{\circ} \mathrm{C}$ e $70^{\circ} \mathrm{C}$ para uma melhor deposição do filme, dependendo da concentração de cromóforos. O critério de escolha dos filmes foi bastante criteriosa, e foram escolhidos apenas os filmes que apresentaram uma área uniforme e homogênea de aproximadamente $1 \mathrm{~cm}^{2}$, para que fosse garantido que a superfície estudada seja plana e com espessura uniforme, de forma a garantir a reprodutibilidade do efeito. A figura 3.14 mostra (a) uma fotografia de um filme utilizado que atende aos critérios de qualidade pré-estabelecidos e (b), a estrutura do polímero com o corante DR-13 ligado à cadeia principal. 


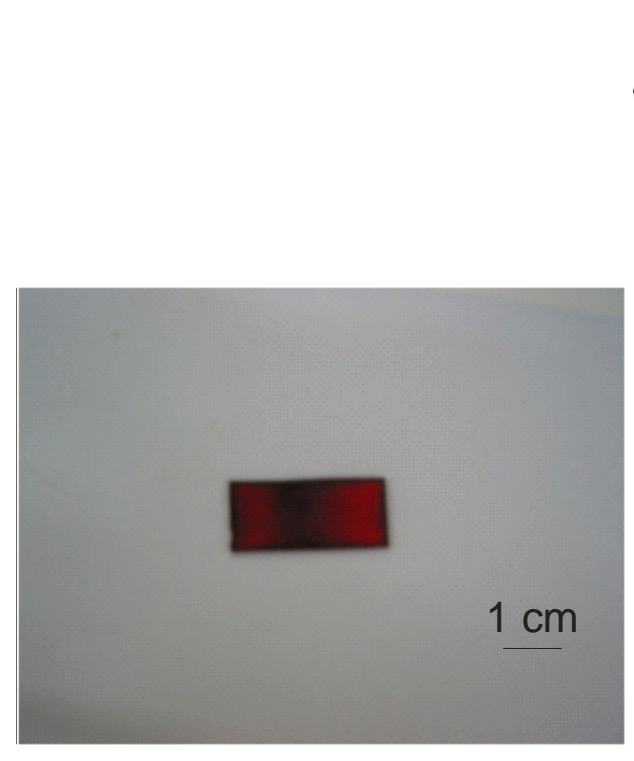

(a)

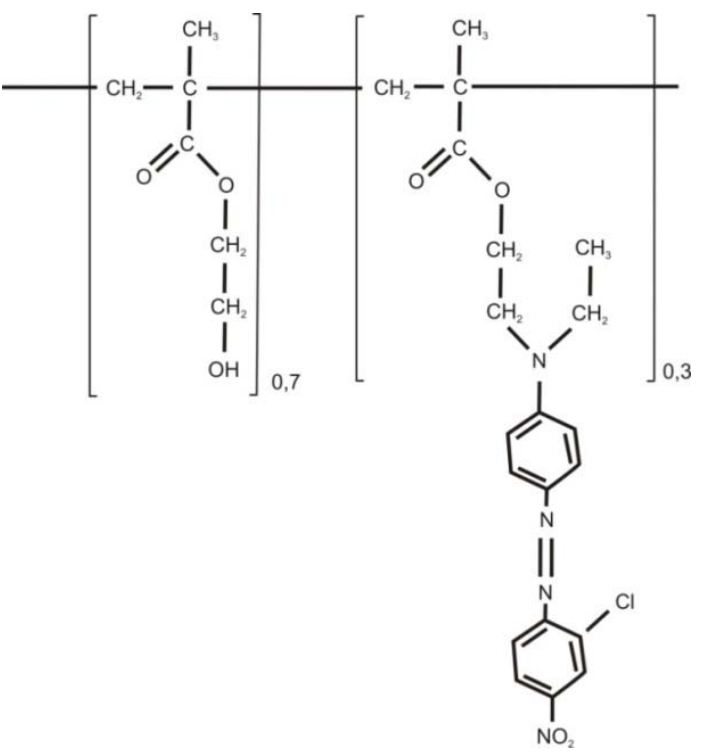

(b)

Figura 3.14: (a) fotografia com escala do filme de PHEMA-DR13 depositado via casting sobre uma lâmina de vidro, e (b) representação da molécula de PHEMA-DR13.

Foi feito então o estudo do efeito de fotoalinhamento para este material, da mesma forma que foi realizada com os polímeros anteriores. A figura 3.15 mostra o comportamento do fotoalinhamento para o PHEMA-DR13 (15\% em massa), mostrando que a birrefringência induzida no material aumenta proporcionalmente com o aumento de energia incidente. 


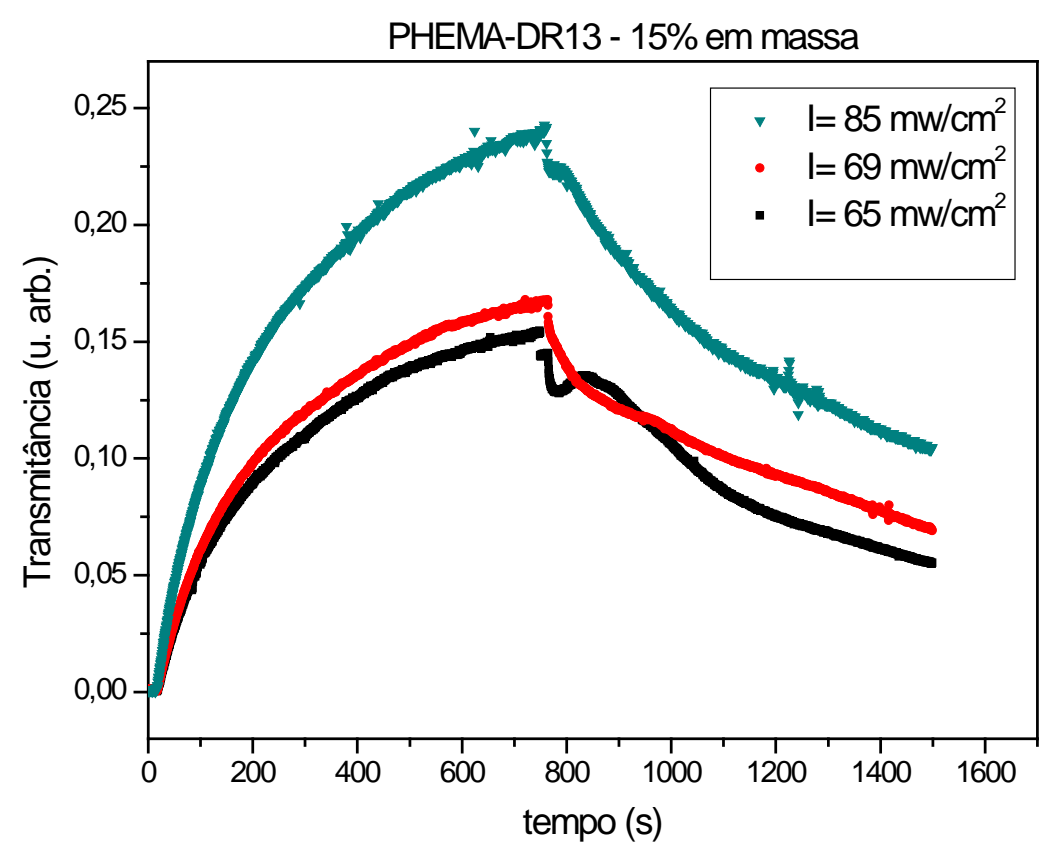

Figura 3.15: Comportamento de fotoalinhamento em função da potência incidente para o PHEMA-DR13 com 15\% de concentração em massa.

Nota-se também pela figura 3.15 que há uma birrefringência remanescente no material, que é proporcional à energia de luz incidente. Foi visto que para potências incidentes inferiores a $60 \mathrm{~mW} / \mathrm{cm}^{2}$, o efeito não ocorre de uma forma reprodutível, e a forma característica da curva de transmitância de luz não é a esperada; além disso, foi verificado que para potências muito baixas não havia praticamente nenhuma birrefringência residual. Foi observado que esse comportamento não é reprodutível para intensidades acima de $100 \mathrm{~mW} / \mathrm{cm}^{2}$, sendo que para potências muito superiores há a degradação do filme. As figuras 3.16 e 3.17 mostram os ajustes bi-exponenciais realizados para o comportamento de formação e relaxação da birrefringência induzida para o filme de PHEMA-DR13 com 15\% de azocorante em massa para uma potência de $85 \mathrm{~mW} / \mathrm{cm}^{2}$ ). Para a relaxação observamos que um ajuste bi-exponencial não é necessário, e que existe apenas um tempo de relaxação. 


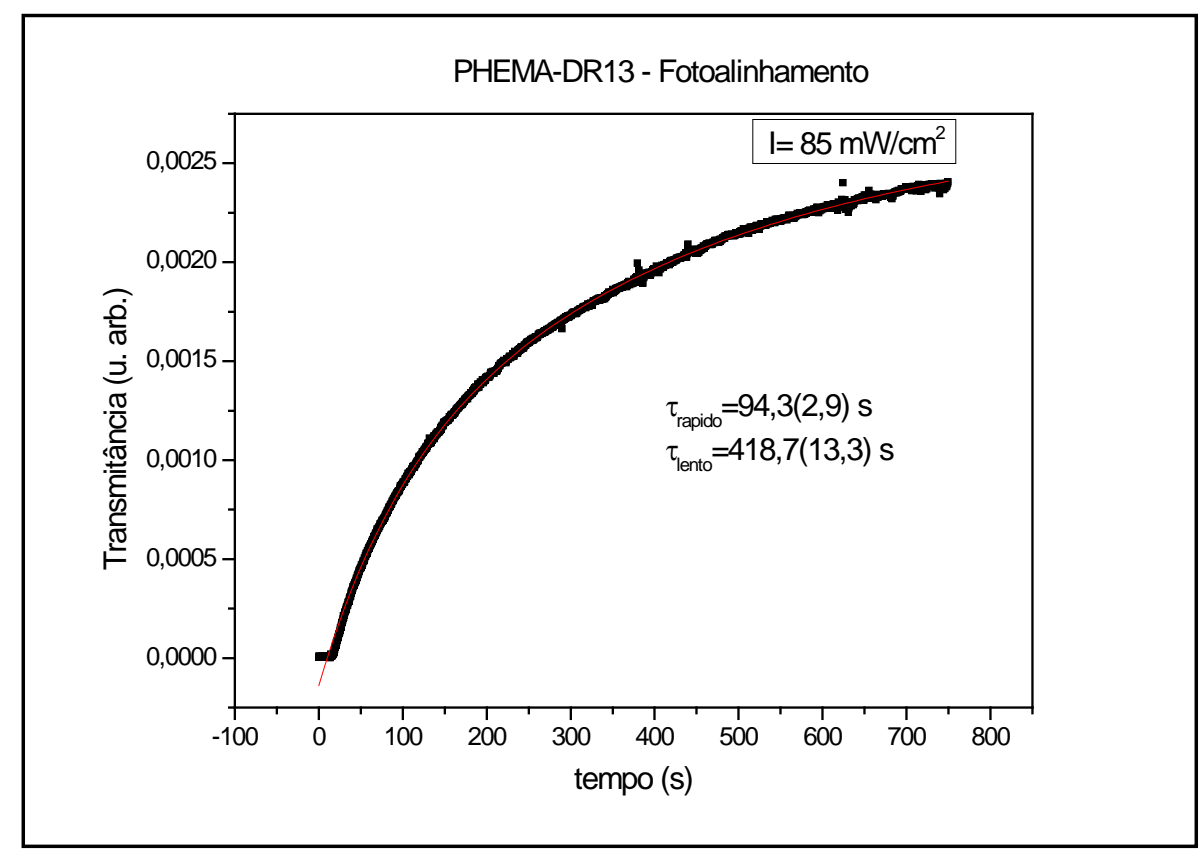

Figura 3.16: Comportamento do processo de fotoalinhamento e relaxação da birrefringência induzida para o filme de PHEMA-DR13 com 15\% de cromóforos em massa, com ajuste biexponencial mostrando os tempos característicos do processo.

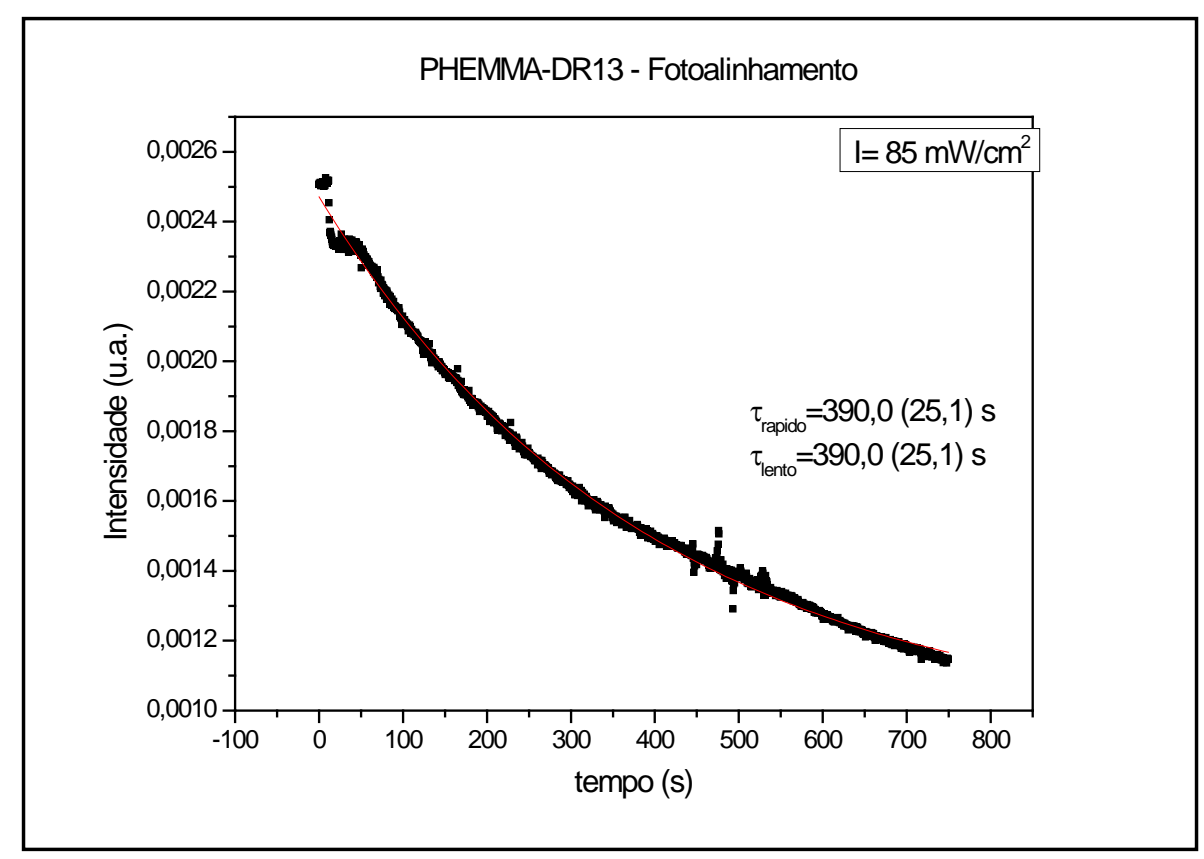

Figura 3.17: Comportamento do processo de fotoalinhamento e relaxação da birrefringência induzida para o filme de PHEMA-DR13 com 15\% de cromóforos em massa, com ajuste biexponencial mostrando os tempos característicos do processo. 


\subsubsection{Discussão dos resultados}

Analisando os ajustes bi-exponenciais realizados, é possível verificar as diferenças básicas entre um material e outro. A tabela mostra os valores de tempos $\tau_{\text {rapido }}$ e $\tau_{\text {lento }}$, relacionados com processos distintos que ocorrem em diferentes escalas de tempo para o aumento da birrefringência induzida para os três fotopolímeros estudados. Conforme sugerido, o modelo trata o comportamento do aumento da birrefringência induzida através de dois processos distintos: um processo rápido, responsável pelo aumento da birrefringência induzida (processo ligado aos grupos azocorantes e o processo de fotoisomerização), e um processo lento, responsável pela saturação do efeito de birrefringência induzida (processo de relaxação térmica e mobilidade da matriz polimérica em resposta às transições conformacionais dos cromóforos).

Tabela 3.1: Tempos característicos ajustados para o aumento da birrefringência induzida para os fotopolímeros estudados.

\begin{tabular}{|l|c|c|}
\hline & $\tau_{\text {rapido }}(\mathrm{s})$ & $\tau_{\text {lento }}(\mathrm{s})$ \\
\hline PS119 & $147,79(1,51)$ & $6265,70(3153,3)$ \\
\hline PMMA-DR13 & $3,22(24)$ & $11,75(4,34)$ \\
\hline PHEMMA-DR13 (15 \%) & $94,34(2,87)$ & $418,69(13,28)$ \\
\hline PHEMMA-DR13 (28 \%) & $88,64(3,55)$ & $275,69(25,43)$ \\
\hline PHEMMA-DR13 (28 \%) & $74,67(1,33)$ & $221(30,81)$ \\
\hline
\end{tabular}


Tabela 3.2: Tempos característicos ajustados para a relaxação da birrefringência induzida para os fotopolímeros estudados.

\begin{tabular}{|l|c|c|}
\hline & \multicolumn{1}{|l|}{$\tau_{\text {rapido }}$} & $\tau_{\text {lento }}$ \\
\hline PS119 & $29,40(47)$ & $1948,96(12,98)$ \\
\hline PMMA-DR13 & $2,42(10)$ & $85,95(1,01)$ \\
\hline PHEMMA-DR13 (15\%) & $390,00(2,51)$ & $390,00(2,51)$ \\
\hline PHEMMA-DR13 (28\%) & $50,24(5,92)$ & $285,56(9,12)$ \\
\hline PHEMMA-DR13 (34\%) & $20,95(3,33)$ & $244,39(14,13)$ \\
\hline
\end{tabular}

As curvas de birrefringência induzida mostram a existência de um limiar na transmitância de luz, uma saturação do efeito mostrando que após certo período de tempo há um equilíbrio entre os processos de alinhamento (fotoinduzido) e desalinhamento (de origem térmica). Desta forma, o comportamento de fotoalinhamento pode ser e descrito por uma função do tipo bi-exponencial com constantes empíricas que dependem da natureza do material estudado (concentração de grupos azo, tamanho da cadeia polimérica etc.). Conforme se pode observar na tabela, os valores do tempo longo aumentam conforme se aumenta a concentração de cromóforos, mostrando que há uma dependência do tempo que se demora em atingir o valor da máxima transmitância com a concentração de grupos azo. Nota-se que a diferença entre os tempos $\tau_{\text {lento }}$ e $\tau_{\text {rapido }}$ aumenta conforme se aumenta a concentração de cromóforos, e também que o tempo longo aumenta consideravelmente conforme se aumenta a concentração.

Comparando os valores entre si, é possível verificar algumas diferenças básicas entre os fotopolímeros estudados. A principal diferença entre as amostra numa primeira análise é certamente magnitude dos tempos característicos, onde o filme de PS119 foi o que apresentou os maiores valores. Conforme sugerido pelo modelo, isso significa que este material deve demorar mais para atingir um limiar de saturação de intensidade de luz transmitida (birrefringência induzida medida através da transmitância) - o filme de PS119 apresentou a característica de não possuir um limiar de saturação, sendo que em 
alguns casos mesmo com potências da ordem de $180 \mathrm{~mW} / \mathrm{cm}^{2}$ não se atingiu esse patamar em 90 min. de exposição. O mesmo comportamento se repete em relação ao decréscimo da transmitância de luz: novamente, o filme de PS119 apresentou o maior valor de tempo, e de fato, foi o filme que mais demorou a atingir um limite inferior de birrefringência remanescente. Foi verificado que a birrefringência remanescente neste material é relativamente baixa para regimes de baixa potência de luz incidente em comparação com regimes de altas potências, onde realmente a birrefringência remanescente é de fato relevante.

Para o PMMA-DR13, um resultado bastante desfavorável em relação ao objetivo deste trabalho foi encontrado no decorrer do estudo: o material se solubiliza na presença do CL. As observações realizadas através da técnica de microscopia ótica mostram que a adesão do filme é perdida, e em alguns casos observamos gotas de cristal líquido dentro da matriz polimérica. Este fato abre novas possibilidades, como usar o polímero em PDLC (da sigla em inglês Polymer-Dispersed Liquid Crystals), que consiste de gotas de cristal líquido dispersas em uma matriz polimérica, ou polímero no volume do cristal líquido. Outro aspecto interessante é que o alinhamento do cristal líquido somente é possível quando irradiamos o filme antes de montarmos a cela. Se montarmos a cela antes, o alinhamento do cristal líquido não é obtido, mesmo para longos tempos de exposição. Esse resultado foi decisivo e nos levou a procurar um material mais adequado para interação com CL.

Para o estudo de efeito de competição de orientação em microtexturas, foi escolhido o azopolímero PS119, onde foram utilizados altos valores de potência de luz incidente. Como o intuito deste estudo é estudar a competição de fotoalinhamento em direções diferentes, pode-se se usar potências relativamente altas (sem que se danifique o material). Além disso, trata-se de um material de fácil manipulação e a deposição dos filmes é bastante reprodutível; porém, trata-se de um produto comercializado, portanto não temos acesso a nenhuma informação sobre a estrutura do polímero e tampouco podemos mudar a concentração de cromóforos. 
Para o estudo de competição de orientação induzida por efeitos topográficos (SRGs), foi escolhido o PHEMA-DR13: este material apresenta a característica de gravar SRGs com potências altas $\left(260 \mathrm{~mW} / \mathrm{cm}^{2}\right)$ sem degradação do filme, e o efeito de fotoalinhamento pode ser conseguido em potências incidentes da ordem de $80 \mathrm{~mW} / \mathrm{cm}^{2}$.

Em seguida, será mostrado o estudo da interação do CL com a superfície fotoalinhada. Para tanto, foi realizado o procedimento padrão para se obter a intensidade de ancoramento azimutal das moléculas de CL quando em contato com este material utilizando-se a técnica de cela híbrida. O critério para a escolha das potências incidentes foi feito pensando-se exclusivamente no estudo do efeito de competição de orientação do CLs, ou seja, deseja-se trabalhar em um regime de baixas potências para evitar deslocamento de material ou a degradação do mesmo. Para potências baixas, não há deformação na superfície e o único efeito observado é o alinhamento dos grupos azocorantes. Conforme mencionado anteriormente, foi escolhido o PHEMA-DR13 para se realizar o estudo de orientação do CL.

\subsubsection{Determinação da intensidade de ancoramento de fotoalinhamento}

Experimentalmente, o procedimento de construção da cela híbrida é bastante conhecido e utilizado para a determinação do ângulo de twist. Conforme mostrado na seção 2.1.5 Basicamente, utilizam-se espaçadores com espessura conhecida, e duas lâminas de vidro de dimensões compatíveis. Uma das superfícies contém o material a ser estudado, e a outra superfície precisa necessariamente de uma condição de contorno que corresponde à energia de ancoramento forte (nesta superfície, as moléculas de CL se alinham exatamente na direção do eixo fácil). Para isso, utiliza-se uma lâmina de vidro recoberta com PVA (acetato de polivinila), tratada através do método de esfregamento. O PVA é um material polimérico bastante utilizado para recobrir superfícies e receber esfregamento para alinhamento de CL. A deposição do PVA é feita utilizando-se a técnica de spin coating, que consiste basicamente em depositar uma macrogota da solução polimérica presa ao suporte da máquina por sucção (vácuo), e realizar uma 
rotação sobre um eixo fixo de forma a espalhar o filme uniformemente sobre a superfície de vidro. Neste caso, o PVA foi dissolvido em água pura na concentração de $20 \%$ em massa e o filme foi depositado em uma lâmina de vidro cortada com as dimensões de $1,3 \times 2,7 \mathrm{~cm}$. Em seguida, os filmes eram postos a secar em uma estufa a $80^{\circ} \mathrm{C}$ por aproximadamente $1 \mathrm{~h}$ para evaporação do solvente.

Para a construção da cela, os espaçadores foram cortados em tiras finas com dimensões aproximadas de $0,1 \times 1,5 \mathrm{~cm}$, e foi feita a montagem conforme ilustrado na figura 3.18. Para a fixação do sistema, eram colocados grampos de pressão do tipo usado em papelaria em geral, pressionando as lâminas de vidro entre si de forma que a espessura do espaçador fosse exatamente a espessura $\boldsymbol{d}$ na Eq. 10 mostrada no capítulo 2.

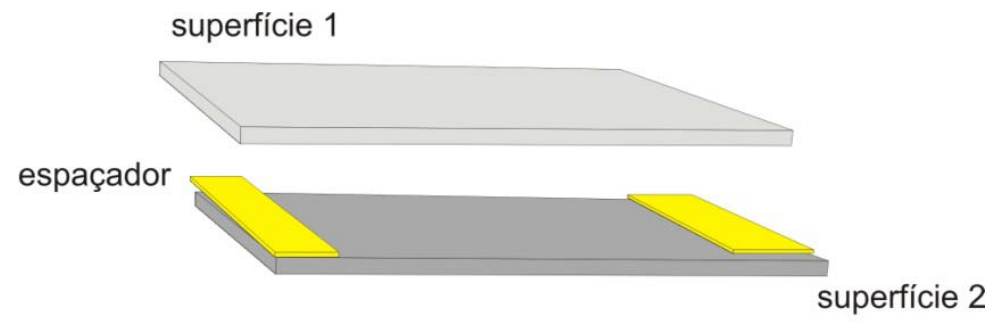

(a)

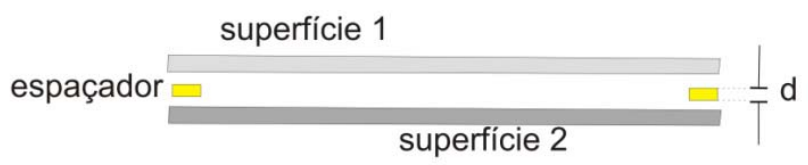

(b)

Figura 3.18 - Visualização do processo de fabricação de uma cela híbrida (a) vista em perspectiva e (b) vista lateral - a cela é fixada de tal forma que a distância $\boldsymbol{d}$ é a própria espessura do espaçador. 
Os valores do tempo de exposição e potência incidente foram escolhidos de forma a garantir a não degradação do filme ou efeitos térmicos relevantes na superfície do azopolímero. Com esses valores fixos, fez-se então o estudo da intensidade de energia de ancoramento azimutal do material em função da energia incidente. Para isto, foi utilizada a técnica de cela híbrida descrita na seção 2.1.5, com uma superfície revestida com PVA (acetato de polivinila) e outra com o PHEMA-DR13.

A determinação experimental do ângulo $\varphi_{2}$ é feita colocando-se a amostra entre polarizadores cruzados, de forma que o diretor esteja paralelo à direção de polarização do feixe de prova incidente, resultando em uma transmitância mínima. Em seguida, inicia-se o processo de fotoalinhamento sobre o filme de azopolímero com o feixe de excitação. Conforme o fotopolímero vai sendo exposto a luz, o eixo fácil na superfície do polímero (inicialmente isotrópico) tende a orientar-se numa direção perpendicular à da polarização da luz incidente. Este processo produz uma reorientação das moléculas de cristal líquido em contato com esta superfície, na direção do eixo fácil. Como a outra superfície tem um ancoramento bastante forte, ocorre uma rotação das moléculas (twist) ao longo da espessura da amostra. Essa configuração, conhecida simplesmente como “cela híbrida twist”, traduz-se por um aumento da transmitância na amostra durante a exposição à luz. Para se determinar o ângulo de twist, gira-se apenas o analisador até encontrar a posição onde a transmitância é mínima; nesta posição sabemos que a direção do diretor na superfície do fotopolímero (superfície de saída da luz) é perpendicular à posição do analisador, e o ângulo de twist $\varphi_{2}$ pode ser medido através de uma marcação graduada localizada no analisador. Os valores de ângulo de twist e $\boldsymbol{W}_{\boldsymbol{f}}$ estão representados na figura 3.19 e 3.20, respectivamente, para as três concentrações diferentes de cromóforos. 


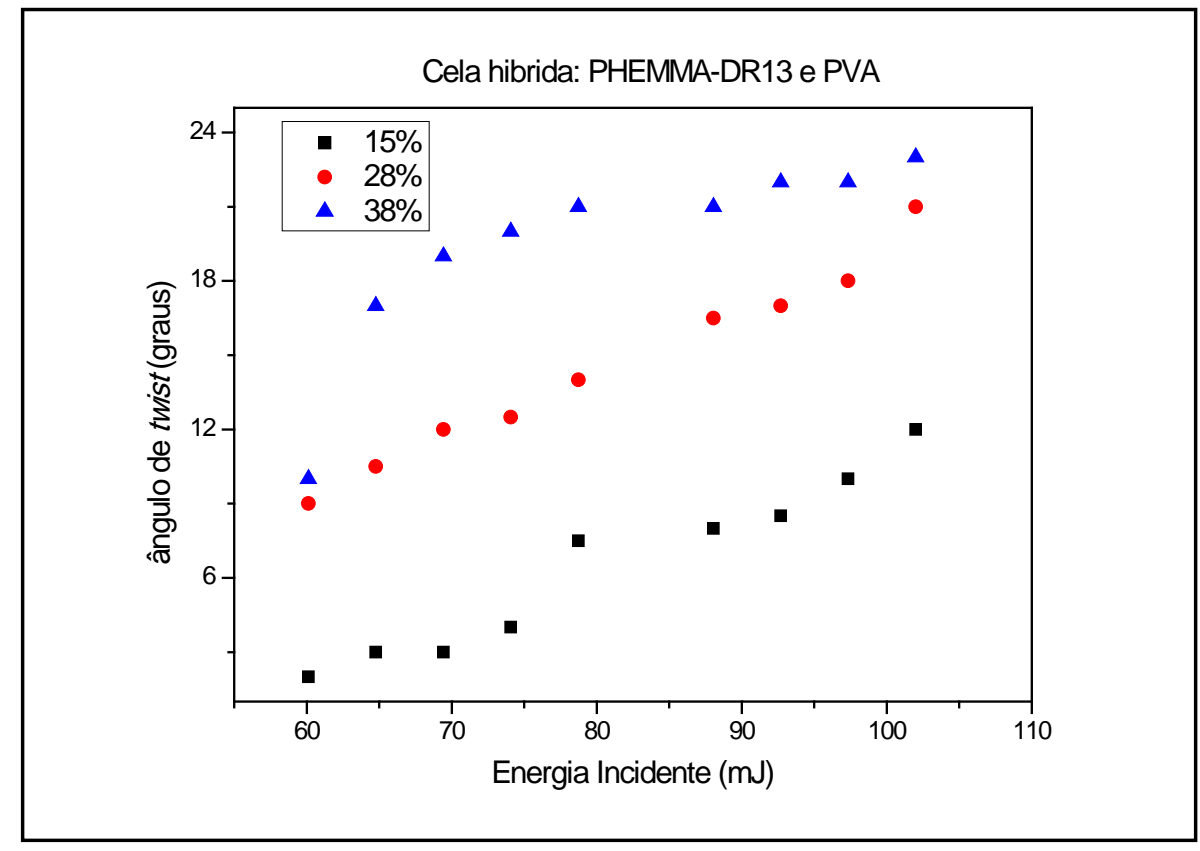

Figura 3.19: Valores de ângulo de twist para a configuração de cela híbrida usando PVA esfregado e PHEMA-DR13 tratado com fotoalinhamento para três concentrações de cromóforos.

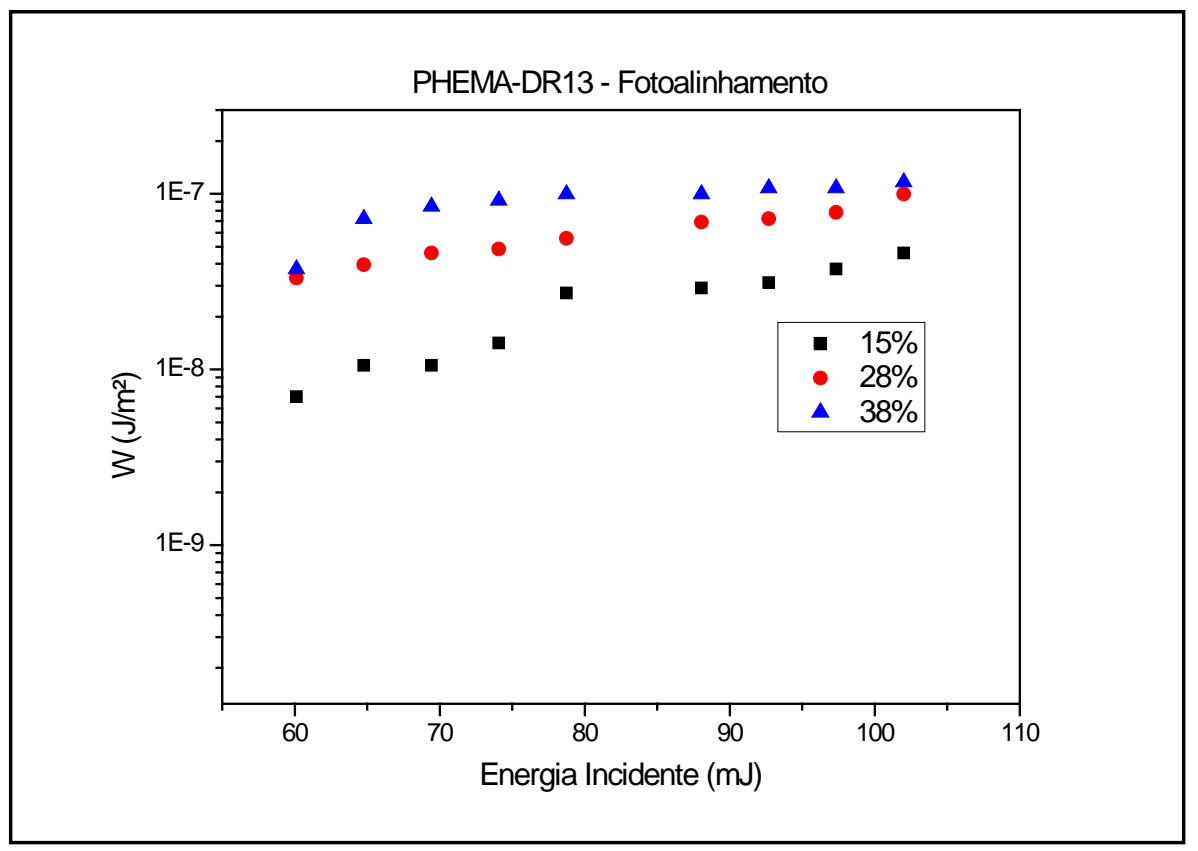

Figura 3.20: Valores da intensidade de energia de ancoramento devido ao fotoalinhamento em função da energia de luz incidente para o PHEMA-DR13 para as três concentrações de cromóforos. 
Analisando a figura 3.20, nota-se que a energia de ancoramento aumenta conforme se aumenta o valor da energia luminosa incidente, e é maior conforme se aumenta a concentração de cromóforos na matriz polimérica. Este comportamento mostra que, de fato, há uma birrefringência induzida no filme que aumenta conforme se aumenta o valor de intensidade luminosa, até atingir um patamar de saturação. Isto faz com que o PHEMA-DR13 seja realmente o candidato ideal para se estudar o efeito de competição de alinhamento através de fotoalinhamento, pois experimentalmente é possível variar a intensidade de energia de ancoramento na superfície através da manipulação da energia de luz incidente (dentro de um limite), e também variando a concentração de cromóforos no material.

\subsection{Efeitos de relevo}

Esta parte do estudo refere-se ao estudo da formação de grades de relevo em azopolímeros, e de como as moléculas do CL interagem com essa deformação da superfície da amostra. A propriedade de fotoisomerização dos azopolímeros faz com que esses materiais sejam adequados para a gravação de SRGs, se os pré-requisitos para que esse efeito ocorra forem obedecidos. De fato, de acordo com o modelo de gradiente do campo elétrico (Apêndice C) ao se usar a técnica de interferência de luz com luz linearmente polarizada na direção do padrão de interferência e com potência suficiente, ocorrerá o transporte de massa de forma a gerar um padrão senoidal na superfície do filme. O interesse principal na gravação de SRGs é se realizar o estudo de competição entre o efeito de alinhamento causado pelo relevo e o efeito de alinhamento causado pelo fotoalinhamento. Desta forma, a escolha do material foi um fator decisivo para a realização das medidas. De acordo com os resultados obtidos anteriormente, nota-se que o material mais adequado para se realizar esse tipo de estudo é o PHEMA-DR13, que possui um comportamento de fotoalinhamento em regimes de baixas potências e não degrada na presença de CL. 


\subsubsection{Caracterização das SRGs}

O arranjo experimental (figura 2.10) para a formação de SRGs é relativamente simples, e bastante funcional. Foi utilizado um laser de argônio (descrito anteriormente) para a gravação de SRG através do fenômeno de interferência de luz: o porta-amostras é acoplado a um espelho colocado perpendicularmente em relação ao substrato com o filme polimérico (este arranjo é conhecido como espelho de Loyd), como mostra a figura 3.21. Deste modo, cria-se um padrão de interferência com franjas periódicas sobre a supefície do filme, onde existe uma região iluminada (interferência construtiva) e uma região escura (interferência destrutiva), dando origem ao fluxo de matéria da região iluminada para a escura, devido à presença de um gradiente no campo elétrico. A distância (período $\boldsymbol{p}$ ) entre os canais gravados depende do ângulo entre espelho e a superfície do filme, e pode ser calculado através da relação $\boldsymbol{p}=2 \pi / \boldsymbol{k}=\boldsymbol{\lambda}(2 \operatorname{sen} \boldsymbol{\theta})$.

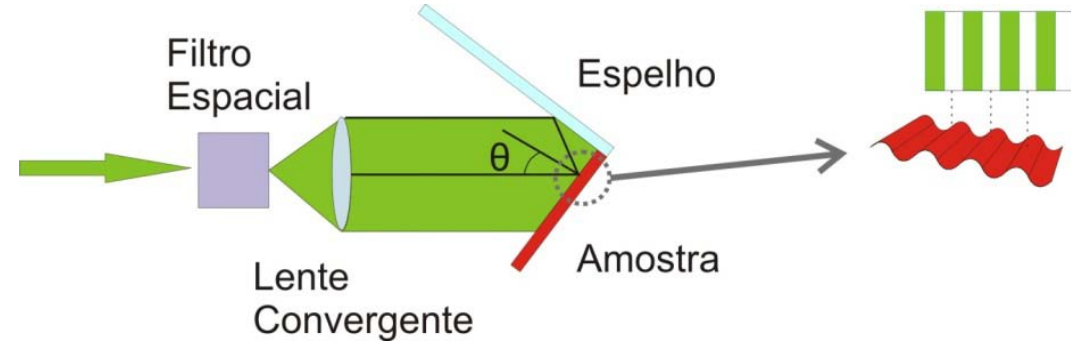

Figura 3.21: Esquema da montagem experimental usada para a formação de SRGs através de interferência de luz em um fotopolímero.

Uma maneira de se monitorar o processo de gravação de SRGs é utilizar um laser de prova de He-Ne que passa pela amostra enquanto ocorre a iluminação da amostra e realiza-se a gravação das grades. O detector é posicionado exatamente na posição onde se encontra o primeiro máximo (maior intensidade de luz) de difração que ocorre devido à formação da grade na superfície do filme, de acordo com a teoria de difração da luz. Desta forma, é possivel observar o aumento da transmitância de luz que chega ao detector, que está diretamente relacionada à profundidade dos canais que estão sendo criados (figura 3.22). Este fenêmeno é mais evidente conforme a espessura do filme 
diminui, e aumenta com o aumento da intensidade de luz incidente sobre a amostra (valor máximo da ordem de $180 \mathrm{~mW} / \mathrm{cm}^{2}$ ).

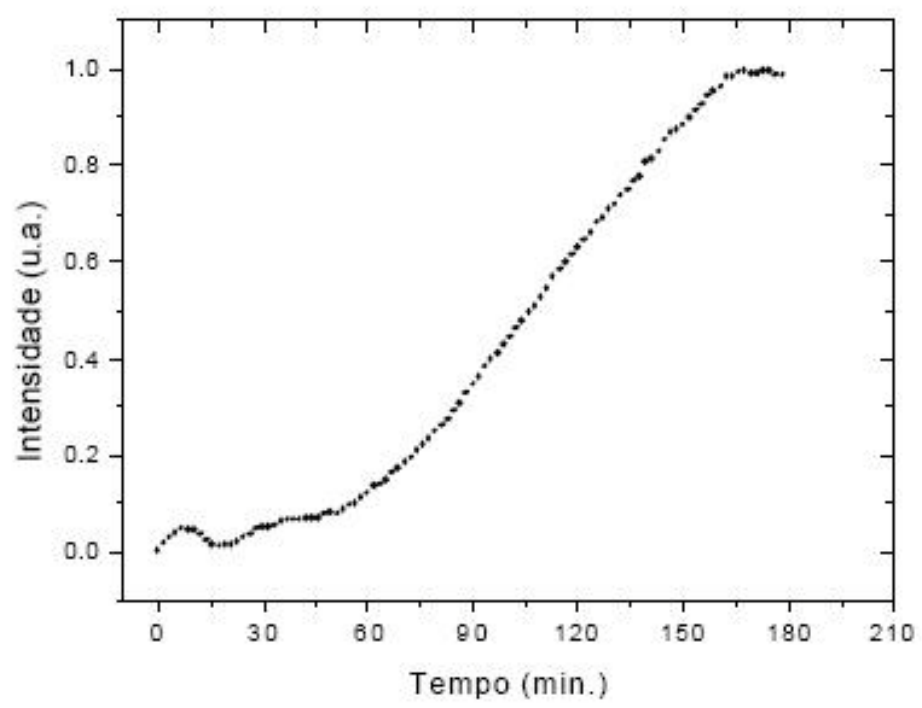

Figura 3.22: Curva típica da formação de SGR através do aumento da intensidade no primeiro máximo de difração para o PMMA-DR13.

A diferença básica entre a gravação de grades de relevo e fotoalinhamento é a existência ou não de deslocamento de massa pelo processo de fotoisomerização. Sempre que existir um gradiente de campo elétrico (com luz polarizada na direção do gradiente de campo elétrico), espera-se que haja deslocamento de massa, ou seja, formação de SRGs. Para o fotoalinhamento, porém, a única condição necessária é a incidência de luz linearmente polarizada, e como resultado final obtém-se um alinhamento dos cromóforos sem deslocamento de massa.

\subsubsection{Estudo da topologia da superfície}

Com o intuito de verificar a qualidade e reprodutibilidade da gravação de SRGs em fotopolímeros, foi realizada uma série de medidas de topografia. Para tanto, foi utilizada a técnica de AFM operando no modo de contato intermitente (tapping mode). O funcionamento básico de um AFM será mostrado no apêndice E. O resultado principal 
dessas medidas foi a caracterização das grades de relevo, obtendo valores do período e da amplitude da modulação em função da energia de luz incidente, que pode ser controlada através da potência de luz incidente e o tempo de exposição à fonte luminosa.

A caracterização topográfica foi realizada no laboratório de Microscopia Eletrônica e Varredura do Instituto de Física de São Carlos (SP). A prioridade da medida era saber com uma precisão mínima a profundidade $\boldsymbol{p}$ gravada num filme com concentração fixa em função do tempo de exposição (potência luminosa incidente fixa). Tentou-se conseguir uma medida confiável, porém com tempo de medida “curto". Uma imagem com resolução “média” de 128x128 linhas em $50 \mu \mathrm{m}$ leva cerca de 40 min. para ser obtida. Para diminuir o tempo de aquisição, as medidas foram realizadas apenas um uma faixa da escala de tela cheia (com $50 \mu$ m consegue-se observar até três períodos gravados pegando somente uma faixa vertical, e não a tela toda da imagem). Desta forma é possível obter uma boa estimativa do perfil topográfico em 2-D, para uma dada concentração e tempo de exposição.

Foram preparadas cerca de 20 (vinte) amostras, e foram medidas 16 (dezesseis) amostras deste total. O lote de amostras constituía-se basicamente de 3 (três) filmes distintos do material PHEMA-DR13 (3 diferentes concentrações 17\%, 28\% e 38\%), com 4 (quatro) tempos de exposição cada (1, 2, 3, 5 min. de exposição com potência incidente de $260 \mathrm{~mW} / \mathrm{cm}^{2}$ em $514 \mathrm{~nm}$ ). Algumas imagens não foram possíveis de ser obtidas, ou estavam planas (flat) e foram descartadas. Para cada amostra, foi feita a análise de seção transversal, que dá uma imagem de um perfil senoidal bidimensional. Foi utilizado o software Nanoscope III fornecido pela Digital Instruments para a análise das figuras obtidas no AFM. O interesse principal das medidas consiste-se em determinar qual a profundidade da grade gravada, bem como sua periodicidade. A análise das imagens será mostrada em seguida nas figuras 3.23 e 3.24, as legendas explicam cada parâmetro relevante. Por questão de simplicidade, serão mostradas apenas as figuras para a concentração de $15 \%$ com 5 min. de exposição, e em seguida uma tabela com todos os valores obtidos através da análise das figuras. No caso da 
profundidade, foram feitos vários tratamentos de imagem para a determinação da amplitude do relevo, e foi calculado o valor médio para cada configuração.
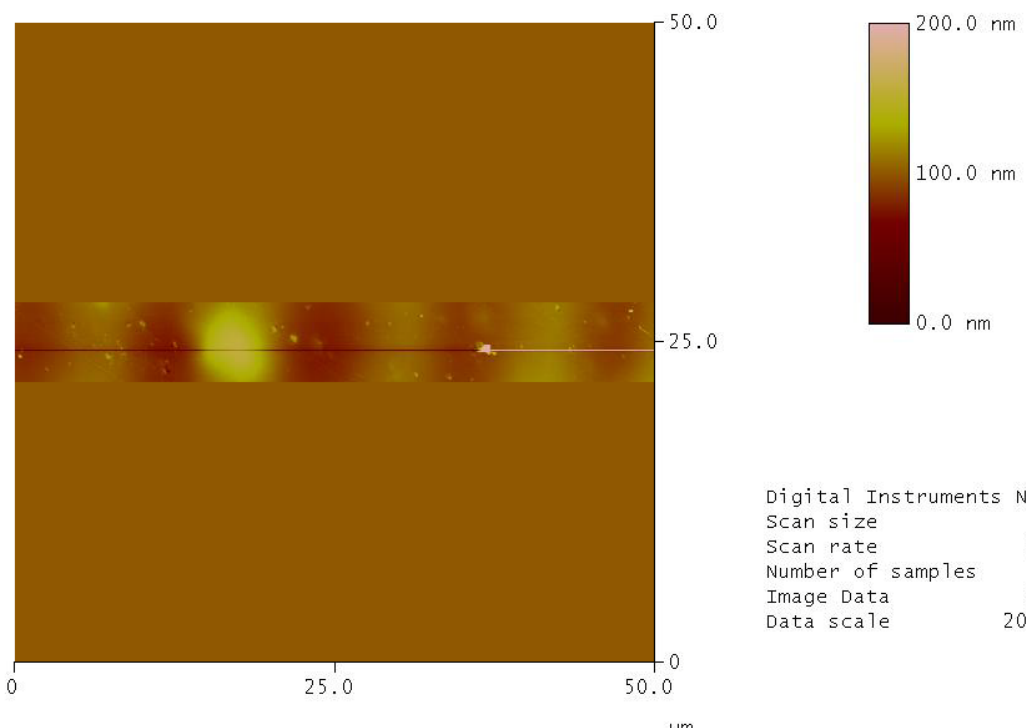

a 5 a. 000

Figura 3.23: Imagem topográfica obtida pela técnica de AFM para o PHEMA-DR13 com concentração de 15\% com 5 min. de exposição. 


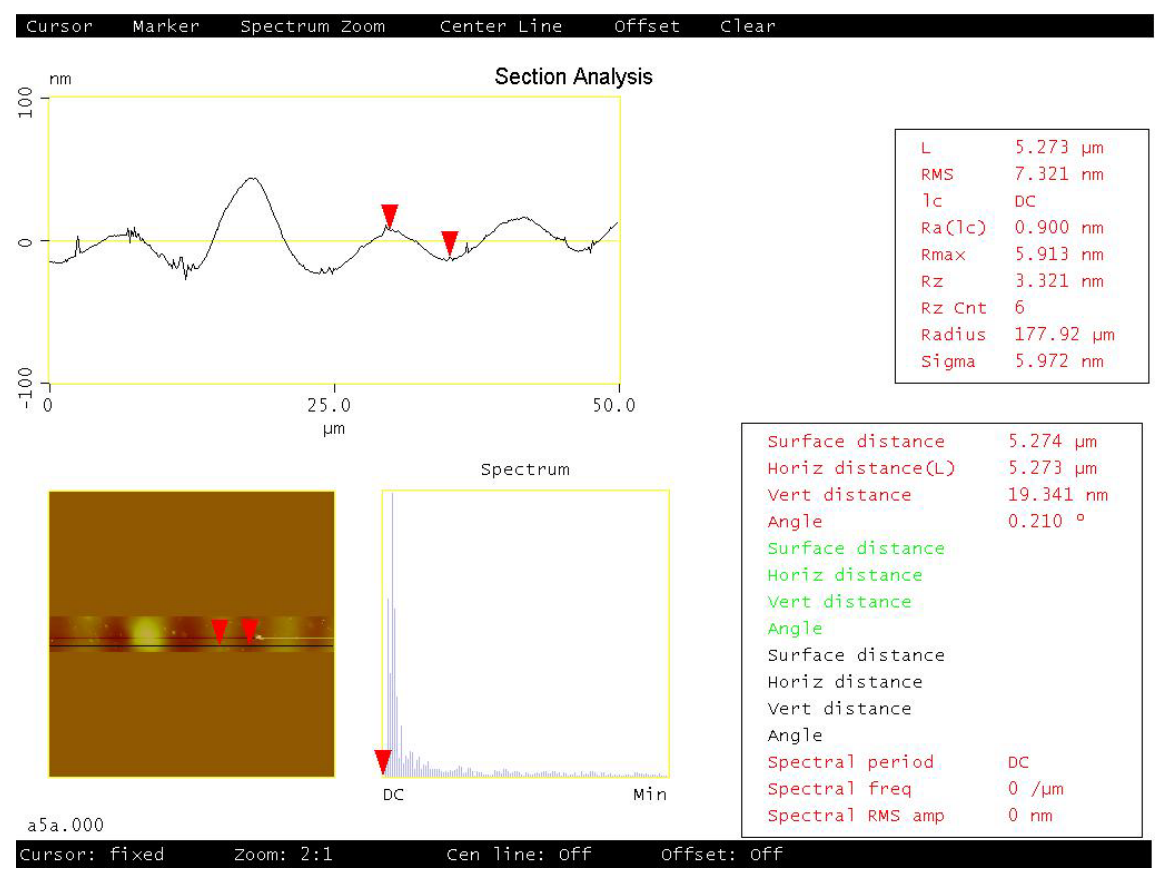

Figura 3.24 Medida de AFM para a concentração de 15\% com 5 min. de exposição: perfil em 2D; o valor de profundidade média encontrado para esta amostra foi de 18,50(0,56) $\mathrm{nm}$.

Foi feita uma imagem inteira e em alta resolução (full resolution) usando o melhor filme disponível, com um filme com 15\% de concentração irradiado por 2 min. na potência citada. Neste filme foi feito o fotoalinhamento a $45^{\circ}$ da direção dos canais da grade, ou seja, para esta concentração é possível realizar os dois efeitos (SRGs e fotoalinhamento) sem que um interfira no outro. A figura 3.25 e 3.26 mostra a imagem obtida: 

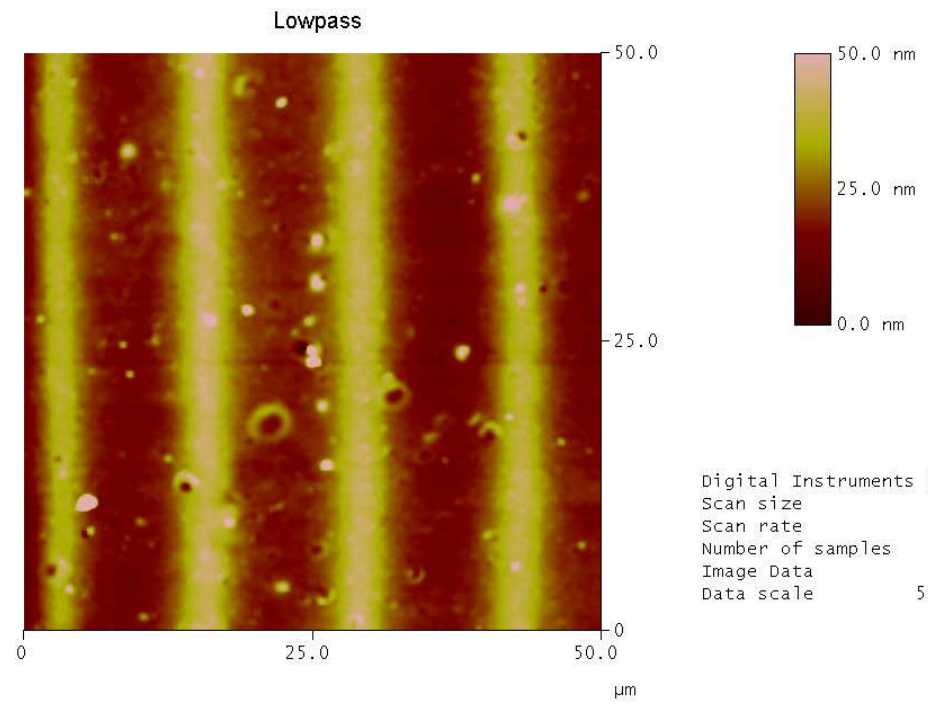

$\mathrm{e} 2 \mathrm{a} .000$

Digital Instruments Nanoscope

Scan size $\quad 50.00 \mu \mathrm{m}$

Scan rate $\quad 0.2196 \mathrm{~Hz}$

Number of samples 256

Data scale $\quad 50.00 \mathrm{~nm}$

Figura 3.25: Imagem topográfica medida por AFM para a concentração de 15\% com 2 min. de exposição.

Cursor Marker Spectrum Zoom Center Line offset Clear
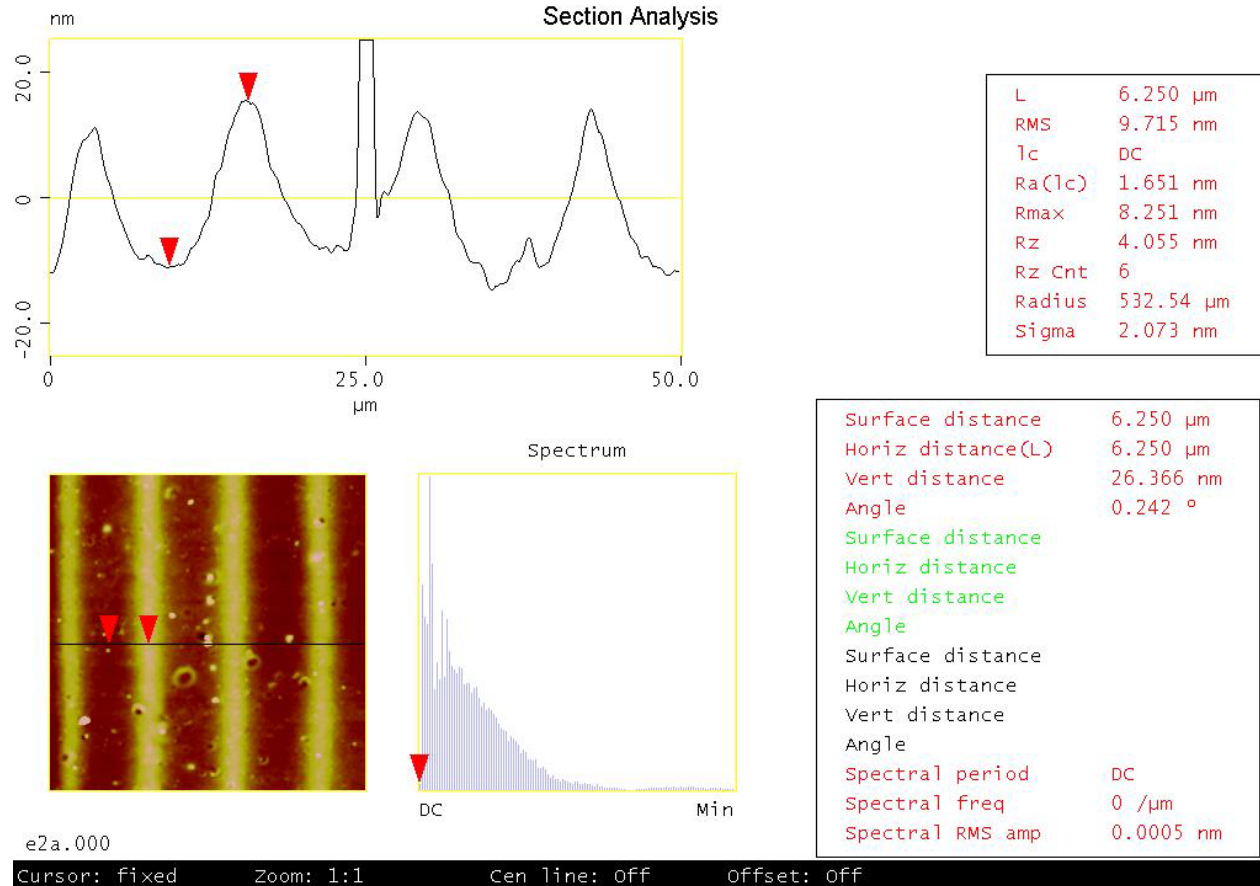

Figura 3.26: Medida de AFM para a concentração de 15\% com 2 min. de exposição: perfil em 2D; a profundidade média obtida foi de 29,86(37) $\mathrm{nm}$. 
Tabela 3.3: Valores medidos para a profundidade da SRG gravada no PHEMMA-DR13, para uma potência incidente constante $\left(180 \mathrm{~mW} / \mathrm{cm}^{2}\right)$ em função do tempo de exposição, para as duas concentrações onde foram observadas SRGs.

\begin{tabular}{|l|l|l|l|}
\hline & \multicolumn{3}{l|}{ Tempo de exposição } \\
\hline concentração & 1 min. & 2 min. & 5 min. \\
\hline $15 \%$ em massa & $15,28(1,31) n m$ & $29,86(3,70) n m$ & $36,85(2,62) n m$ \\
\hline $28 \%$ em massa & $19,12(1,08) n m$ & $36,68(2,65) n m$ & $50,12(1,45) n m$ \\
\hline
\end{tabular}

Foi observado que havia várias impurezas na superfície do filme. De acordo com as imagens registradas foi descartada a possibilidade de ser poeira depositada, pelo tamanho das estruturas encontradas, e também foi descartada a possibilidade da existência de artefatos na aquisição da imagem que podem resultar nessas imagens. Inclusive, observaram-se pequenas "esferas" alinhadas nesses filmes de maior concentração. O mais incomum nesta figura é que as partículas (ou aglomerados) são aparentemente do mesmo tamanho, e aparentemente alinhadas numa mesma direção. Além disso, essa estrutura foi observada em dois filmes diferentes (todos com concentração alta de cromóforos e com tempo de exposição superior a 3 min.). Foi adquirida apenas uma imagem (figura 3.27) pra registrar esse fato. 

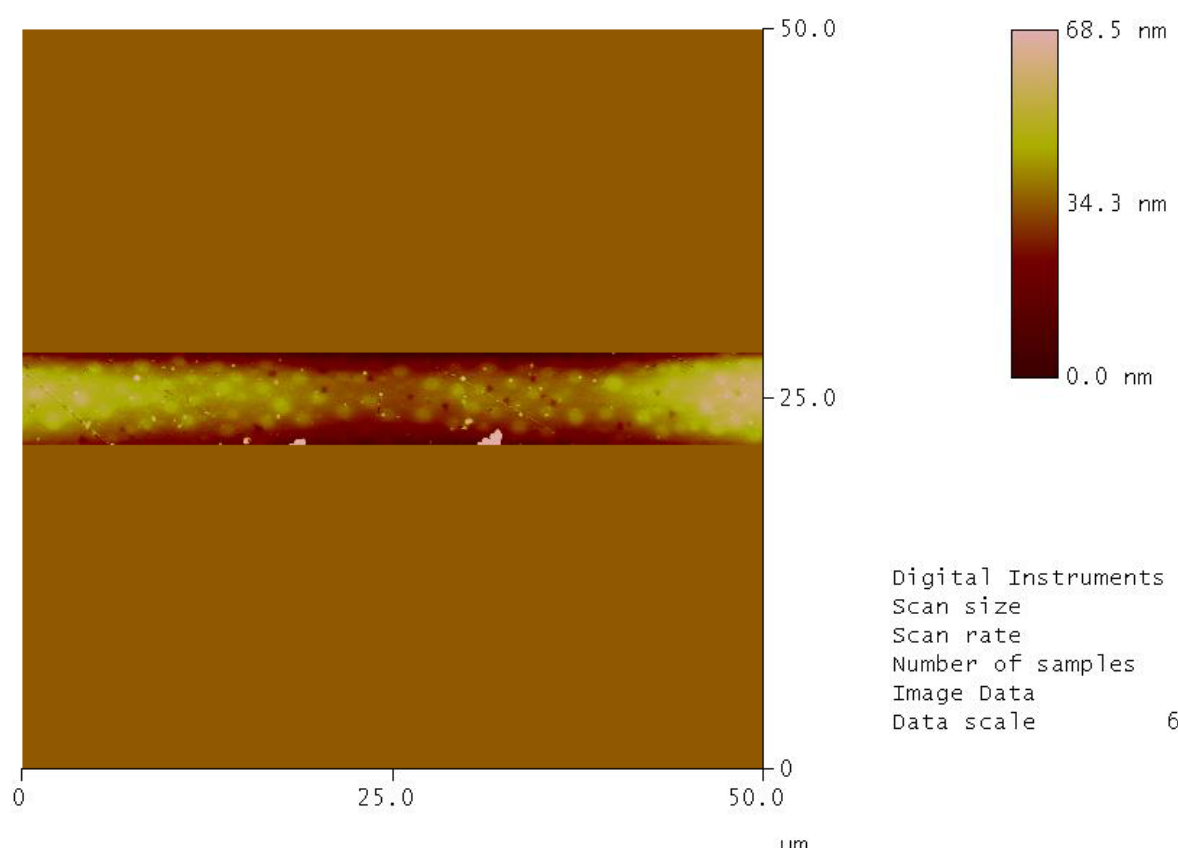

Digital Instruments Nanoscope

Figura 3.27: Imagem de pequenos defeitos encontrados no filme, onde inicialmente deveria haver apenas SRGs gravadas.

Uma possível explicação para a formação desses tipos de estruturas pode ser feita levando-se em conta a evaporação irregular do solvente, que eventualmente pode gerar uma aglomeração dos cromóforos resultando em uma micro-separação de fases. Para este material, a secagem foi realizada em uma estufa a vácuo, justamente para aumentar a velocidade de evaporação do solvente. Desta forma, pode haver uma evaporação heterogênea do solvente devido a um gradiente de temperatura no substrato, que pode resultar em um filme não uniforme na sua superfície. No processo de deposição do filme foi observado que dependendo das condições iniciais na estufa (pressão de vácuo e temperatura) o filme se depositava de maneira irregular, com alta variação de concentração de material na superfície. Desta forma, o surgimento da estrutura 
observada pode ser explicada em função da variação de concentração do polímero disperso no solvente em conjunto com uma evaporação irregular deste solvente.

\subsubsection{Intensidade de ancoramento topográfico $\mathrm{W}_{\underline{T P}}$}

Para se determinar a intensidade de ancoramento induzida pelo relevo, foi utilizado a expressão (eq. 17) dada pelo modelo de Berreman, que relaciona a intensidade de ancoramento com o período e profundidade das SRGs gravadas. Analisando os dados obtidos com a técnica de AFM, foi possível fazer uma média da profundidade dos canais em função da energia incidente e concentração de cromóforos, e as energias de ancoramento de topografia calculadas através do modelo de Berreman [D.W. Berreman, 1972] são mostradas na figura 3.28:

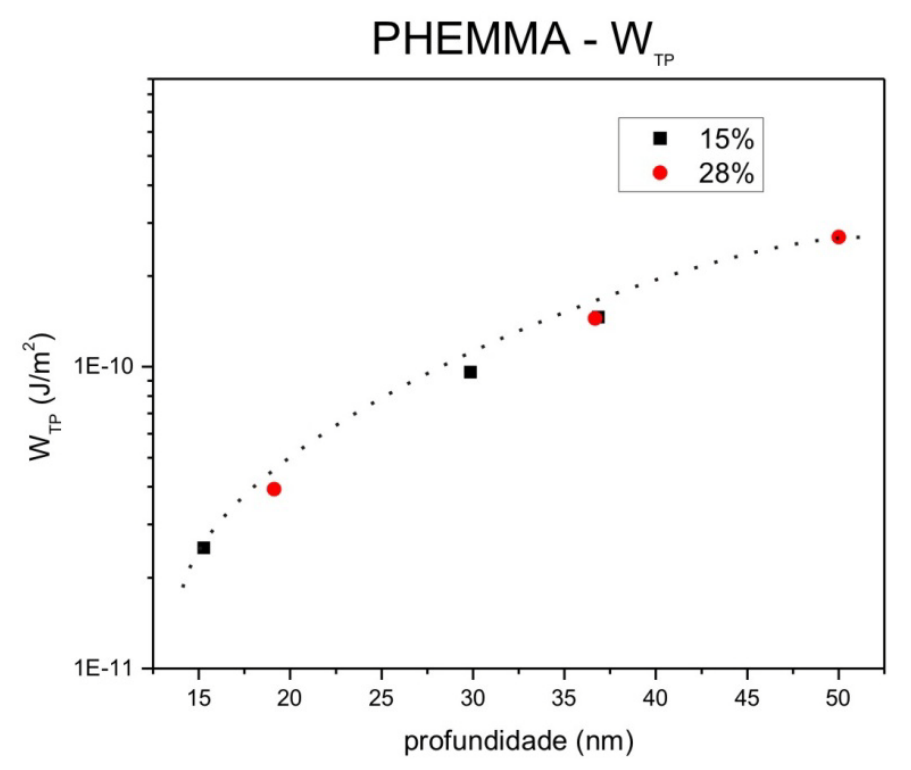

Figura 3.28: Valores calculados do modelo de Berreman da intensidade de energia de ancoramento devido às SRGs em função da profundidade das mesmas - a linha tracejada é meramente um guia para os olhos. 
O estudo foi realizado em uma região dentro do limite de validade do modelo de Berreman, pois segundo a teoria, o modelo é válido quando o fator $\boldsymbol{A q}=2 . \pi / \boldsymbol{p}$ é de pequena magnitude. Neste caso, $\boldsymbol{p}=15 \mu \mathrm{m}$ e $\boldsymbol{A} \sim 20 \mathrm{~nm}$, de forma que o produto $\boldsymbol{A \boldsymbol { q } =}$ 0,08 pode ser considerado pequeno e o modelo é válido. Aparentemente o trabalho foi realizado no limite de gravação de grades, ou seja, de acordo com as medidas realizadas não se espera conseguir gravar grades mais profundas sem que o efeito térmico seja predominante e ocorra a degradação do filme. Uma possível solução poderia ser diminuir o período para aumentar o valor da energia de ancoramento, porém quanto menor o período menor é a área iluminada no espelho de Loyd (região onde é gravada a SRG), no caso de $15 \mu \mathrm{m}$ a área gravada é menor do que $0,4 \mathrm{~cm}$ - o que já é quase um limite experimental para se observar o efeito de competição no método de cela cruzada. É necessário garantir que na área gravada a superfície de grades seja homogênea e com dimensões maiores do que a distância de separação entre as lâminas que formam a cela.

De acordo com o modelo de Berreman, a energia de ancoramento de relevo depende do período e da profundidade dos canais gravados. Um resultado das medidas realizadas foi a obtenção da intensidade de ancoramento induzida por relevo, que chega a ser duas ordens de grandeza menor do que a energia de ancoramento induzida por fotoalinhamento. Apesar de haver a gravação de SRGs com o período esperado, a profundidade é muito pequena e a intensidade de energia de ancoramento resultante é pequena quando comparada com outros métodos de tratamento de superfície. Uma alternativa proposta foi realizar outro tipo de tratamento de superfície, que tivesse a magnitude da intensidade de energia de ancoramento por fotoalinhamento, e será descrita a seguir. 


\subsection{Esfregamento}

Uma alternativa para contornar o problema de SRGs foi então proposta, fazendose outro tratamento de superfície para realizar o estudo de competição de alinhamento. A técnica escolhida foi a técnica de esfregamento (rubbing), que é o método mais utilizado para construção de displays de LCD por ser altamente eficaz (no sentido de fornecer uma energia de ancoramento “forte”). O processo de esfregamento, como o próprio nome sugere, consiste de um processo de esfregar levemente uma superfície adequada (no presente caso, foi usado um tecido macio tipo veludo) contra a superfície a ser tratada, numa direção preferencial. O grande inconveniente deste método está justamente na irregularidade do esfregamento, que eventualmente induz algumas ranhuras, introduz impurezas e eventualmente até cargas superficiais [I. H. Bechtold et al., 2003]. Como no caso anterior, o material adequado para essa finalidade é o PHEMA-DR13. O regime de fotoalinhamento em potências relativamente baixas é um pré-requisito para este estudo, pois foi verificado que potências altas podem prejudicar o tratamento de superfície feito previamente, e em casos extremos podem danificar e degradar o filme.

\subsubsection{Introdução}

No caso de superfícies poliméricas, duas hipóteses são aceitas para explicar o alinhamento das moléculas de CL através da técnica de esfregamento. A primeira hipótese é de que o alinhamento do CL é devido à introdução de ranhuras no substrato, que segundo o modelo de Berreman discutido anteriormente, é o estado que minimiza a energia livre do sistema quando as moléculas se alinham na direção das ranhuras. Em outras palavras, o modelo prevê que efeitos elásticos anisotrópicos de longo alcance induzidos por uma superfície de relevo periódica são responsáveis pelo alinhamento de CL. A outra hipótese foi introduzida por Castellano [J. A. Castellano, 1983], e considera 
que o esfregamento produz um alinhamento nas cadeias poliméricas, e que a interação dessas moléculas alinhadas na superfície com o CL através de forças de van der Waals é o processo responsável pelo alinhamento do CL. De fato, experimentalmente as duas situações são possíveis, mudando-se alguns parâmetros como o tipo de polímero estudado, o tipo de superfície utilizada para o esfregamento, a pressão entre as superfícies esfregada, entre outros.

\subsubsection{Procedimento experimental}

Com o intuito de garantir a reprodutibilidade da intensidade de energia de ancoramento devido ao processo de rubbing $W_{r}$, foi usado um aparato que visa ter controle sobre este efeito. A montagem experimental (mostrada na figura 3.29) constituía-se basicamente de uma esteira móvel onde a amostra era fixada, e um cilindro fixo recoberto com um tecido macio era usado para o esfregamento propriamente dito (foi utilizado veludo neste estudo). Uma fonte de alimentação DC movimentava um pequeno motor de passo que fazia a esteira mover-se para frente e para trás num eixo fixo, com o cilindro fixo a uma altura pré-determinada. Esse aparato visa, principalmente, garantir que a força aplicada sobre o filme seja exatamente a mesma em todos os casos, ou seja, estamos interessados em garantir a reprodutibilidade do esfregamento. A velocidade de translação da esteira foi fixada, bem como a altura $\mathbf{z}$ da superfície da amostra e o tecido responsável pelo esfregamento. 


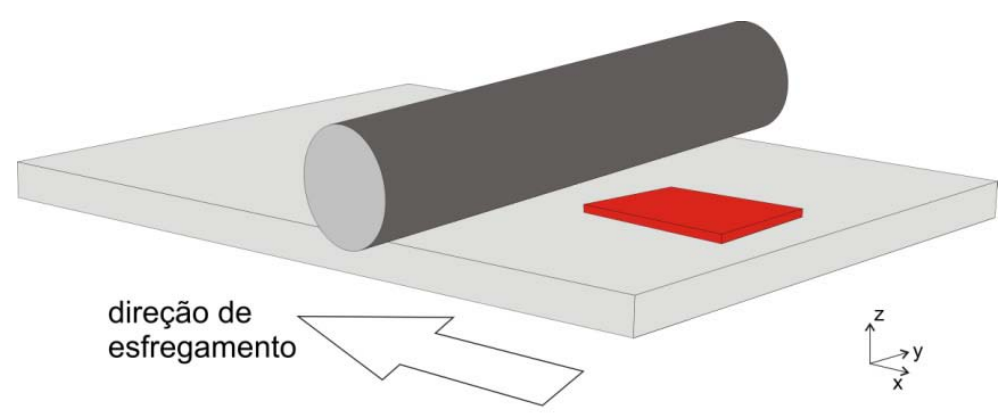

(a)

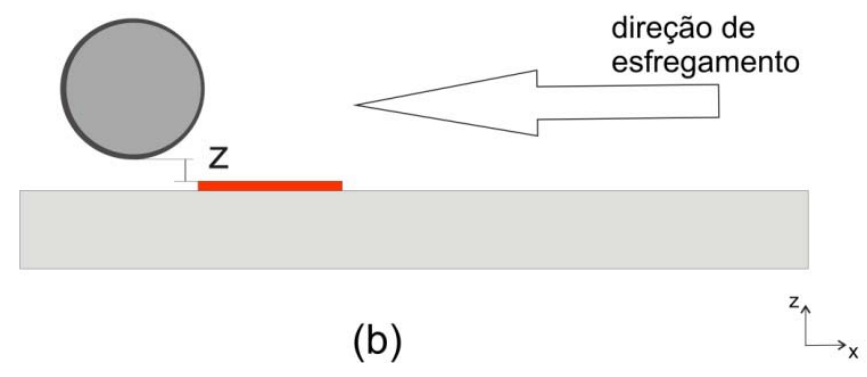

Figura 3.29: Esquema experimental da montagem utilizada para a realização de esfregamento no material (a) vista em perspectiva, e (b) vista lateral.

Um cilindro recoberto com o tecido era posicionado a certa altura da superfície do filme, de modo a tocar levemente a superfície do mesmo. Na verdade, foram feitos testes preliminares para determinar qual a distância ideal entre o tecido e o filme a ser esfregado, de modo a conseguir o efeito sem realizar muita pressão no esfregamento e eventualmente sujar e arrastar material indesejavelmente. Como o método de tratamento de superfície não nos permite manipular a formação de ranhuras na superfície de modo reprodutivo, optamos por fazer um esfregamento suave, visando apenas o alinhamento das cadeias principais do azopolímero. Foi escolhido um valor de altura em que o processo fosse o mais suave possível, de modo que o veludo tocasse levemente na superfície do filme de forma a minimizar efeitos não desejados.

Foram realizadas séries de um até quatro esfregamentos na mesma direção para cada concentração de cromóforos disponíveis. Cada amostra era cuidadosamente posicionada e alinhada no porta-amostras, e então o esfregamento era realizado. Escolhia-se um valor fixo na fonte de alimentação DC para garantir que o motor de 
passo mantivesse sempre a mesma velocidade, e a distância entre a superfície do filme e o tecido $\mathbf{z}$ (figura 5.9-b) foi previamente escolhida e mantida constante.

\subsubsection{Estudo da topologia da superfície}

Para o estudo da topologia da superfície, foi utilizada uma montagem especial operando no modo de AFM. Este aparelho não é um microscópio de AFM comercial como os utilizados anteriormente neste estudo, porém opera de maneira similar e usando os mesmos softwares e placas de controle que um AFM comercial. Este é um projeto desenvolvido pelo prof ${ }^{0}$ Dr. Antônio Domingues dos Santos no Laboratório de Materiais Magnéticos (LMM) do IFUSP-SP. Um inconveniente encontrado na realização dessas medidas é a própria geometria da amostra, que deveria ser da ordem de $1,0 \times 1,0 \mathrm{~cm}$ para o posicionamento do porta-amostras. Para amostras maiores existe a dificuldade de se manter a estabilidade do filme, que fica apoiado sobre uma superfície com uma área útil da ordem de $1,0 \mathrm{~cm}^{2}$. Um dos objetivos na caracterização morfológica é saber qual é basicamente a origem do efeito de alinhamento, se é devido a imperfeições na superfície da amostra (onde se aplica o modelo de Berreman), ou se há apenas o alinhamento das cadeias poliméricas devido ao esfregamento.

Foram realizadas diversas medidas, e foi observado que as imagens são praticamente indistinguíveis, sendo difícil (senão impossível) determinar qual a concentração de cromóforos ou número de esfregamentos realizados somente analisando as imagens. Por questão de clareza, são mostradas somente três imagens distintas na figura 3.30. A título de comparação, foi realizado um esfregamento bastante extremo, a ponto de se notar visualmente arranhões na superfície do filme. Isso foi feito porque é necessário ter uma idéia da qualidade do processo de esfregamento realizado, e saber a princípio se o fenômeno de alinhamento de CL é causado por efeito topográfico ou pela interação do CL com as moléculas alinhadas do substrato. 


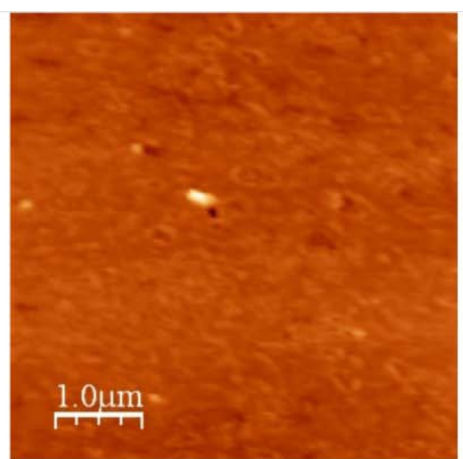

(a)

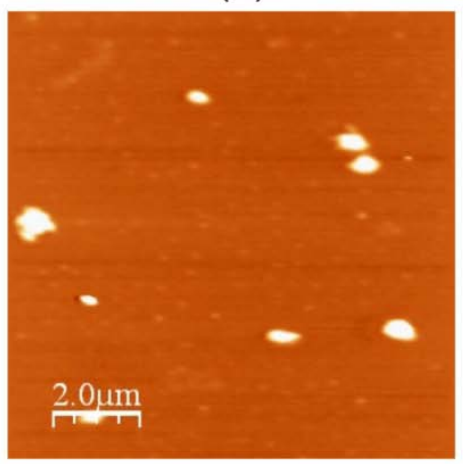

(c)

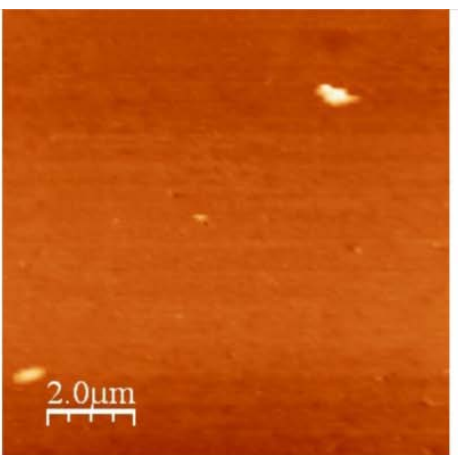

(b)

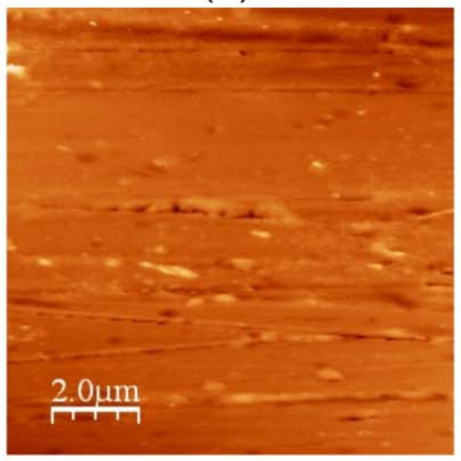

(d)

Figura 3.30: Imagem topográfica obtida pela técnica de AFM para o PHEMA-DR13 tratado através do esfregamento da superfície para uma amostra com $28 \%$ de concentração esfregada uma vez (a) e (b), duas vezes (c) e com esfregamento extremo (d).

Analisando a figura 3.30 (a, b e c), nota-se que o esfregamento foi realizado sem danificar a superfície, e que as maiores ranhuras apresentam profundidade da ordem de 5 nm. A imagem da figura 3.30-a foi feita numa resolução 5,0x5,0 $\mu$ m, e mostra a mesma área da figura 3.30-b, que foi feita em uma área de 10,0x10,0 $\mu$ m. Nota-se que a amostra é basicamente plana, com alguns defeitos de superfície mostrando alguma irregularidade, porém ao se realizar várias medidas em pontos distintos nota-se que as imagens são bastante semelhantes. Um resultado importante do ponto de vista de operação foi que a medida de topologia não altera a superfície varrida: uma das grandes dificuldades encontradas foi justamente a de se achar um bom valor de setpoint para se trabalhar sem criar ranhuras ou defeitos na superfície do polímero. 
O resultado mais importante dessa medida de caracterização foi poder verificar a qualidade de esfregamento, para se evitar uma situação de desgaste e possível degradação do filme, prejudicando o processo de alinhamento das moléculas de CL. Foi feito uma medida com um filme esfregado de maneira intensa, para se ter uma idéia de quais seriam os efeitos não desejáveis para este processo. A imagem 3.30-d mostra que de fato há a formação de ranhuras consideráveis, com indícios de remoção de material. A ordem de grandeza das ranhuras é cerca de $20 \mathrm{~nm}$, e não se observou nenhum padrão de relevo na superfície do filme, embora a direção das ranhuras seja dada pela direção de esfregamento.

\subsubsection{Intensidade de ancoramento de esfregamento $\mathrm{W}_{\underline{\underline{r}}}$}

Para cada série de esfregamento e concentração, foi montada uma cela híbrida e à partir da medida do ângulo de twist determinamos a intensidade de energia de ancoramento $W_{r}$ devido ao fenômeno de esfregamento em função da quantidade de esfregamentos realizados através da expressão mostrada na Eq.10. A figura 3.31 ilustra o comportamento da intensidade de energia de ancoramento em função do número de esfregamentos, para cada concentração de cromóforos. 


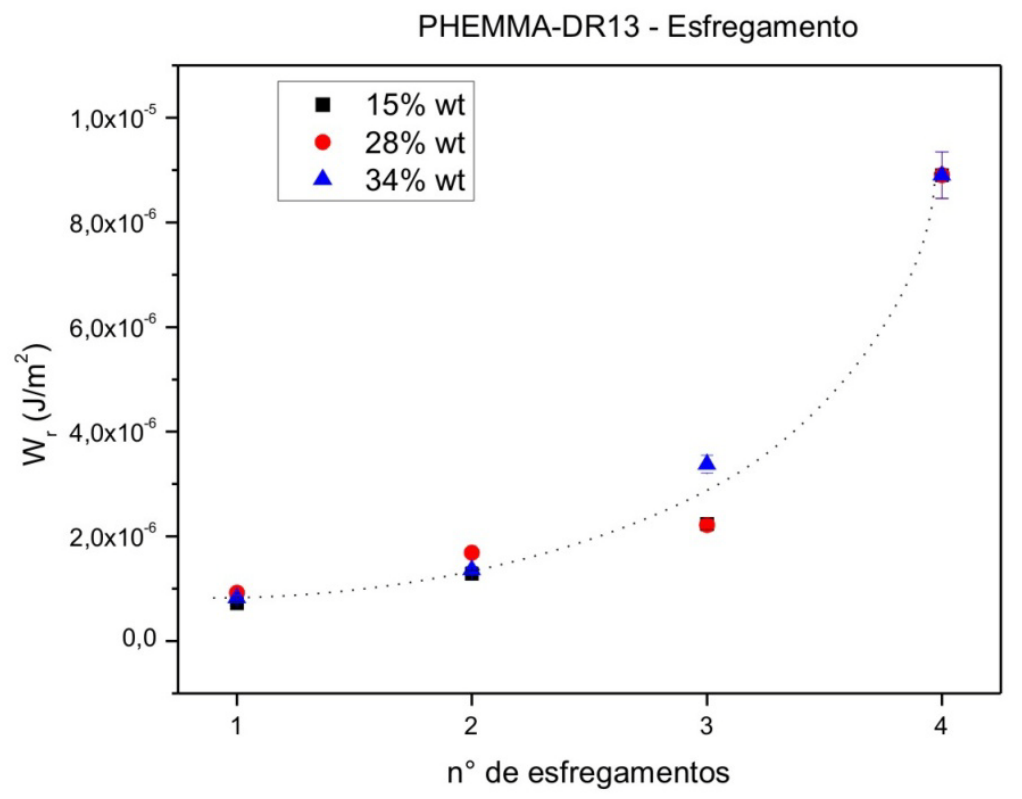

Figura 3.31: Intensidade de energia de ancoramento obtida através do método de cela híbrida para processo de esfregamento para o PHEMA-DR13 - a linha tracejada serve apenas de guia para os olhos.

Observa-se que o valor de intensidade de energia de ancoramento não depende da concentração de cromóforos para este material, porém há dependência em relação ao número de esfregamentos realizados. Esse resultado não é surpreendente, uma vez que o processo de esfregamento resulta em um certo ordenamento das cadeias mais longas do polímero (cadeia principal). A interação das cadeias principais alinhadas com as moléculas do CL induz um ordenamento a essas moléculas. Quanto maior o número de esfregamentos, maior a quantidade de cadeias principais do polímero alinhadas na direção do esfregamento, e conseqüentemente, maior será a interação de alinhamento das moléculas do CL. No azopolímero utilizado, isso significa que as cadeias principais serão susceptíveis ao esfregamento, mas não os grupos azo laterais (não tão intensamente quanto a cadeia principal). Dessa forma, a direção de orientação se dá preferencialmente na direção do esfregamento, que é a direção de alinhamento das cadeias principais. A interpretação deste resultado foi proposta por S. Kumar et al, [S. Kumar et. al. 2095], e segundo os autores a direção de alinhamento das moléculas de CL 
ocorre devido a uma anisotropia de rugosidade da superfície: ou seja, a direção de alinhamento se dá na direção de menor variação da rugosidade na superfície.

\subsection{Conclusões}

A importância dos resultados obtidos até agora foi verificar o comportamento de fotoalinhamento para três azopolímeros distintos. Para o estudo que se pretende realizar, deseja-se comparar dois efeitos de orientação: inicialmente com o mesmo potencial de orientação, porém com direções diferentes; em seguida, a competição de orientação entre o potencial fotoinduzido e efeitos topográficos. Para isso, é importante que um efeito não interfira em outro previamente gravado. Desta forma, a escolha de um material adequado para que o efeito de fotoalinhamento ocorra para baixas potências de iluminação e tempos relativamente curtos é imprescindível. É necessário também que haja uma birrefringência remanescente após a relaxação, e é desejável que esta seja proporcional à potência utilizada para realizar o fotoalinhamento para que seja possível controlar a intensidade de ancoramento na superfície. Todas essas medidas preliminares servem como base para a escolha do material adequado, dependendo do tipo de estudo a ser realizado. Para efeitos de interação do substrato com CL, o material PMMA-DR13 pode ser desconsiderado, pois foi observado que este material se degrada na presença de CL. O filme de PS119 apresenta um comportamento de fotoalinhamento viável para regimes de altas potências quando há uma birrefringência remanescente. Devido à facilidade de preparação de filmes que recobrem bem a superfície e são homogêneos, esse material foi utilizado para o estudo de efeitos de competição em substratos com microtexturas.

O filme de PHEMA-DR13 apresentou um comportamento de fotoalinhamento reprodutível em regimes de baixas potências, e também é possível variar a concentração de cromóforos neste material. Nos filmes de PHEMA-DR13 verificamos que é possível gravar SRGs com potências moderadas, porém a profundidade dos canais produzidos é 
muito pequena. Concluímos que não seria possível estudar o efeito de competição devido aos efeitos topográficos e o fotoalinhamento porque a intensidade de ancoramento devido aos efeitos topográficos é muito menor do que a intensidade de ancoramento devido ao fotoalinhamento dos grupos azocorantes.

O grande resultado encontrado neste capítulo pode ser resumido a uma expressão: manipulação da intensidade de ancoramento em azopolímeros. Com este estudo preliminar, foi possível saber de antemão qual a magnitude de intensidade de ancoramento que se consegue usando-se três técnicas distintas. Para um mesmo material, observou-se que a intensidade de ancoramento de relevo apresentou o menor valor entre as três técnicas, e isso pode ser explicado pelo produto $\boldsymbol{A q}$ no modelo de Berreman (Eq. 17) que mostra a relação do período da SRG com a profundidade atingida. De fato, para o período de $15 \mu \mathrm{m}$ conseguiu-se a profundidade máxima de $50 \mathrm{~nm}$, o que de acordo com nossos resultados significa um ancoramento fraco. Outro resultado importante encontrado foi que a intensidade de ancoramento de esfregamento é maior do que a intensidade de ancoramento fotoinduzida. Esse resultado pode ser explicado ao se notar como se dá a orientação das moléculas do CL, em cada caso. Para o fotoalinhamento, o efeito principal é causado pela interação das moléculas do CL com os grupos azocorantes orientados em uma direção preferencial. Neste caso, somente as cadeias laterais do polímero estão promovendo a orientação do CL, e conforme observado depende principalmente da natureza e concentração de cromóforos e da potência de luz incidente. Já para o esfregamento, entende-se que há o alinhamento das cadeias principais na direção do esfregamento. Neste caso, a orientação do CL é devido a interações entre as moléculas do CL e as cadeias principais da matriz polimérica. É de se esperar, portanto, que a interação entre as cadeias principais e o CL seja mais intensa do que a interação dos grupos laterais e o CL. 


\section{Competição de orientação: substrato com microtextura}

Neste capítulo, será apresentado o estudo do alinhamento induzido ao cristal líquido por superfícies com texturas na escala micrométrica e submicrométrica, onde serão utilizados polímeros fotossensíveis. Inicialmente será introduzido o conceito de microtextura e o procedimento experimental adotado neste trabalho.

Vale lembrar que neste caso está sendo feito o estudo do efeito de competição de alinhamento em CLs a partir do mesmo potencial de alinhamento, só que em direções distintas. Nestas condições, pode-se supor que a intensidade de energia de ancoramento possui a mesma magnitude em cada canal gravado, mudando somente a direção do eixo fácil induzido.

\subsection{Introdução}

O objetivo desta parte do trabalho é estudar efeitos de competição de orientação para o cristal líquido 5CB utilizando os filmes de fotopolímero para produzir substratos com padrões de microtextura com diferentes orientações dos grupos azo seguindo uma distribuição periódica no filme. Quando a periodicidade da textura gravada no substrato torna-se pequena, e comparável ao comprimento de correlação da ordem orientacional. Neste caso, se as moléculas seguem a orientação imposta pela superfície a deformação elástica resultante na camada superficial é muito grande. O uso de filmes de fotopolímeros permite a gravação de uma textura periódica sobre o filme, com trilhas com diferentes direções de orientação e com mesma intensidade de ancoramento. Nesse caso, a contribuição da energia elástica também estará presente, porém devido às 
distorções de orientação resultante da configuração do diretor na camada superficial, em princípio apenas no plano paralelo à superfície. Tais tratamentos de superfície também oferecem interesse tecnológico na aplicação em dispositivos eletro-óticos de cristal líquido [B. Lee et al., 2001], pois possibilitam o controle do alinhamento da amostra, além de resultar em novos estados orientacionais.

\subsection{Aspectos teóricos}

Nesta seção, será feita uma investigação teórica dos estados orientacionais induzidos a uma amostra de cristal líquido por um substrato texturizado com alternância periódica das direções de orientação impostas pela superfície [F. Batalioto et. al., 2005]. Na figura 4.1 é apresentado um desenho esquemático desta textura, juntamente com os eixos cartesianos.

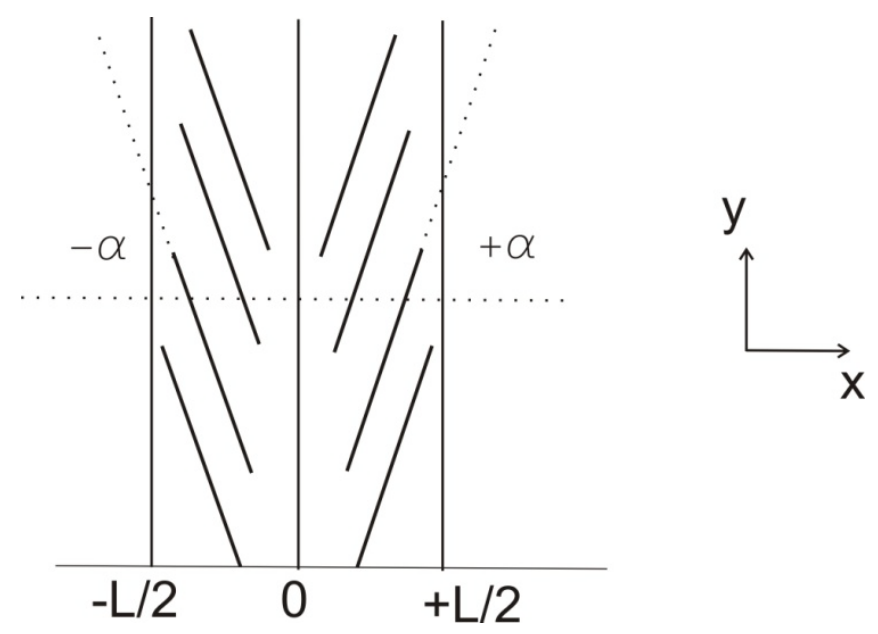

Figura 4.1. Desenho esquemático da textura superficial investigada teoricamente.

Na figura 4.1 as linhas diagonais representam a direção do eixo fácil, ou seja, a direção eixo fácil gravado sobre o substrato, onde $\alpha$ é o ângulo entre o eixo fácil e o eixo cartesiano $\boldsymbol{x}$. O período $\boldsymbol{L}$ é definido pela orientação na direção $-\boldsymbol{\alpha}$ no intervalo de $-\boldsymbol{L} / 2$ a 0 (zero) e $\boldsymbol{\alpha}$ no intervalo de 0 (zero) a $\boldsymbol{L} / 2$. Cada região entre $\boldsymbol{m} \boldsymbol{L} / 2$ e $(\boldsymbol{m}+1) \mathbf{L} / 2$, com m inteiro (positivo ou negativo), representa um domínio da textura. Havendo esta 
simetria, o ângulo $\phi_{0}$ entre o diretor $\mathbf{n}$ (que caracteriza a direção de alinhamento do cristal líquido) e o eixo $\boldsymbol{x}$ nas bordas dos domínios só pode assumir dois valores: $\phi_{0}=0$ ou $\phi_{0}=\pi / 2$. Cada uma destas duas situações gera um padrão diferente para o diretor $\boldsymbol{n}$, que é representado pelo Estado I e Estado II, como na figura 4.2. A pergunta a ser respondida é: dada uma microtextura, ou seja, para um valor de $\alpha$ e com periodicidade fixados, qual das duas configurações o sistema vai adotar? A resposta é encontrada comparando-se a energia de cada uma dessas duas configurações: a configuração que possuir menor energia é a configuração de equilíbrio adotada pelo sistema (figura 4.2).
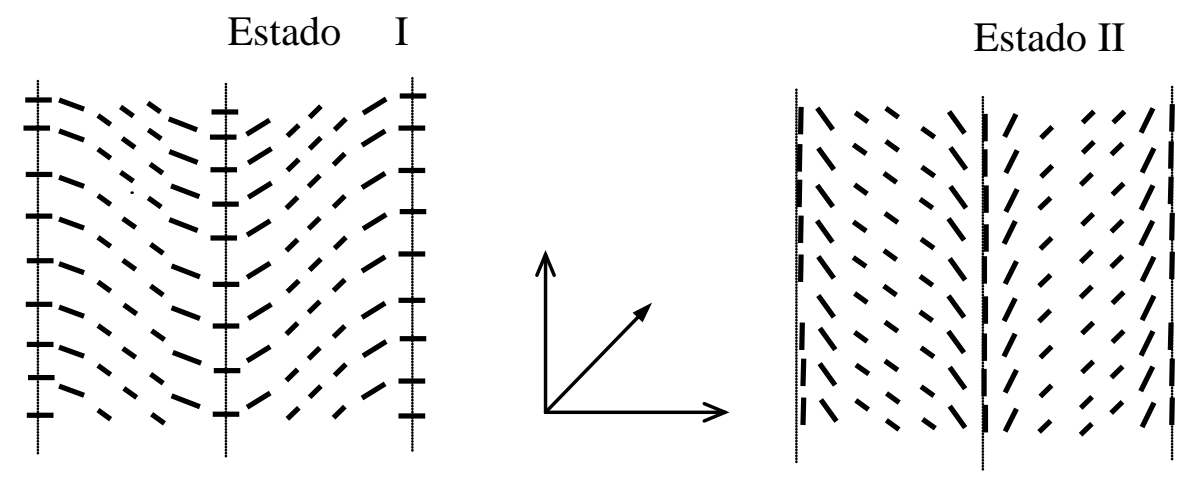

Figura 4.2: Estados orientacionais esperados para a amostra de cristal líquido. $\phi_{0}=0 \rightarrow$ Estado I e $\phi_{0}=\pi / 2 \rightarrow$ Estado II.

Desta forma, a energia do sistema pode ser escrita como:

$$
F=\int\left[F_{e l}(\vec{r})+F_{S}\right] d^{3} r
$$

onde

$$
F_{e l}(\vec{r})=\frac{1}{2} K_{1}(\vec{\nabla} \cdot \vec{n})^{2}+\frac{1}{2} K_{3}(\vec{n} \times \vec{\nabla} \times \vec{n})^{2}
$$

é a densidade de energia elástica do cristal líquido empregado, e na aproximação de constante única [P. G. de Gennes, 1993] a energia de superfície é dada por:

$$
F_{S}=\frac{1}{2} W \operatorname{sen}^{2}(\phi-\alpha)
$$


Os termos $\frac{1}{2} K_{1}(\vec{\nabla} \cdot \vec{n})^{2}$ e $\frac{1}{2} K_{3}(\vec{n} \times \vec{\nabla} \times \vec{n})^{2}$ são as densidades de energia elástica devido às deformações elásticas de splay e bend, respectivamente. No sistema de coordenadas cartesianas descrito na figura 4.1, tais termos podem ser escritos como:

$$
\frac{1}{2} K_{1}(\vec{\nabla} \cdot \vec{n})^{2}=\frac{1}{2} K_{1} \operatorname{sen}^{2}[\varphi]\left(\frac{d \varphi}{d x}\right)^{2}
$$

e

$$
\frac{1}{2} K_{3}(\vec{n} \times \vec{\nabla} \times \vec{n})^{2}=\frac{1}{2} K_{3} \cos ^{2}[\varphi]\left(\frac{d \varphi}{d x}\right)^{2},
$$

Considerando a simetria do sistema, podemos escrever a energia livre total (que possuí uma contribuição elástica e outra de superfície) de 0 (zero) a $\boldsymbol{L} / \mathbf{4}$ como:

$$
F=4 \int_{0}^{L / 4}\left[\frac{1}{2} K_{1} \operatorname{sen}^{2}[\varphi]\left(\frac{d \phi(x)}{d x}\right)^{2}+\frac{1}{2} K_{3} \cos ^{2}[\phi]\left(\frac{d \phi(x)}{d x}\right)^{2}+\frac{1}{2} W \operatorname{sen}^{2}(\phi-\alpha)\right] d x,
$$

na qual as derivadas parciais foram substituídas por derivadas totais.

A minimização de $\boldsymbol{F}$ leva à seguinte equação:

$$
\left(\frac{d \phi}{d x}\right)^{2}=\left(\frac{W}{d}\right) \frac{\operatorname{sen}^{2}[\phi(x)-\alpha]-c t e}{K_{1} \operatorname{sen}^{2}[\phi(x)]+K_{3} \cos ^{2}[\phi(x)]} .
$$

O procedimento geral para encontrar a solução $\phi(x)$ é substituir (19) em (18) e minimizar com relação à constante cte. No limite para $\boldsymbol{L}$ grande, porém, o cálculo pode ser enormemente simplificado percebendo-se que

$$
\left(\frac{d \phi}{d x}\right)_{x=n L / 2+L / 4}=0,
$$

ou seja, no meio dos domínios a variação do ângulo deve ser nula. Isso somente reflete o fato de que longe das bordas dos domínios o diretor $\boldsymbol{n}$ não varia mais, isto é, no limite de $\mathbf{L}$ grande $\phi(x) \rightarrow \alpha$ no meio dos domínios. Desta forma, a constante cte em (19) é igual a zero. Então, no limite para $L$ grande, a equação a ser resolvida é: 


$$
\left(\frac{d \phi}{d x}\right)^{2}=\left(\frac{W}{d}\right) \frac{\operatorname{sen}^{2}[\phi(x)-\alpha]}{K_{1} \operatorname{sen}^{2}[\phi(x)]+K_{3} \cos ^{2}[\phi(x)]} .
$$

Neste trabalho, foi utilizado um estudo variando o período $\boldsymbol{L}$ dos padrões de textura, e foi estudado em especial o caso em que o ângulo entre o eixo fácil e o eixo $x$ é $\alpha= \pm 60^{\circ}$. Mais uma vez usando a simetria do sistema, a integração da energia livre (eq. 19) pode ser feita entre os extremos zero e $\boldsymbol{L} / 4$ em vez de um período completo (- $\boldsymbol{L} / 2 \mathrm{e}$ $+\boldsymbol{L} / 2$ ), se $\boldsymbol{L}$ é considerado grande ou quando $\boldsymbol{K}_{11}=\boldsymbol{K}_{33}$. Desta forma, definimos um ângulo médio $\phi_{M}$ dado por:

$$
\varphi_{M}=\frac{\int_{0}^{L / 4} \varphi(x) d x}{\left(\frac{L}{4}\right)}=4 \frac{\int_{0}^{L / 4} \varphi(x) d x}{L}
$$

Um aspecto deste modelo é que se considera o substrato como sendo estritamente plano, de forma que a configuração do diretor do CL é sempre planar.

\subsection{Resultados experimentais: Transições de orientação}

\subsubsection{Caracterização ótica e morfológica (SNOM)}

Este estudo foi feito em colaboração com o Prof. Dr. Antônio Domingues dos Santos do Laboratório de Materiais Magnéticos do Instituto de Física - USP, São Paulo, utilizando o SNOM (Scan Near-Field Optical Microscope) existente neste grupo de pesquisa [J. Schoemmaker, 2004]. Este microscópio apresenta as mesmas facilidades de um microscópio de força atômica, no que diz respeito à obtenção de imagens topográficas na escala nanométrica, com a principal diferença que a ponta de varredura é uma fibra ótica afinada por meio de ataque químico (com 200 nm de diâmetro na 
extremidade), pela qual é injetado um feixe laser de diodo com $\lambda=632 \mathbf{n m}$. A luz que sai da ponta é refletida pela superfície e captada por um fotodiodo, e com isso obtém-se simultaneamente uma imagem topográfica e ótica durante a varredura da superfície, ver esquema na figura 4.3.

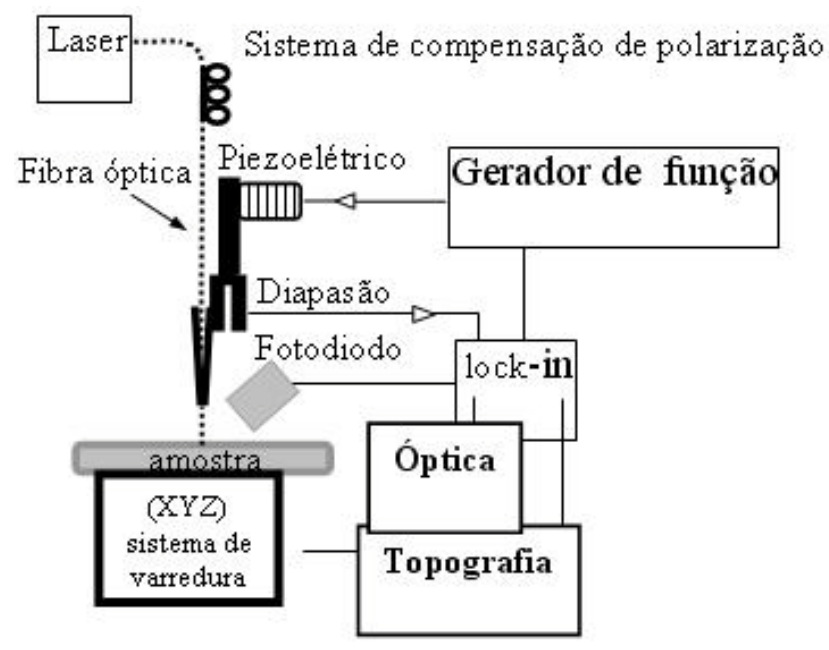

Figura 4.3: Desenho esquemático do SNOM.

A varredura no SNOM é feita em modo não-contato, mantendo-se a distância ponta-superfície constante em torno de $20 \mathrm{~nm}$. O sistema constituído pela fibra ótica e diapasão é posto para oscilar na sua freqüência de ressonância através do gerador de função. Dessa forma, no processo de aproximação da ponta, quando ela começa a interagir com a superfície e entra em regulação, a amplitude de oscilação diminui. A distância é fixada estabelecendo-se um set point para o sistema de retroalimentação manter a oscilação a 10\% abaixo da freqüência de ressonância. Este sinal é armazenado em função da varredura da ponta, formando a imagem topográfica da superfície. A imagem ótica é obtida através da luz refletida pela superfície e que é captada pelo fotodiodo. Para se obter uma qualidade maior, os filmes foram depositados sobre superfícies refletoras, onde utilizamos substratos de silício polidos. É importante salientar que como a superfície é iluminada em campo próximo (ou seja, a uma distância muito menor que o comprimento de onda da luz) a limitação do comprimento de 
Rayleigh para resolução da imagem é suprimida, e com isso obtém-se uma resolução ótica na escala submicrométrica (que é limitada pelo diâmetro da ponta). Em geral, tal resolução não é atingida por técnicas óticas convencionais como microscopia ótica.

O sistema de roldanas, indicado na figura 4.3 permite variar a direção de polarização da luz que sai na extremidade da fibra através de um sistema de compensação. Isso é controlado pela intensidade de luz que chega ao fotodiodo, visto que existe um analisador com a direção do eixo óptico conhecido e fixo na frente do mesmo. Portanto, quando se seleciona a condição de máximo de intensidade transmitida, sabe-se que a polarização incidente no filme está paralela ao analisador, quando se tem um mínimo é perpendicular.

Para este estudo, foi utilizado o filme de PS-119 (Aldrich) e foi padronizado o tempo de irradiação do fotoalinhamento em 60 segundos e do padrão de interferência em 30 segundos, com uma intensidade de $160 \mathbf{m W} / \mathbf{c m}^{2}$. Foi utilizado um laser de estado sólido da marca Coherent VERDI de Nd:YVO $(\lambda=532$ nm) como fonte de excitação. A irradiação com o padrão de interferência foi feita com a metade do tempo do fotoalinhamento, para garantir que a energia de irradiação nas regiões construtivas fosse a mesma do fotoalinhamento inicial mantido nas regiões escuras, pois precisamos lembrar que nas franjas construtivas existe uma superposição de intensidades. Para obter um contraste máximo entre as franjas, as irradiações foram feitas de modo que a orientação induzida aos cromóforos varie de $45^{\circ}$ de uma franja para outra. Para isso, na primeira etapa o filme foi irradiado homogeneamente a $45^{\circ}$, seguido da irradiação com o padrão de interferência com a polarização a $0^{\circ}$. Uma imagem ótica do filme com esse tratamento foi captada através de uma câmera digital acoplada a um microscópio óptico de luz polarizada, e pode ser vista na figura 4.4. Nesta figura, pode-se notar que quando a amostra é girada de $45^{\circ}$ entre polarizadores cruzados, os máximos e mínimos de intensidade se alternam (tomar como referência a linha que passa sobre os dois defeitos), correspondendo às direções indicadas pelas linhas desenhadas. 

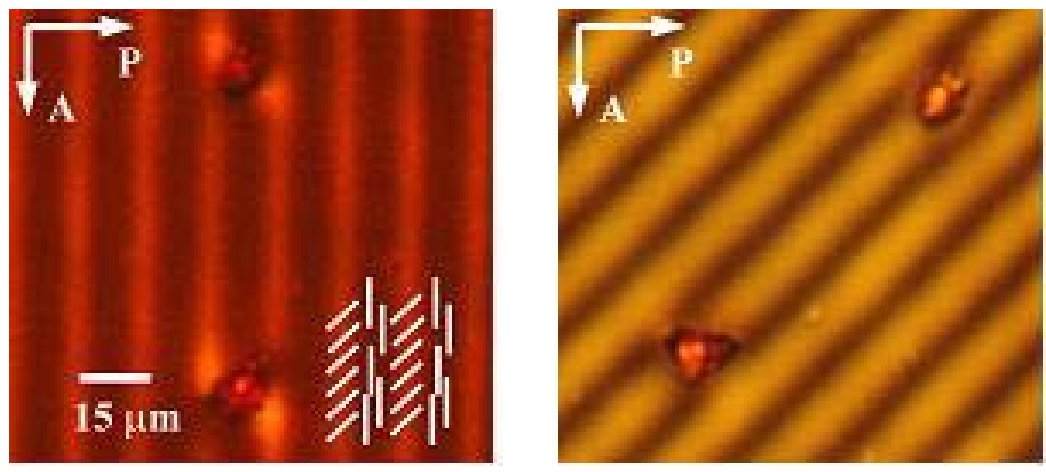

Figura 4.4: Imagem ótica de uma textura com período de $15 \mu m$, as linhas desenhadas indicam as direções de alinhamento dos cromóforos nas linhas individuais.

Foram realizadas medidas com o SNOM em texturas inscritas com períodos de 3,0, 1,6 e 0,6 $\mu \mathrm{m}$. A intenção era caracterizar texturas na escala submicrométrica, para a qual a caracterização com o microscópio convencional não é mais possível, e com isso ter certeza que este padrão ainda é gravado. Em todas as figuras apresentadas daqui adiante, as imagens do lado esquerdo correspondem ao perfil topográfico enquanto que as imagens do lado direito ao perfil óptico correspondente. A figura 4.5 refere-se ao período de 3,0 $\mu$ m.
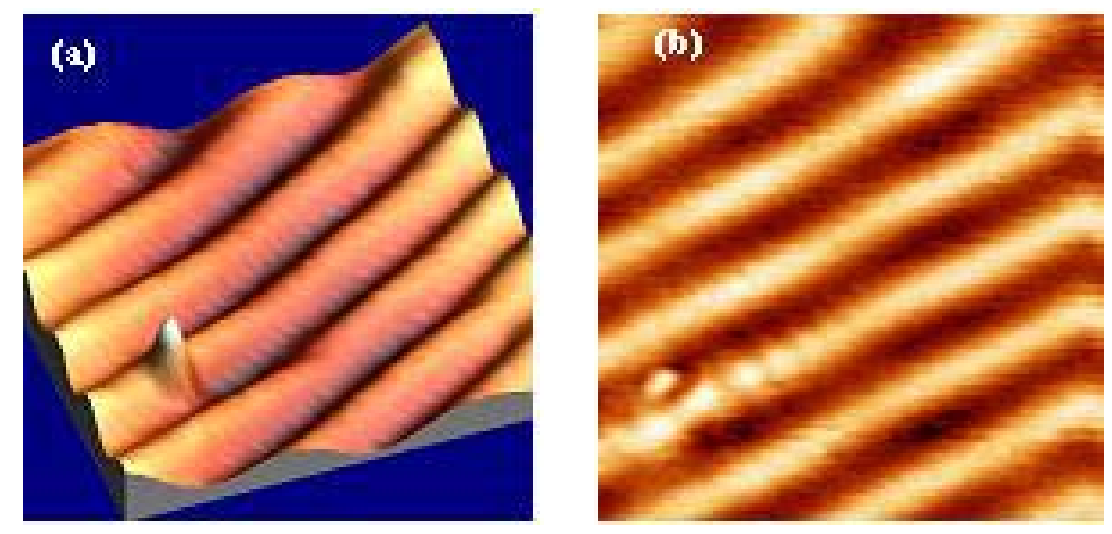

Figura 4.5: Imagens obtidas com o SNOM para período de 3,0 $\mu$ m. (a) topográfica em 3D e (b) ótica. 
Na figura anterior, observa-se um padrão periódico bastante nítido, tanto na imagem topográfica como na imagem óptica. A amplitude dos canais superficiais é bem baixa (aproximadamente $10 \mathrm{~nm}$ ), como era de se esperar para um tempo tão curto de irradiação. É possível notar que o defeito (pico) que aparece na imagem topográfica também aparece na imagem óptica, onde causa um espalhamento da luz incidente. Para o período de 1,6 $\mu$ m observa-se o mesmo padrão, porém é interessante perceber que os defeitos que aparecem na imagem ótica não aparecem na imagem topográfica, indicando não se tratar de defeitos superficiais (figura 4.6). Para este período a amplitude média dos canais é de aproximadamente $5 \mathrm{~nm}$.
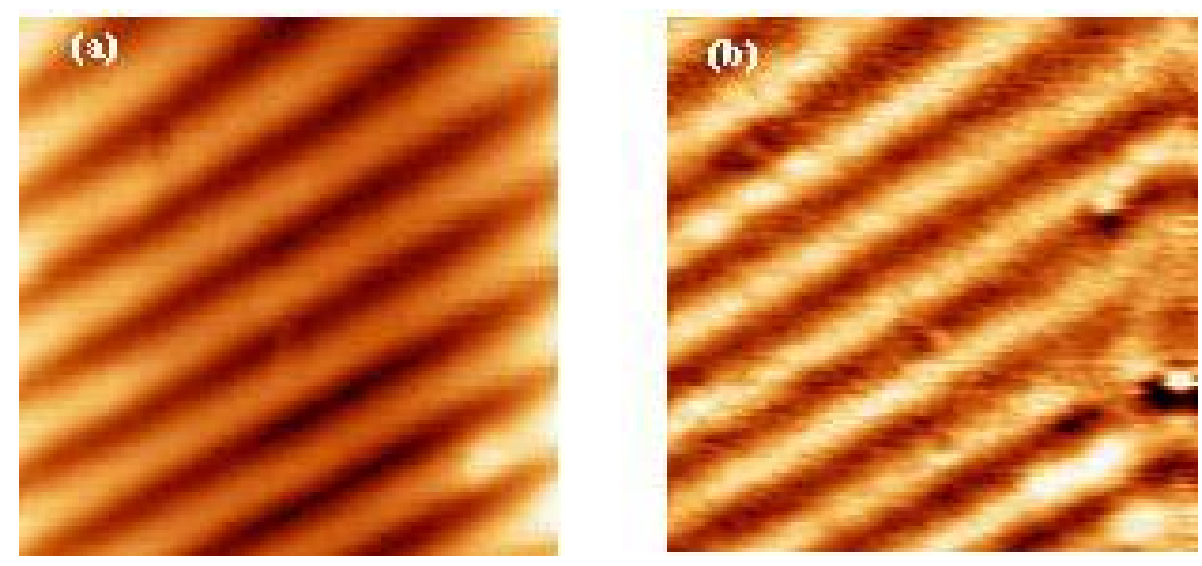

Figura 4.6: Imagens obtidas com o SNOM para período de 1,6 $\mu$ m. (a) topográfica e (b) ótica.

Os resultados obtidos para o período de 0,6 $\mu$ m estão apresentados na Figura 4.7. Observa-se que os padrões topográfico e ótico continuam sendo observados, apesar de não serem mais tão nítidos. Neste caso, a amplitude dos canais é de apenas 2,5 $\mathrm{nm}$ e podemos concluir que a redução do período implica na diminuição da amplitude dos canais, que pode ser explicada pela diminuição do volume livre de material necessário para formar as grades de relevo. 

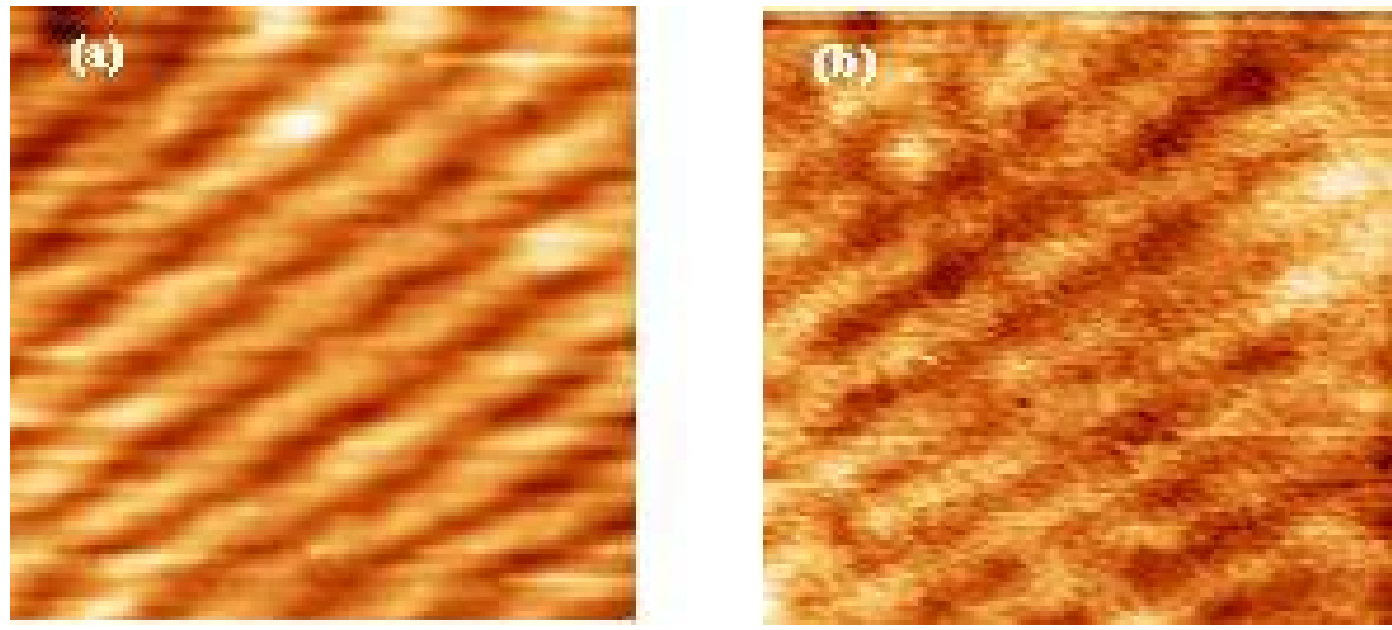

Figura 4.7 Imagens obtidas com o SNOM para período de 0,6 $\mu \mathrm{m}$. (a) topográfica e (b) óptica.

Na seqüência, foram investigados experimentalmente os estados orientacionais induzidos ao cristal líquido por texturas inscritas com $\alpha=+60^{\circ}$ e $-60^{\circ}$ (ver esquema da figura 4.1) no fotopolímero PS119. De acordo com as previsões teóricas apresentadas anteriormente, a redução do período implicaria numa transição orientacional do cristal líquido para um estado homogêneo ao longo da direção $y$. Isso se deve ao fato de a energia necessária para manter o sistema distorcido com períodos pequenos e direções distintas nas franjas individuais ser maior que a energia do estado homogêneo. Na figura 4.8 estão apresentadas imagens óticas de uma textura com $15 \mu m$ de período, captadas com uma câmera digital acoplada a um microscópio óptico de luz polarizada, onde se observa que ao girarmos o filme de $30^{\circ}$ para a direita e para a esquerda existe alternância entre máximos e mínimos de luz, confirmando as direções esperadas para o alinhamento dos cromóforos. 

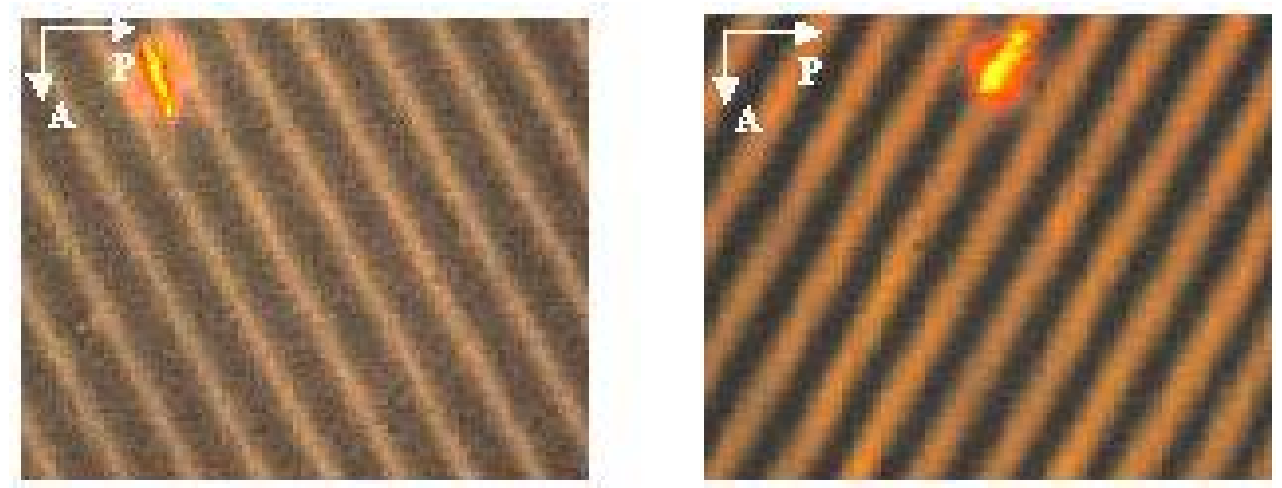

Figura 4.8: Imagem ótica de uma textura com $\alpha=+60^{\circ}$ e $-60^{\circ}$ e período de $15 \mu \mathrm{m}$.

Primeiramente foi realizado um procedimento padrão para as direções de polarização da luz incidente durante o processo de inscrição, e em seguida foi realizada a diminuição dos períodos até a escala submicrométrica, pois com as medidas realizadas com a técnica de SNOM foi comprovado que o padrão se mantém. Com estes substratos de um lado e lâminas de vidro com tratamento de PVA do outro, foram construídas celas de $20 \mu m$ de espessura (a qual foi fixada com espaçadores mylar). Foi utilizado o cristal líquido 5CB, o qual foi inserido nas celas à temperatura ambiente (na fase nemática) por efeito de capilaridade. Todas as observações foram feitas em um microscópio ótico de luz polarizada.

Para períodos grandes como o da figura 4.8, observa-se que a orientação induzida ao CL segue exatamente o padrão da superfície. No entanto, para períodos abaixo de 3,0 $\mu m$ observamos que o ângulo de alinhamento do cristal líquido em relação ao eixo $x$ vai gradativamente aumentando até atingir o valor de $90^{\circ}$ para o período de $0,6 \mu \mathrm{m}$. Isso indica que o alinhamento torna-se homogêneo com a direção do diretor paralela à direção $y$. Na figura 4.9 são apresentadas as imagens óticas do filme e da cela com cristal líquido para uma textura com período de 0,6 $\mu$ m, onde foi focalizada a interface entre a região com textura e a região sem textura (região onde não foi inscrita a textura, e o alinhamento é homogêneo). Na coluna B as franjas estão ao longo do analisador, na coluna C a amostra foi girada de $30^{\circ}$ para a direita e em $\mathrm{D}$ foi girada de $30^{\circ}$ para a esquerda. 

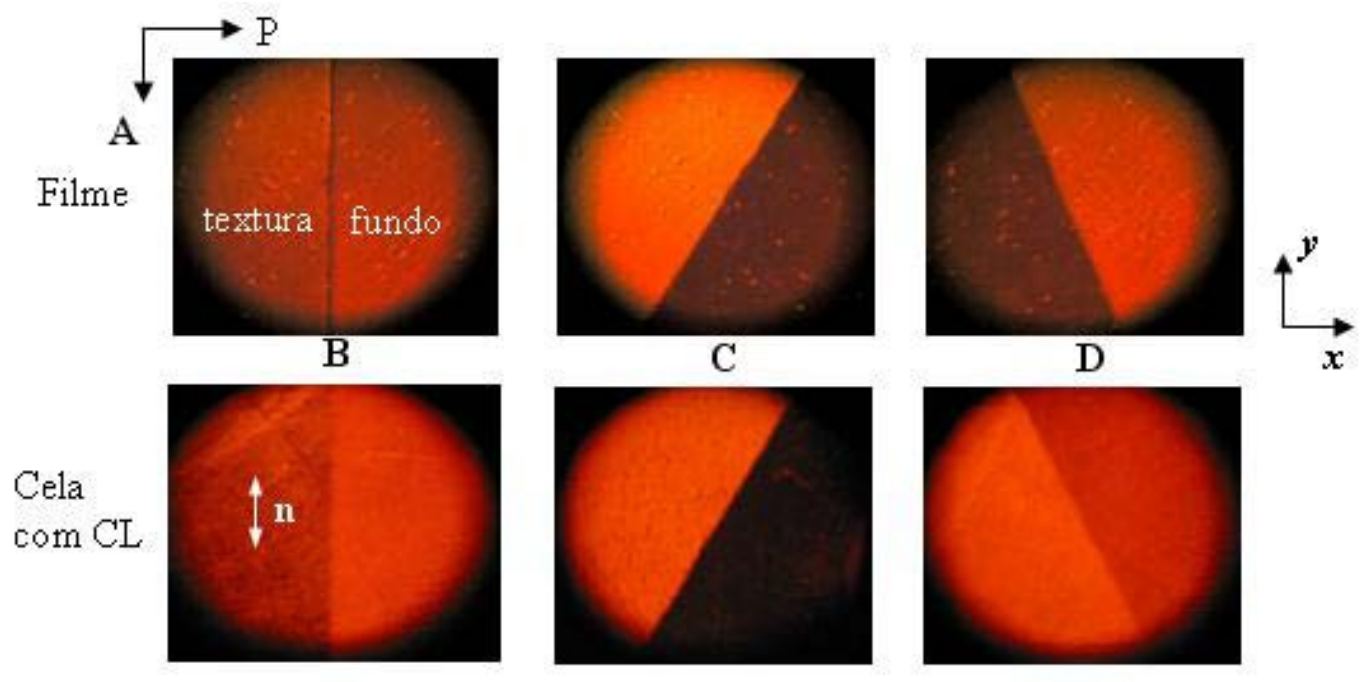

Figura 4.9: Imagem ótica na interface do alinhamento do fundo e de uma textura com $\alpha=+60^{\circ} \mathrm{e}$ $-60^{\circ}$ e com período de 0,6 $\mu \mathrm{m}$. A primeira linha mostra apenas o filme de azopolímero, e a segunda linha mostra a cela com cristal líquido. As colunas B, C e D representam diferentes posições relativas com a direção do polarizador e analisador.

Para este período, não foi possível identificar as linhas individuais, e desta forma na região onde está a textura o que se vê é uma imagem macroscópica homogênea que segue a direção de alinhamento induzida pelo segundo processo de fotoalinhamento (padrão de interferência). Na primeira linha, quando o filme é girado de $30^{\circ}$ para a direita o fundo fica escuro (coluna $\mathbf{C}$ ) e quando o filme é girado de $30^{\circ}$ para a esquerda a região da textura fica escura (coluna D). Em ambos os casos, isso indica que o alinhamento do filme está paralelo ao analisador. Ao se adotar o mesmo procedimento com a cela que possui cristal líquido (segunda linha), observa-se um comportamento bastante diferente na região da textura quando o filme é girado de $30^{\circ}$ para a esquerda (coluna D). Agora, esta região não fica mais escura, indicando que o cristal líquido não seguiu o alinhamento imposto pela superfície, mas que houve uma transição orientacional no plano do substrato (plano $\boldsymbol{x y}$ ). Na verdade, identificamos como mínimo de transmissão na região da textura a posição indicada pela coluna B. No entanto, como pode ser visto na figura, esse mínimo não representa uma extinção total da luz, 
indicando que além da transição orientacional no plano também ocorreu uma transição fora do plano xy com uma orientação média em torno da direção $y$.

Para comparação, foi repetido o mesmo procedimento realizado nas colunas $\mathbf{B}$ e D para uma textura com período de 1,0 $\mu$ m (figura 4.10). Observa-se que na região da textura o mínimo de transmissão para a cela com cristal líquido (segunda linha) é obtido para um giro de $10^{\circ}$ para a esquerda, onde é importante perceber que esse mínimo representa uma extinção total da luz, indicando que está ocorrendo uma transição contínua no plano $x y$. No entanto, quando é atingido o período de 0,6 $\mu m$ ocorre também uma transição fora do plano que parece ser descontínua.

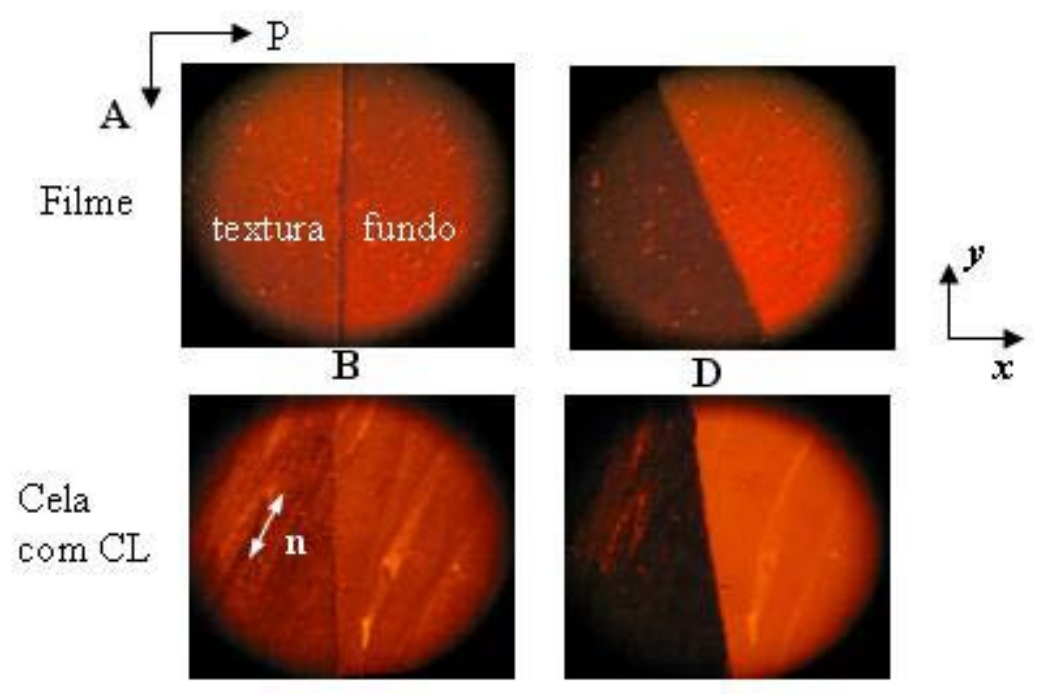

Figura 4.10: Imagem ótica na interface do alinhamento do fundo e de uma textura com $\alpha=+60^{\circ}$ e $-60^{\circ}$ e com período de $1,0 \mu \mathrm{m}$. Na primeira linha apenas do filme e na segunda linha da cela com cristal líquido. As colunas B e $\mathbf{D}$ representam diferentes posições relativas com a direção do polarizador e analisador.

Com os ângulos de alinhamento do CL obtidos sobre a textura gravada no fotopolímero para a cela com cristal líquido, variando-se períodos de 0,6 a 3,0 $\mu \mathrm{m}$, foi construído o gráfico apresentado na figura 4.6. Nesta figura, fica evidente a transição orientacional do cristal líquido com a variação do período da textura. Para periodicidades maiores que 3,0 $\mu \mathrm{m}$ o cristal líquido segue a orientação imposta pelo 
alinhamento dos cromóforos nas franjas individuais da textura $\left(60^{\circ}\right)$, mas para 0,6 $\mu \mathrm{m}$ observamos o alinhamento na direção $y$ (que equivale a $90^{\circ}$ ), onde se pode notar que esta transição ocorre de forma contínua. A linha contínua na figura 4.11 representa uma simulação com o modelo teórico apresentado no começo deste capítulo, tomando a aproximação de $K_{1} / K_{3}=1$. Apesar de a linha não passar exatamente sobre os dados experimentais, como primeira aproximação a comparação é válida, pois o comportamento das curvas é semelhante.

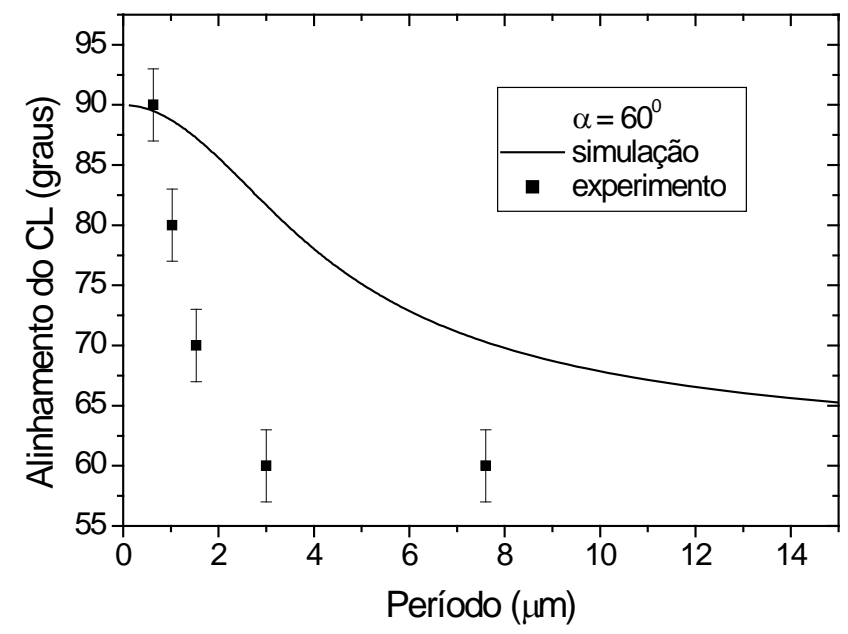

Figura 4.11: Dados experimentais da transição orientacional no plano do substrato em função do período da textura. A linha contínua representa uma simulação teórica.

\subsection{Conclusões}

Para as microtexturas, o resultado mais importante foi verificar que é possível gravar uma textura alternando periodicamente a direção de orientação dos grupos azocorantes. Foi observada a gravação de microtexturas realizada através da técnica de fotoalinhamento, e conseguiu-se gravar texturas com periodicidade desde dezenas de mícrons até décimos de mícron. Essa gravação foi verificada por meio de medidas realizadas com o SNOM, que se mostrou uma excelente ferramenta para o estudo da 
topologia da superfícies dos fotopolímeros. Além disso, é possível variar o período espacial da microtextura desde dezenas de mícrons até décimos de mícrons usando a própria luz da ponta do microscópio SNOM, o que abre possibilidade de gravação e armazenamento de informação ótica.

Neste trabalho, foi feito o estudo de competição de orientação onde tínhamos duas direções preferenciais de alinhamento com a mesma intensidade de energia de ancoramento. Foram observadas as configurações de equilíbrio para diferentes periodicidades, e foi feita a comparação com previsões do modelo teórico [F. Batalioto et. al., 2005]. Um resultado importante deste trabalho foi a confirmação experimental da transição orientacional para um estado de orientação homogênea, conforme previsto pelo modelo proposto para periodicidades acima de 1,0 $\mu \mathrm{m}$. Para periodicidades de décimos de mícron, há a transição orientacional para uma orientação homogênea, mas com o diretor saindo do plano do substrato [B. Zhang et. al., 2003]. Essas medidas estão de acordo com resultados encontrados na literatura [J. H. Jim et. al., 2002], onde foram observadas transições orientacionais com a mesma periodicidade, porém realizando-se nanolitografia com a ponta de um microscópio de AFM. Concluímos por fim que essas transições orientacionais não dependem somente da construção da textura gravada, mas também dependem das distorções elásticas impostas ao diretor do CL, da periodicidade das texturas gravadas, e também da energia elástica do CL no volume. Este trabalho foi aceito para publicação no ano de 2006 (apêndice B). 


\section{Competição de orientação: topografia versus fotoalinhamento}

Este capítulo trata sobre o efeito competição de orientação em CL induzido através de dois processos distintos. Inicialmente, o objetivo seria realizar o estudo de competição entre o efeito de fotoalinhamento e por efeitos topográficos. Efeitos topográficos são relacionados à deformação elástica, onde o relevo da superfície introduz uma nova configuração onde a energia é minimizada quando, por exemplo, as moléculas de CL se alinham na direção dos canais formados. O efeito de fotoalinhamento, por sua vez, é um efeito onde as moléculas de CL se alinham preferencialmente na direção dos grupos azocorantes, onde a direção de foto-orientação pode ser manipulada através da exposição à luz polarizada. O principal objetivo deste estudo é promover a superposição de SRGs e fotoalinhamento, com direções de orientações distintas e diferentes intensidades de energia de ancoramento.

Por fim, será realizado o estudo do efeito de competição de alinhamento em CLs através dos processos de fotoalinhamento e esfregamento, e serão apresentados os resultados da competição de orientação das moléculas de CL.

\subsection{Introdução}

Uma conseqüência dos resultados mostrados no capitulo 3 foi a possibilidade de manipulação da intensidade de ancoramento em azopolímeros, através de diversas técnicas distintas. Para efeito fotônicos, foi observado que a energia de luz incidente (dada pelo produto entre a intensidade luminosa e o tempo de exposição) e a concentração de azocorantes são fatores decisivos no fotoalinhamento do material, e 
conseqüentemente na orientação do CL. As intensidades de ancoramento induzidas por fotoalinhamento são da ordem de $10^{-6} \mathrm{~J} / \mathrm{m}^{2}$ para o material PHEMA-DR13. Outra possibilidade de tratamento de superfície estudada foi a formação de SRGs neste material. A profundidade máxima dos canais gravados foi de $50 \mathrm{~nm}$, com $15 \mu \mathrm{m}$ de periodicidade, que de acordo com o modelo de Berreman introduzem uma intensidade de ancoramento da ordem de $10^{-8} \mathrm{~J} / \mathrm{m}^{2}$ na direção dos canais. Para a técnica de esfregamento da superfície, consegue-se valores da ordem de $10^{-5} \mathrm{~J} / \mathrm{m}^{2}$.

A idéia inicial seria realizar a competição entre dois efeitos fotoinduzidos: um no plano do substrato, induzido por fotoalinhamento, e outro efeito de formação de grades de relevo, onde o efeito do relevo da superfície é o fator determinante no alinhamento de CL. Porém, foi verificado que as ordens de grandezas dos dois efeitos são incompatíveis entre si, e não foi possível experimentalmente se realizar o estudo do efeito de competição de orientação: o efeito de fotoalinhamento sempre será predominante, mesmo para baixas energias luminosas.

Foi feito então o estudo de competição de orientação para os efeitos de esfregamento e fotoalinhamento. A princípio, as ordens de grandeza das intensidades de ancoramento devido aos dois efeitos distintos são compatíveis entre si. Em uma primeira aproximação, considera-se que o esfregamento, que é dado pelo alinhamento das cadeias principais da matriz polimérica não é afetado pelo fotoalinhamento, que será considerada como um alinhamento apenas das cadeias laterais da matriz polimérica.

\subsection{Consideraç̧ões teóricas}

Nesta etapa será descrito o processo realizado para o estudo de efeito de competição de alinhamento de CL com a superposição de dois potenciais de orientação. Foram realizados dois tratamentos de superfície na mesma região da amostra, em direções distintas conforme ilustrado na figura 5.1, de forma a se fazer uma superposição dos efeitos. 


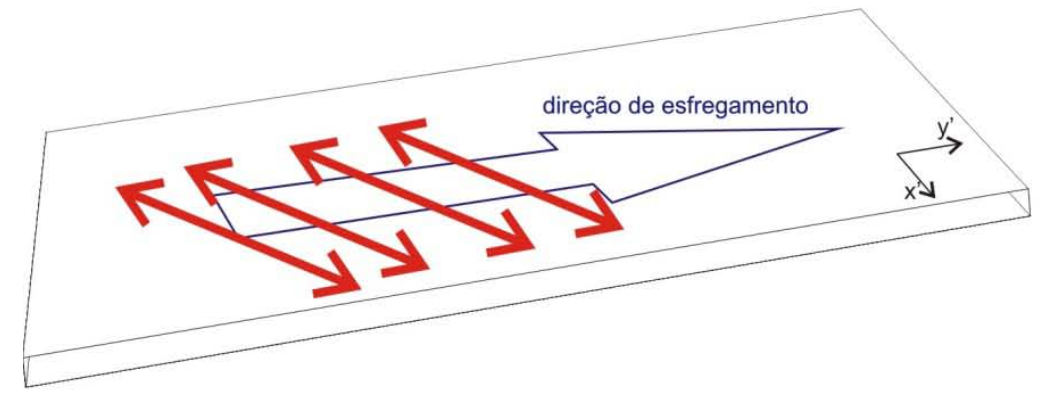

(a)

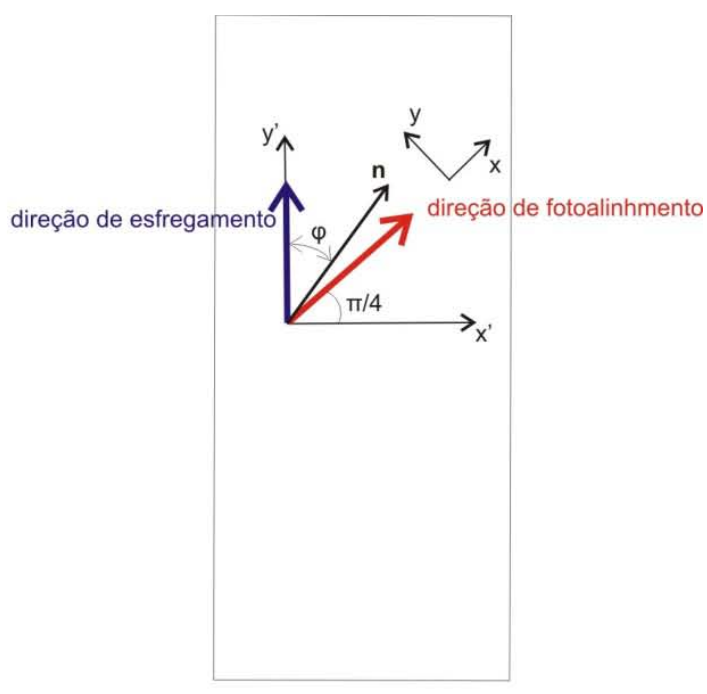

(b)

Figura 5.1: Representação dos efeitos de superfícies gravados em duas direções distintas (a) vista em perspectiva, e (b) vista por cima.

O primeiro tratamento de superfície aplicado ao filme de fotopolímero consiste no esfregamento com um tecido de veludo, conforme descrito na seção 3.3. De acordo com a figura 5.1, o esfregamento é feito na direção $y$. Em seguida, usando-se luz polarizada no comprimento de onda adequado, é produzido o fotoalinhamento dos grupos azocorantes em uma direção, formando um ângulo de $\pi / 4$ com o eixo $y$. Assim, esperase que a orientação imposta às moléculas resulte da competição dos dois potenciais de alinhamento, e em uma direção intermediária entre os eixos fáceis produzidos por métodos diferentes. A intensidade de ancoramento devido ao esfregamento será chamada de $\boldsymbol{W}_{\boldsymbol{r}}$ e a intensidade de ancoramento devido ao fotoalinhamento será $\boldsymbol{W}_{\boldsymbol{f}}$. Como estamos trabalhando em uma faixa de potências entre 20 e $80 \mathrm{~mW} / \mathrm{cm}^{2}$, supõe-se que não há movimento de massa na superfície do material, e que o efeito de fotoalinhamento ocorre somente nos grupos laterais da cadeia polimérica de forma a não alterar o esfregamento realizado anteriormente. Em uma situação limite, se o fotoalinhamento induzir um ancoramento forte, a condição de equilíbrio de dá com as moléculas e CL orientadas na direção de fotoalinhamento (de acordo com a figura 5.11b isso ocorre para $\varphi=0$ ). A configuração de equilíbrio das moléculas do CL em contato 
com esse substrato é obtida pela minimização da energia de distorção na camada superficial. A densidade de energia na superfície será dada por:

$$
f=\frac{1}{2} W_{r} \sin ^{2}(\varphi)+\frac{1}{2} W_{f} \sin ^{2}\left(\frac{\pi}{4}-\varphi\right)
$$

que satisfaz as condições de contorno do problema.

A condição de minimização da equação em função do ângulo é:

$$
\begin{gathered}
\frac{d}{d \varphi} f=0 \Rightarrow \\
W_{r} \sin (\varphi) \cos (\varphi)-W_{f} \cos \left(\frac{\pi}{4}-\varphi\right) \sin \left(\frac{\pi}{4}-\varphi\right)=0 \Rightarrow \\
\tan (2 \varphi)=\frac{W_{f}}{W_{r}}
\end{gathered}
$$

Assim, ao se construir um gráfico dos valores experimentais de $\tan (2 \varphi)$ em função da intensidade de energia de fotoalinhamento $W_{f}$, será possível obtermos um ajuste linear em função de $1 / W_{r}$, que será o coeficiente angular da reta ajustada.

\subsection{Experimental}

O procedimento adotado consistiu basicamente de dois processos distintos e independentes, realizados com extremo cuidado e atenção para garantir a reprodutibilidade do experimento. Primeiramente, foi realizado o processo de esfregamento utilizando-se um aparato mecânico montado no próprio laboratório de Fluidos Complexos, conforme descrito na seção 3.3.

Este procedimento foi adotado para todas as concentrações do polímero, e foi escolhido por conveniência somente um valor de energia de ancoramento. A saber, foi escolhido o menor valor de energia de ancoramento, justamente para ser possível o estudo de competição com o efeito de fotoalinhamento.

Depois de realizada toda a etapa de esfregamento, foi então feito o processo de

fotoalinhamento. Foi escolhida uma direção de $45^{\circ}$ para realizar o fotoalinhamento, e o 
procedimento usado foi o mesmo para todas as amostras e concentrações. Para cada amostra devidamente esfregada, foi feita uma irradiação de luz de forma que o alinhamento resultante fosse de $45^{\circ}$ em relação à direção de esfregamento. Desta forma, produzimos dois potenciais distintos na superfície do polímero. A figura 5.1 ilustra o problema de duas condições de contorno em duas direções distintas.

Para determinar a configuração de equilíbrio do CL em contato com o filme que recebeu os dois tipos de tratamentos de superfície apresentados acima, foi depositado o cristal líquido 5CB diretamente sobre a superfície do filme. O CL foi então espalhado por toda a extensão da amostra, sendo feito uma retirada do material excedente para evitar a formação de meniscos. Feito isso, a amostra foi cuidadosamente posicionada num microscópio ótico de luz polarizada (MOLP). Girando-se o substrato entre polarizadores cruzados observamos que para determinadas posições há um mínimo de transmitância que corresponde à orientação das moléculas do CL paralelo ou perpendicular à direção do analisador. Tomando como referência os eixos $\boldsymbol{x}$ e $\boldsymbol{y}$ ilustrados na figura 5.1 determinamos experimentalmente o valor de $\boldsymbol{\varphi}$.

Um cuidado experimental tomado foi a questão da reprodutibilidade do efeito estudado. Para isso, para cada configuração foi realizada uma série de medidas com a finalidade de se obter uma boa representação do efeito que ocorre na amostra como um todo. Assim, para cada concentração e energia de ancoramento de fotoalinhamento fixadas, foram realizadas medidas em vários pontos da amostra, em todas as direções possíveis (por simetria sabemos que os diretores $\boldsymbol{n}$ e $-\boldsymbol{n}$ são indistinguíveis). Além disso, as medidas foram tomadas em diversos pontos da amostra, para se obter um valor médio que fosse condizente com o observado em toda a extensão da amostra. A figura 5.2 mostra os resultados obtidos para os filmes com as três concentrações estudadas e para diferentes intensidades de ancoramento de fotoalinhamento. 


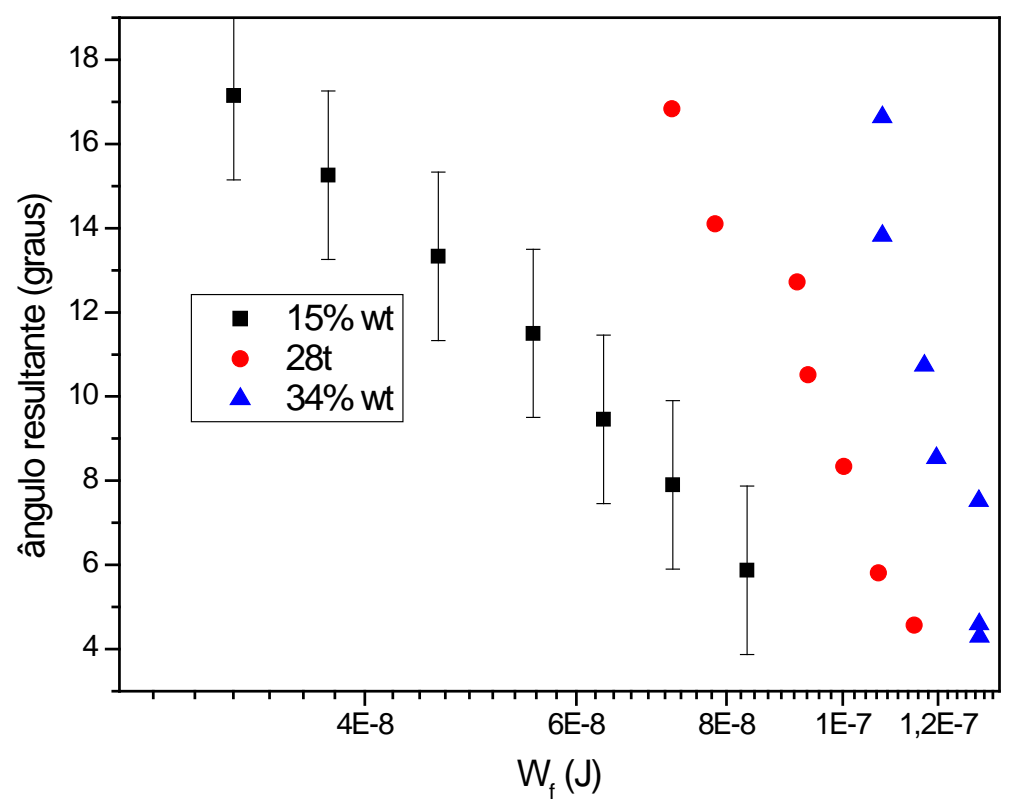

Figura 5.2: Ângulo resultante mostrando o alinhamento das moléculas de CL quando em contato com uma superfície com dois tratamentos de superfície distintos (em duas direções).

De acordo com a Eq. 23, se representarmos $\tan (\mathbf{2} \varphi)$ em função da intensidade de ancoramento devido ao fotoalinhamento, esperamos obter uma reta cujo coeficiente angular é $\mathbf{1} / \mathbf{W}_{\mathbf{r}}$. Os resultados experimentais são representados desta maneira na figura 5.3. O valor de Wr obtidos pelo ajuste são paresentados na tabela 5.1, juntamente com os valores experimentais determinados pelo método de cela híbrida. Para o ajuste, foram desconsiderados os dois últimos pontos das concentrações de $28 \%$ e $34 \%$, pois para potências altas pode haver aquecimento da amostra, e esses efeitos térmicos podem afetar também a cadeia principal do azopolímero. 


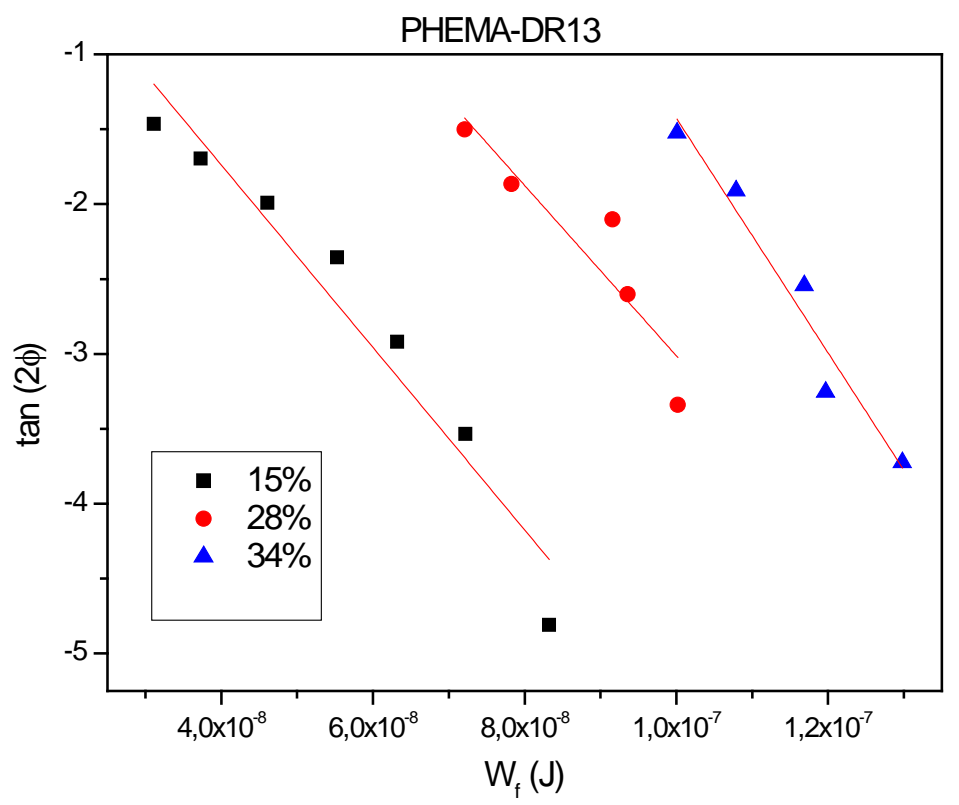

Figura 5.3 - Ajustes obtidos em função dos dados obtidos experimentalmente para as concentrações de 15\% 28\% e 34\% de cromóforos (em massa) para o PHEMA-DR13.

Tabela 5.1: Valores ajustados para a energia de ancoramento

\begin{tabular}{|l|l|l|l|}
\hline \multicolumn{1}{|c|}{$\mathbf{W}_{\mathbf{r}}$} & $15 \% \mathrm{wt}$ & $28 \% \mathrm{wt}$ & $34 \% \mathrm{wt}$ \\
\hline Experimental & $7,25(0,50) \mathrm{E}-7$ & $9,22(0,87) \mathrm{E}-7$ & $8,29(0,71) \mathrm{E}-7$ \\
\hline Ajustado & $1,64(0,41) \mathrm{E}-8$ & $1,76(1,37) \mathrm{E}-8$ & $1,28(0,99) \mathrm{E}-8$ \\
\hline
\end{tabular}

Vemos que os valores obtidos para $\boldsymbol{W}_{\boldsymbol{r}}$ pelo método de cela híbrida são sistematicamente maiores que os valores obtidos usando o efeito de competição com o fotoalinhamento. Supomos que o esfregamento induz uma orientação das cadeias principais do azopolímero e que o fotoalinhamento dos grupos laterais não afetaria a orientação previamente induzida pelo esfregamento. No entanto, é possível que durante o esfregamento também os grupos laterais possam ser alinhados na direção di esfregamento. Durante o processo de fotoalinhamento esses grupos laterais tendem a se 
reorientar em uma direção à $45^{\circ}$ da direção de esfregamento. Ainda esta reorientação pode produzir também movimento nas cadeias principais.

\subsection{Conclusão}

Neste trabalho, realizou-se o estudo do efeito de competição de orientação induzida ao CL entre as técnicas de esfregamento e fotoalinhamento. É conhecido que o esfregamento possui uma intensidade de energia de ancoramento que pode ser considerada forte, e desta forma foi possível realizar a superposição dos efeitos e realizar o estudo de competição. De fato, observou-se que os valores de intensidade de energia de ancoramento devido ao esfregamento são da ordem de $10^{-6} \mathrm{~J} / \mathrm{m}^{2}$, e que esse valor é independente da concentração de cromóforos.

Foi feito então o estudo do efeito de competição de alinhamento de CLs devido aos efeitos de fotoalinhamento e esfregamento sobrepostos, e de acordo com a teoria elástica contínua, foi obtida uma expressão que pode ajustar os dados obtidos experimentalmente. Nota-se que com o ajuste que os resultados obtidos são maiores do que os valores obtidos pelo método de cela híbrida. Isso se deve principalmente ao fato de que foi assumido que o efeito de fotoalinhamento não altera o alinhamento induzido por esfregamento, o que pode não ser verdade. Em uma primeira aproximação, espera-se que o esfregamento cause um alinhamento das cadeias principais do polímero. Quando o fotoalinhamento é realizado sobrepondo o esfregamento, assume-se que somente as cadeias laterais vão se mover e alinhar, devido à incidência de luz linearmente polarizada. Porém, isso pode não ser verdade, pois o esfregamento pode produzir também alinhamento dos grupos laterais. No processo de fotoalinhamento os grupos laterais são reorientados em outra direção. Desta forma, para uma primeira aproximação os resultados se mostram consistentes, pois o comportamento linear previsto pôde ser verificado pelo ajuste de acordo com a minimização da energia livre do sistema. 


\section{Conclusões finais e perspectivas}

O grande diferencial deste trabalho foi a possibilidade de se utilizar azopolímeros para se estudar o efeito de competição de orientação em CLs. Em especial, foi feito um estudo em relação à técnica de fotoisomerização para três polímeros distintos, e usando um modelo teórico empírico conhecido como ajuste bi-exponencial, pode-se diferenciar e entender algumas diferenças básicas entre os filmes. A caracterização dos fotopolímeros nos forneceu um bom critério de comparação entre os filmes, pois foi feito um estudo relacionando a intensidade de energia de ancoramento fotoinduzida com a energia de luz incidente e a concentração de cromóforos no polímero.

Foi feito também um estudo relacionado a competição de orientação utilizando a gravação de microtexturas periódicas na superfície do fotopolímero. Na investigação das texturas de fotoalinhamento, o estudo teórico previu transições orientacionais no plano da superfície (para um estado homogêneo) com a diminuição do período da textura. Isso foi verificado experimentalmente para uma textura gerada com $\alpha= \pm 60$ graus, onde observamos que essa transição ocorre no intervalo de $(0,6<\boldsymbol{L}<3,0) \mu m$. Além disso, observamos uma transição fora do plano da superfície quando o período atinge 0,6 $\mu \mathrm{m}$. É importante enfatizar que o SNOM foi utilizado pela primeira vez na caracterização óptica e morfológica de padrões texturizados em superfícies poliméricas na escala submicrométrica. Com isso, verificamos que esse equipamento é uma ferramenta importantíssima para esse tipo de análise, e que pode ser empregado em filmes finos em geral. Adicionalmente, através de testes iniciais observamos que o SNOM também pode ser utilizado para gravar estruturas na escala submicrométrica sobre polímeros fotossensíveis, através da injeção de um laser com comprimento de onda dentro do espectro de absorção do material através da fibra de varredura. Isso pode ter interesse tecnológico para armazenamento ótico em escalas muito pequenas. 
Foi feito também o estudo da formação de SRG em fotopolímeros, que a princípio seria uma técnica utilizada para o estudo do efeito de competição em CLs. Porém, foi verificado que a intensidade de energia de ancoramento devido à topografia das SRGs é muito pequena quando comparada à energia de ancoramento induzida por fotoalinhamento. Uma conseqüência desta observação foi a impossibilidade de se fazer a competição entre os efeitos fotoinduzidos (SRGs e fotoalinhamento), e foi visto que as condições experimentais acessíveis fazem com que as ordens de grandeza das energias de ancoramento induzidas sejam incompatíveis entre si.

Como alternativa, foi feito o estudo qualitativo do efeito de competição entre as técnicas de esfregamento e fotoalinhamento. Neste caso, foi verificado que a energia de ancoramento induzida por esfregamento é maior do que a intensidade de energia de ancoramento induzida por fotoalinhamento. Isto se deve ao fato de que, ao se realizar um tratamento mecânico como o esfregamento, será introduzido um alinhamento das cadeias principais na direção de esfregamento, que por sua vez induz um alinhamento às moléculas do CL através de interações do tipo van der Waals. No processo de fotoalinhamento, apenas os grupos laterais sofrem o processo de fotoisomerização, alinhando as moléculas azocorantes em uma direção preferencial. Essa ordenação dos grupos laterais causa o alinhamento do CL, também por interações do tipo van der Waals: como a cadeia lateral é menor que a cadeia principal, é de se esperar que a magnitude de interação também a seja.

Outro efeito observado durante os estudos de fotoalinhamento é o comportamento não linear apresentado pela curva de transmitância de luz para potências elevadas de luz incidente. Desta forma, várias medidas de efeitos não lineares podem ser realizadas nestes materiais, de forma a tentar de alguma forma reforçar os modelos teóricos que tratam de explicar os mecanismos de alinhamento fotoinduzido.

De fato, um dos problemas em se modelar o fenômeno de fotoalinhamento é conseguir separar efeitos de transição conformacional com efeitos térmicos, cuja compreensão é fundamental para o entendimento do problema como um todo. Nesta linha, as técnicas de Geração de Segundo Harmônico (SHG) e Z-Scan [M. Sheik-Bahae 
et al., 1991; R. deSalvo et. al., 1993] são, por exemplo, candidatas a nos fornecer algum esclarecimento adicional no que se refere ao comportamento não linear de fotoalinhamento em fotopolímeros. Medidas feitas com laser pulsado podem nos fornecer uma excelente ferramenta para se conseguir separar os efeitos de fotoorientação de efeitos de origem térmica, que são predominantes para potências elevadas.

Uma alternativa para se realizar o efeito de competição entre um fenômeno de relevo e o fotoalinhamento é a chamada nanolitografia, que pode ser realizada utilizando um AFM. Adicionalmente, foi realizado um pequeno estudo de nanolitografia, que consiste no uso do AFM operando no modo de contato (contact mode) visando usar a própria sonda do microscópio como agente causador do relevo (em outras palavras, usar a ponta para literalmente riscar e gravar relevo na superfície). Como se trata de um ensaio isolado, esta parte será mostrada com maiores detalhes no apêndice F. 


\section{Apêndice A - Modelo para descrição da birrefringência induzida em fotopolímeros}

Esta seção descreve teoricamente o alinhamento induzido em filmes de polímero contendo azocorantes. O modelo é conhecido como modelo de Sekkat, e trata de explicar o fenômeno de fotoisomerização tratando a evolução temporal da distribuição angular das moléculas benzênicas. O desenvolvimento teórico foi realizado em sua grande parte pelo Dr. Fernando Batalioto, co-autor do artigo apresentado no apêndice B.

Inicialmente, consideremos um filme de polímeros de espessura $\boldsymbol{d}$ constituído de moléculas de azobenzeno dispostas aleatoriamente no plano $\boldsymbol{x}-\boldsymbol{y}$ do substrato. Além disso, supomos também que as direções dos momentos de dipolo de tais moléculas coincidam com a direção de seus eixos longos, e que somente reorientações no plano sejam permitidas.

Para descrever a anisotropia criada nos filmes de fotopolímeros define-se uma função $A(t)$ como:

$$
A(t)=\int_{-\pi / 2}^{\pi / 2} g(\theta, t) \cos ^{2} \theta d \theta
$$

na qual $g(\theta, t)$ é o número de moléculas de azobenzeno cujos eixos longos estão dispostos entre $\theta$ e $\theta+d \theta$ no instante $\boldsymbol{t}$ depois de iniciada a iluminação com luz linearmente polarizada. Esta função é, portanto, proporcional à espessura $\boldsymbol{d}$ do filme e à concentração de cromóforos, e $\theta$ é o ângulo entre a polarização da luz incidente e o eixo longo das moléculas. A integração em (A1) entre os extremos de integração $-\pi / 2$ a $\pi / 2$, leva em conta todas as posições angulares possíveis para moléculas de azobenzeno, porém por simetria a integração pode também ser realizada no intervalo de 
0 a $\pi$ ou qualquer outro intervalo $\theta_{1}$ a $\theta_{2}$ desde que $\theta_{2}-\theta_{1}=\pi$. A função $A(t)$ é também uma medida da anisotropia criada no filme, por causa do termo $\cos ^{2} \theta$ no integrando. O máximo desta função se dá quando as moléculas de azobenzeno estão completamente desalinhadas e, conforme as moléculas são alinhadas na direção ortogonal à polarização da radiação da iluminação, seu valor diminui podendo, inclusive, ser zero no caso particular em que as moléculas estejam perfeitamente alinhadas, isto é, $\theta=\pi / 2$ ou $-\pi / 2$ para todas as moléculas.

O valor máximo de $A(t)$ no início da iluminação $(t=0)$ é

$$
A(t=0)=\int_{-\pi / 2}^{\pi / 2} \frac{n}{\pi} \cos ^{2}(\theta) d \theta=\frac{n}{2}
$$

em que $n$ é o número total de azobenzenos por unidade de área. Note que devido à isotropia inicial do filme, temos $g(\theta, t=0)=n / \pi$.

Quando a iluminação se inicia, o valor de $A(t) \rightarrow c t e<n / 2$. O valor da constante cte depende da temperatura que desalinha as moléculas já alinhadas.

Para descrever o comportamento temporal da anisotropia criada no filme, consideremos a seguinte equação diferencial de primeira ordem

$$
\frac{d A(t)}{d t}=-k_{1} \alpha I A(t)+B[A(t)]
$$

em que $\boldsymbol{I}$ é a intensidade de luz incidente, $\alpha$ é um coeficiente de absorção do filme, $\boldsymbol{k}_{\mathbf{1}}$ é a taxa com a qual a função $A(t)$ diminui e $\boldsymbol{B}$ é um funcional presente na equação para levar em conta o desalinhamento das moléculas. O funcional $\boldsymbol{B}$ é definido como sendo dependente de $A(t)$ para evidenciar que este termo depende da ordem promovida pela iluminação. No caso em que as moléculas estão completamente desalinhadas, isto é, em $t=0$, não há contribuição deste termo, pois não é possível desalinhar um sistema completamente desalinhado. Pelo mesmo motivo, $\boldsymbol{B}$ também deve se anular no limite onde $I \rightarrow 0$.

Para encontrar a expressão de $\boldsymbol{B}$, é feita uma expansão em série da forma: 


$$
B=a+b A(t)+\ldots
$$

Considerando apenas os dois primeiros termos, e que $B[A(t=0)]=0$, temos

$$
a+b A(t=0)=a+b n / 2=0
$$

portanto, $a=-b n / 2$. Substituindo na Eq. (A4) obtemos

$$
B=b[A(t)-n / 2]
$$

Como $\boldsymbol{B}$ deve ser positivo para todo $t$, a constante $b$ é negativa. Evidenciando o sinal de menos temos

$$
\frac{d A(t)}{d t}=-k_{1} \alpha I A(t)+b\left[\frac{n}{2}-A(t)\right]
$$

em que $b$ se torna uma constante positiva.

Considerando novamente $A(t=0)=n / 2$, a solução de Eq. (A7) é

$$
A(t)=\frac{b n}{2 K}\left(1-e^{-K t}\right)+\frac{n}{2} e^{-K t}
$$

em que $K=k_{1} \alpha I+b$. Note que o decréscimo na função $A(t)$ é devido ao alinhamento das moléculas de azobenzeno na direção ortogonal à direção de polarização da luz incidente. Portanto, qualquer diminuição na função $A(t)$ corresponde a um aumento na birrefringência $\Delta n$ do filme. Assim, podemos escrever

$$
\frac{d \Delta n(t)}{d t}=-\beta \frac{d A(t)}{d t}
$$


em que $\beta$ é uma constante de proporcionalidade que leva em conta as unidades e depende da interação da luz com as moléculas alinhadas. Da Eq. (A8) e Eq. (A9) podemos obter a seguinte expressão para a birrefringência

$$
\Delta n(t)=\frac{1}{2} \beta n\left(1-\frac{b}{K}\right)\left(1-e^{-K t}\right) .
$$

Do ponto de vista experimental, deseja-se empregar a Eq. (A10) na descrição de medidas de transmitância normalizada $T_{N}$. A relação entre a transmitância normalizada $T_{N}$ e a birrefringência $\Delta n$ é dada por

$$
\Delta \phi=\arcsin \left(\sqrt{T_{N}}\right)
$$

em que

$$
\Delta \phi=\frac{2 \pi}{\lambda} d \Delta n
$$

é a diferença de fase ótica e $\lambda$ o comprimento de onda do feixe de luz que atravessa a amostra. De Eq. (A10), Eq. (A11) e Eq. (A12) temos

$$
T_{N}(t)=\sin ^{2}\left[\beta n \pi\left(\frac{d}{\lambda}\right)\left(1-\frac{b}{K}\right)\left(1-e^{-K t}\right)\right] .
$$

Na expressão acima vamos fazer a aproximação tornando o argumento da função seno muito pequeno, de forma que

$$
T_{N}(t) \approx\left[\beta n \pi\left(\frac{d}{\lambda}\right)\left(1-\frac{b}{K}\right)\left(1-e^{-K t}\right)\right]^{2}
$$


É possível notar que a transmitância normalizada $T_{N}$ aumenta monotonicamente com o tempo de iluminação $t$ até atingir um valor de saturação máxima $T_{N \max }$.

Este valor de saturação pode ser calculado fazendo o limite de $T_{N}$ quando $t \rightarrow \infty$. Este limite é

$$
T_{N} \approx\left[\beta n \pi\left(\frac{d}{\lambda}\right)\left(1-\frac{b}{k_{1} \alpha I+b}\right)\right]^{2} .
$$

O valor de saturação, porém, depende da intensidade de iluminação assim como das características do material. Da Eq. (15) podemos observar que existe um valor máximo de $T_{N \max }$ dado por

$$
T_{N}(I \rightarrow \infty) \approx\left[\beta n \pi\left(\frac{d}{\lambda}\right)\right]^{2}
$$

que é obtido fazendo $I \rightarrow \infty$ na Eq. (A15). 


\section{Apêndice B - Publicação}




\title{
Transitions in the orientational order of liquid crystals induced by periodic patterned substrates
}

\author{
I. H. Bechtold, ${ }^{1}$ F. Batalioto, ${ }^{2}$ L. T. Thieghi, ${ }^{2}$ B. S. L. Honda, ${ }^{2}$ M. Pojar, ${ }^{2}$ J. Schoenmaker, ${ }^{2}$ A. D. Santos, ${ }^{2}$ \\ V. Zucolotto, ${ }^{3}$ D. T. Balogh, ${ }^{3}$ O. N. Oliveira, Jr., ${ }^{3}$ and E. A. Oliveira ${ }^{2}$ \\ ${ }^{1}$ Departamento de Física, Universidade Federal de Samta Catarina, 88040-900 Florianópolis-SC, Brazil \\ ${ }^{2}$ Instituto de Fisica, Universidade de São Paulo, P.O. Box 66318, 05315-970 São Paulo-SP, Brazil \\ ${ }^{3}$ Instituto de Física de São Carlos, Universidade de São Paulo, P.O. Box 369, 13560-970 São Carlos-SP, Brazil \\ (Received 16 March 2006; published 31 August 2006)
}

\begin{abstract}
The orientational order of liquid crystals (LCs) induced by periodic patterned substrates has been investigated with cells coated by azopolymer films that could be photoaligned in a controlled way. Two regimes were observed depending on the period of the patterns: (i) above $3.0 \mu \mathrm{m}$ the LC follows the direction imposed by the patterned substrate since the energy stored in the surface potential minimizes the elastic energy of the LC medium. (ii) For periods smaller than $1.0 \mu \mathrm{m}$ a homogeneous in-plane state was induced and the LC did not follow the orientation imposed by the surface. This in-plane transition could be explained qualitatively by a theoretical model based on the competition between the Frank-Oseen elastic energy and the phenomenological surface potential. The results also suggest an out-of-plane transition for the LC director as the period was reduced. These results agree with data in the literature for patterned substrates with completely distinct architectures. This indicates that for a particular LC sample the overall behavior depends basically on the texture period instead of the texture architecture. The textures were characterized with a scanning near-field optical microscope (SNOM), which allowed simultaneous morphological and optical images in the submicrometer range.
\end{abstract}

DOI: 10.1103/PhysRevE.74.021714

\section{INTRODUCTION}

The development of experimental techniques to control liquid crystal (LC) alignment in the submicrometer scale has become of special interest in many technological areas, such as photonics and optoelectronics. Nanorubbing of polymers with an atomic force microscope (AFM) tip provides local alignment [1], which may produce surface patterns with neighboring orthogonal square domains and surface bistability [2]. For example, the reduction in periodicity of the texture to less than $0.8 \mu \mathrm{m}$ induced a uniform configuration of the LC director with a large pretilt of approximately $40^{\circ}$ [2]. This transition was theoretically investigated using a model based on the competition between the Frank-Oseen elastic energy and the phenomenological surface potential, which exhibited good agreement with the experiment [3]. Polymers bearing azogroups (azopolymers) have also been used to induce LC alignment, by exploiting the photoalignment of azogroups with linearly polarized light. Owing to a series of trans-cis-trans photoisomerization cycles, the azodyes tend to align perpendicularly to the polarization direction, thus creating a film anisotropy that is ultimately responsible for the orientation of the LC molecules. The magnitude of such interaction (the anchoring energy) depends on the concentration of the chromophores in the film and on the irradiation time [4]. A further use for LC alignment is with surface relief gratings (SRGs) photoinscribed on azopolymers, where the $\mathrm{LC}$ molecules tend to align along the grooves of the SRGs due to minimization of the elastic distortions close to the surface $[5,6]$. Such photoinduced methods are considered "clean," i.e., there is no mechanical contact with the surface during preparation. In addition, they are reversible and the anchoring energy can be easily controlled.

In an earlier work, the preferred LC configuration for the director induced by flat periodic patterned substrates with different aligning directions was theoretically obtained. We
PACS number(s): 61.30.Hn, 61.30.Dk, 61.41.+e, 68.37.Uv

observed that in the limit of large periods, this configuration depended on the aligning directions of the individual stripes and the ratio of the elastic constants $K_{1} / K_{3}$ [7]. This model also predicts an orientational in-plane transition to a homogeneous state as the period of the pattern is reduced. Here the in-plane transitions for the configuration described in Ref. [7] are experimentally and theoretically investigated, considering the system initially in state $\Pi\left(\alpha \approx \pm 60^{\circ}\right)$ and reducing the period. The patterns have been recorded on polymers containing azogroups covalently attached to the main chain, by illuminating the film with a periodic pattern of constructive and destructive interference fringes. This resulted in alternating patterns with different orientation directions in the microsize domain. We changed the period of the patterns down to the submicrometer range for a fixed irradiation time. Such substrates were optically and morphologically characterized with a scanning near-field optical microscope (SNOM).

\section{THEORETICAL MODEL}

Consider a nematic LC sample of thickness $d$ bounded at both sides at $z=0$ and $z=d$ by two identical, aligned patterned substrates, as depicted in Fig. 1. Due to this special

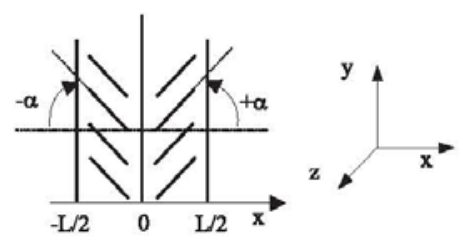

FIG. 1. Schematic representation of the pattern periodic microtextured substrate used in this work. 
substrate structure, the angle between the LC director $\mathbf{n}$ and the $x$ axis can be either $\varphi=0$ or $\pi / 2$, in the boundary of the domains, i.e., at $x=n L / 2(n=0, \pm 1, \pm 2, \ldots)$. In Ref. [7] we calculated the preferred $\varphi_{0}$ value and the $\varphi(x)$ profile with the Frank-Oseen continuum elastic theory, with the profile being given by

$$
\left[\frac{d \varphi(x)}{d x}\right]^{2}=\frac{\left(\frac{W}{d}\right) \sin ^{2}[\varphi(x)-\alpha]-C}{K_{1} \sin ^{2}[\varphi(x)]+K_{3} \cos ^{2}[\varphi(x)]},
$$

where $\alpha$ is the angle between the easy axis and the $x$ axis, and $C$ is an integration constant, written as

$$
C=\left(\frac{W}{d}\right) \sin ^{2}\left[\varphi_{\mathrm{nL} / 4}(x)-\alpha\right],
$$

where $\varphi_{\mathrm{nL} / 4}$ is the angle of the LC director at $x=n L / 4$. In the limit of large $L, \varphi_{\mathrm{nL} / 4} \rightarrow \alpha$ and, consequently, $C \rightarrow 0$. For a general $L, \varphi_{\mathrm{nL} / 4}$ can be determined from Eq. (1) with the initial condition of either $\varphi=0$ or $\pi / 2$ and by noting that

$$
\left[\frac{d \varphi(x)}{d x}\right]_{x=n L / 2+L / 4}=0 .
$$

The stable configuration of $\varphi(x)$ is the one that minimizes the energy per unit area given by

$$
\begin{aligned}
\frac{F}{l d}= & 4 \int_{0}^{L / 4} \frac{1}{2}\left\{K_{1} \sin ^{2}[\varphi(x)]\left[\frac{d \varphi(x)}{d x}\right]^{2}+K_{3} \cos ^{2}[\varphi(x)]\right. \\
& \left.\times\left[\frac{d \varphi(x)}{d x}\right]^{2}+\left(\frac{W}{d}\right) \sin ^{2}[\varphi(x)-\alpha]\right\} d x,
\end{aligned}
$$

where $l$ is a length due to the integration in $y$, and $d$ is the sample thickness, resulting from the integration in $z$. Integration from zero to $L / 4$, instead of over the whole period (from $-L / 2$ to $L / 2$ ), can be performed if $L$ is very large, or when $K_{1}=K_{3}$.

In this work, the pattern period $L$ of the substrate was systematically varied in order to investigate the LC configuration. In particular, we simulate the special case where the angle between the easy axis and the $x$ axis is $\alpha= \pm 60^{\circ}$. Let us, first, define a mean angle $\varphi_{\mathrm{M}}$ as

$$
\varphi_{\mathrm{M}}=\frac{\int_{0}^{\mathrm{L} / 4} \varphi(x) d x}{\left(\frac{L}{4}\right)}=4 \frac{\int_{0}^{\mathrm{L} / 4} \varphi(x) d x}{L} .
$$

The model considers a flat substrate, with a planar configuration of the director. The assumption of a flat substrate may not hold experimentally, and then the LC molecules may suffer elastic distortions along the out-of-plane direction, resulting in a nonzero initial pretilt at the patterned surface. However, this effect is not important for deformations that are much smaller than the period of the patterns, as we shall indicate as being the case in the experiments performed in this paper. Furthermore, this approximation enabled us to solve the equations analytically.

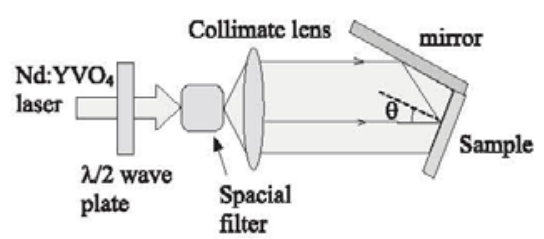

(a)
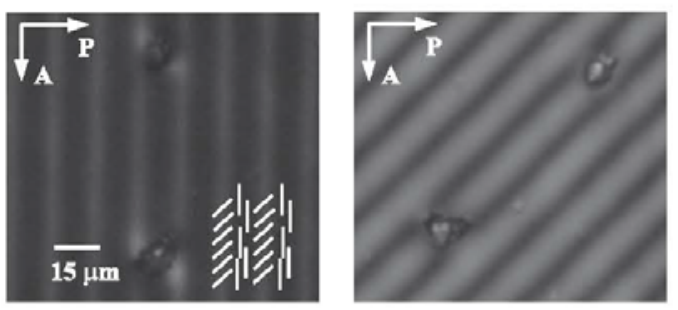

(b)

FIG. 2. (a) Experimental setup for the texture inscription; (b) optical image of a texture with $15 \mu \mathrm{m}$ period. The lines indicate the alignment direction of the azogroups at the individual stripes.

\section{EXPERIMENTAL DETAILS}

The azopolymer PS119, purchased from Aldrich and used as received, was dissolved at $0.2 \mathrm{wt} \%$ in water and cast on the substrates. LC cells were prepared using glass plates. For SNOM measurements the substrates were polished silicon wafers to increase the light reflectivity by the surface. The process responsible for the pattern formation is the wellknown photoalignment of the azogroups induced by linearly polarized light, which is reversible and governed by transcis-trans photoisomerization cycles [8]. We used a $\mathrm{Nd}: \mathrm{YVO}_{4}$ laser of $\lambda=532 \mathrm{~nm}$ passing through a spatial filter and collimated by a lens. The light intensity measured at the sample position was $160 \mathrm{~mW} / \mathrm{cm}^{2}$. The pattern inscriptions were performed in two steps: (i) the film was first homogeneously photoaligned at a given direction (perpendicularly to the light polarization direction), with normal incidence on the polymer surface; (ii) this film was then irradiated again with the interferometric setup described in Fig. 2(a) using a different light polarization direction. Using the latter procedure, a new orientation direction is induced in the illuminated regions, i.e., at the constructive interference fringes, whereas the first photoalignment direction remains unchanged at the dark regions given by the destructive interference fringes. The incidence of interference fringes can also produce SRGs $[9,10]$.

The period of the fringes corresponds to the period of the texture $(L)$ and can be easily controlled, according to the equation $L=2 \pi / k=\lambda / 2 \sin \theta$, where $\theta$ is given by the sample holder position. For $\lambda=532 \mathrm{~nm}$ it is possible to obtain a period ranging from 0.5 to $15 \mu \mathrm{m}$. The irradiation time was 60 and $30 \mathrm{~s}$, in the first and second steps, respectively, in order to keep the same irradiation at the illuminated regions, because in the second step (on the constructive fringes) the light intensity is doubled. It is important to emphasize that 


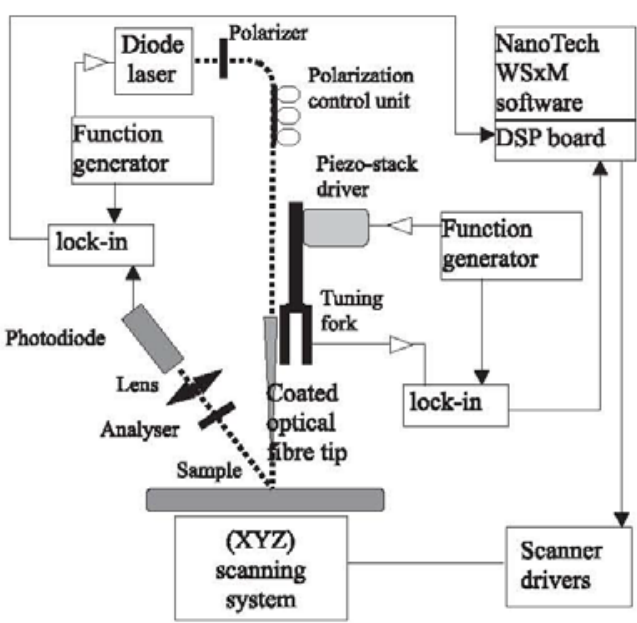

FIG. 3. Scheme of the SNOM.

this irradiation time is much lower than the time required for saturation of the photoalignment process, which is approximately $120 \mathrm{~min}$. for this polymer. We chose a short irradiation time to avoid formation of SRGs with large amplitudes.

Figure 2(b) shows an optical image of a patterned substrate with $L=15 \mu \mathrm{m}$, collected with a digital camera coupled to a polarized microscope. By rotating $45^{\circ}$ one can identify the orientation of the chromophores, as represented schematically in the figure. We infer that the difference in orientation for the azogroups along two neighboring stripes is $45^{\circ}$. This pattern was used in the SNOM measurements because it represents the maximum optical contrast between two neighboring stripes. SNOM operates in the noncontact mode at a fixed distance of $20 \mathrm{~nm}$ from the surface, where the tip comprises a tapered optical fiber with $200 \mathrm{~nm}$ diameter at the end. The light of a diode laser $(\lambda=670 \mathrm{~nm})$ is transmitted through the fiber, which illuminates the surface in the near field and is detected by a photodiode in the far field after interaction, giving the optical image of the surface with a resolution of approximately $\lambda / 5$. The topographic image is obtained in the shear force mode, with contrast originating from changes in the mechanical vibrations of the tip fixed on a tuning fork oscillating near the resonance frequency [11]. Therefore during the scanning, it is possible to
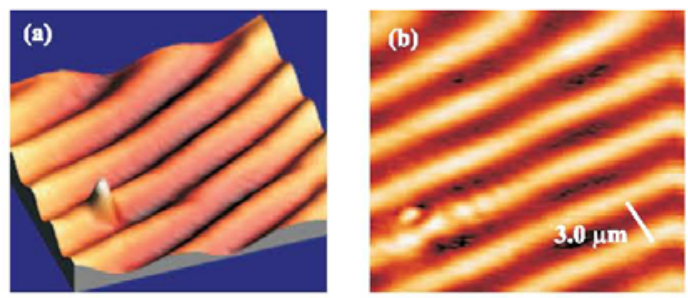

FIG. 4. (Color online) Images obtained simultaneously with the SNOM for a period of $3.0 \mu \mathrm{m}$; (a) topography and (b) optical image.
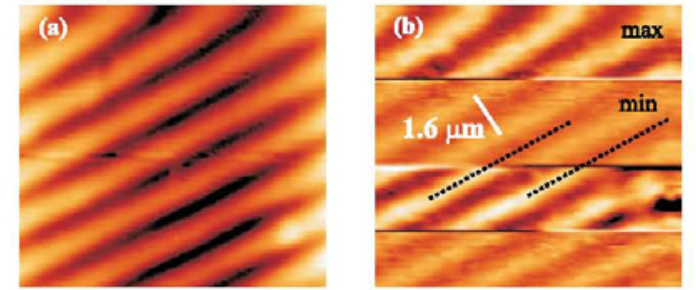

FIG. 5. (Color online) Images obtained simultaneously with the SNOM for a period of $1.6 \mu \mathrm{m}$; (a) topography and (b) optical images. The polarization of light was changed during the measurement between maximum $(\max )$ and minimum $(\min )$ of transmitted light to the photodetetor.

obtain simultaneously the optical and morphological images in the submicrometer range. The SNOM scheme is presented in Fig. 3, where the polarization control unit allows for manipulation of the direction of the light polarization impinging on the film. The polarization can be controlled by monitoring the intensity of the light captured by the photodiode coupled to an analyzer, in such a way that a maximum means that the incident polarization direction is parallel to the analyzer. In the experiments with LC, performed at room temperature, we used the 4-cyano-4'-n-pentylbiphenyl (5CB, Merck).

\section{RESULTS AND DISCUSSIONS}

SNOM images of the textured films are presented in Figs. 4-6, for periods of $3.0,1.6$, and $0.6 \mu \mathrm{m}$, respectively, with those on the left representing topography and those on the right corresponding to the optical image of the substrate. Figure 4(a) shows the periodic deformations in the surface topography, with a period of $3.0 \mu \mathrm{m}$ and amplitude of $10.0 \mathrm{~nm}$. A perfect correlation in terms of the period is observed in the optical image of Fig. 4(b). However, one may wonder whether the patterns in the optical image were caused by distinct directions of alignment of the azogroups in the stripes or by interference due to the light traveling different thicknesses in the film. To check this point, we scanned a patterned surface, by imposing variations in the incident light polarization during the scanning process, which are identified by maximum (max) and minimum ( $\min )$ of the captured light. If the correlation resulted from the
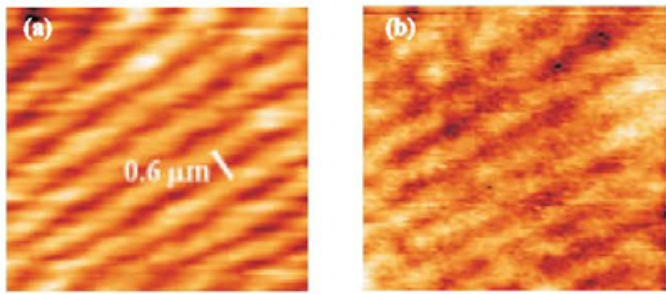

FIG. 6. (Color online) Images obtained simultaneously with the SNOM for a period of $0.6 \mu \mathrm{m}$; (a) topography and (b) optical image. 
azogroups' orientation, then a given stripe should alternate between dark and bright domains, whereas no changes would be observed if topography governed the optical images. As shown in Fig. 5 for a period of $1.6 \mu \mathrm{m}$, the optical patterns are due to the azogroups' orientation. The measured amplitude of the surface deformations was $5.0 \mathrm{~nm}$, which is negligible compared to the period of the pattern.

Figure 6 was obtained for a period of $0.6 \mu \mathrm{m}$ and in this case the measured amplitude was only $2.5 \mathrm{~nm}$. Although the morphological and optical images are not so clear, the optical effect is still present in the submicrometer range. This observation has important implications, as we shall discuss later on. It is important to note that the amplitudes of the surface deformations are very small compared to the corresponding periods (about $0.4 \%$ ), which justifies the assumption of a flat substrate in the theoretical model.

The LC alignment was investigated for surface textures as the one presented in Ref. [7], see Fig. 1, where the orientation of the azogroups had periodic angles of $+60^{\circ}$ and $-60^{\circ}$ with the $x$ axis (which is perpendicular to the stripes direction). The idea was to check the transition to a homogeneous state along the $y$ axis $\left(90^{\circ}\right)$, by reducing the period, as it is expected theoretically. The patterned substrates with different periodicities in the submicrometer range were used to build LC cells $20 \mu \mathrm{m}$ thick, using glass plates with polyvinyl alcohol (PVA) at the other side. The LC was inserted in the nematic phase by capillarity and the alignment direction (given by the director $\mathbf{n}$ ) was determined with an optical polarized microscope. The images were captured with a digital camera coupled to the microscope. In comparing the optical images of the patterned substrate with the LC orientation, the substrate was divided into two regions: one with the pattern itself and another reference region, referred to as background, corresponding to a uniform orientation of the azodye groups performed in the first step of the pattern inscription. For periods above $3.0 \mu \mathrm{m}$ we observed that the LC follows exactly the direction imposed by the patterned substrate, which means that the energy stored in the surface potential minimizes the elastic energy of the LC medium. However, for smaller periods the LC director points to the direction of $90^{\circ}$.

Figure 7 shows a pattern with a period of $0.6 \mu \mathrm{m}$, with a comparison on the right for the uniform orientation imposed by the photoalignment (background). For this period it is not possible to identify the orientation of individual stripes with a conventional microscope. We could only identify the macroscopic alignment of the polymeric film and the alignment induced to the LC molecules. Despite the limitation of the microscopy, significant differences could be observed: the first and the second rows represent the optical image only of the polymeric film (patterned substrate) and the LC cell at the same position, respectively. The columns named B, C, and D represent different relative orientations of the sample, rotated between crossed polarizers. In column B, the patterned region on the left side is positioned with the stripes along the analyzer direction. According to the first row of Fig. 7, when the sample is rotated by $30^{\circ}$ to the right, the background becomes dark, indicating that the film is oriented at $60^{\circ}$ from the horizontal direction, i.e., along the $x$ axis (see column C). When the sample is rotated by $30^{\circ}$ to the left, the
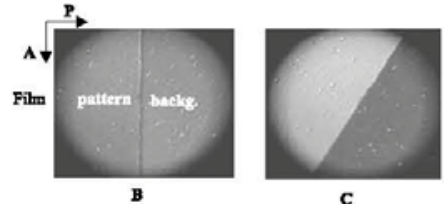

c
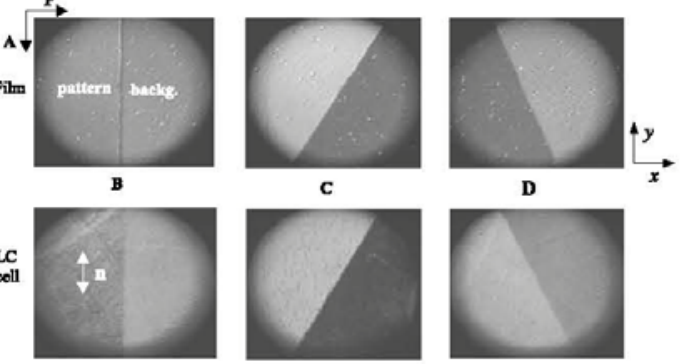

FIG. 7. Optical image at the border of the pattern and the background, for a texture period of $0.6 \mu \mathrm{m}$ with $\alpha= \pm 60^{\circ}$. The first row is the image of the film and the second row is the image at the same position of a LC cell mounted with the film. The colums B, C, and $D$ represent different relative positions of the sample between the crossed polarizers ( $\mathrm{A}$ and $\mathrm{P}$ ).

patterned region becomes dark, i.e., it is oriented at $-60^{\circ}$ from the $x$ axis (see column D). This observation agrees with the proposed pattern of periodic stripes with angles of $\alpha$ $= \pm 60^{\circ}$.

If we compare the first row with the second row of Fig. 7 , which represents the LC alignment at the same position, a different behavior induced by the patterned structure (column D) appears. By rotating the sample $30^{\circ}$ to the left, the patterned region did not become dark anymore. In this case, the sample position with lowest intensity of transmitted light was in column B, with the LC director along the $y$ axis $\left(90^{\circ}\right)$. Therefore we conclude that the LC did not follow the orientation imposed by the surface and an orientational transition occurred, which means that the energy of the system is minimized by a homogeneous alignment along the $y$ axis. This position, however, does not represent a complete extinction of light on the patterned region; instead, it indicates that despite an in-plane transition there is also an out-of-plane transition, in which the director adopts a tilted angle, whose value exhibits some dispersion around the $y$ axis.

Further analysis can be performed for a texture with period of $1.0 \mu \mathrm{m}$, as shown in Fig. 8. For the sake of clarity, we present only columns B and D. The minimum in transmitted light for the LC cell (second row) occurs at approximately $10^{\circ}$ from the $y$ axis direction, i.e., the director is aligned at $80^{\circ}$. In addition, the transmittance is quite low at this position, suggesting that the director lies in the $x-y$ plane and well aligned along the $80^{\circ}$ direction. The same was done for higher periods, with the plot for the final LC alignment direction with respect to the $x$ axis being shown in Fig. 9(a).

Figure 9(b) shows the mean angle $\varphi_{M}$ as a function of the pattern period $L$ for $\alpha= \pm 60^{\circ}$. As a result, a continuous increase of $\varphi_{\mathrm{M}}$ from $60^{\circ}$ towards $90^{\circ}$ is expected by decreasing L. This simulation was made using Eqs. (1), (4), and (5), assuming $W=1.5 \times 10^{-5} \mathrm{~J} / \mathrm{m}^{2}$ that was estimated for PS119 using the hybrid twisted cell method, with a rubbed PVA film at one side of the cell and a homogeneous film of PS119 photoaligned for $60 \mathrm{~s}$ at the other side [12]. In a polarized light microscope we observed a texture consistent with a totally twisted angle, indicating that the planar alignment im- 

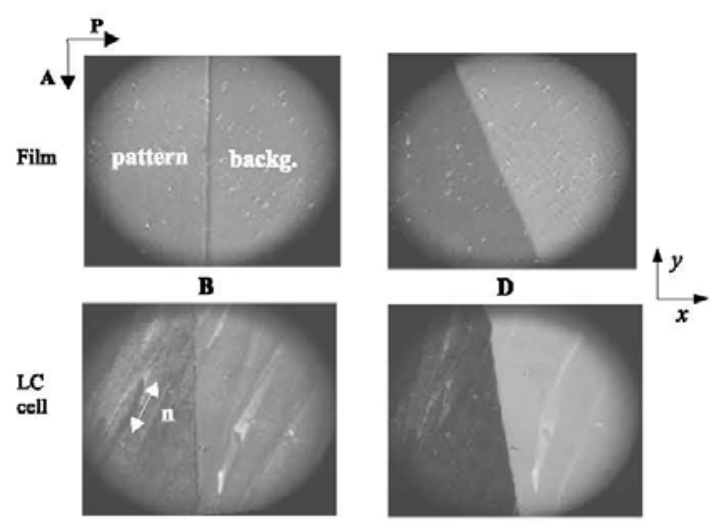

FIG. 8. The same as Fig. 7 for a texture period of $1.0 \mu \mathrm{m}$. Here only the colums B and D are shown.

parted to the LC exhibits strong anchoring properties, comparable to the rubbed PVA [13]. We have tested the possibility of using different values for $W$ (higher and lower than $\left.1.5 \times 10^{-5} \mathrm{~J} / \mathrm{m}^{2}\right)$ and we found that significant effects on the $\varphi_{\mathrm{M}}(L)$ curve are observed only if $W$ changes by one order of magnitude. A comparison between the experimental data and the theoretical simulation of Fig. 9 shows a continuous orientational transition from $60^{\circ}$ to $90^{\circ}$ due to the reduction of the pattern period. This transition is sharper experimentally, and for lower values of the period, since for periods higher than $3.0 \mu \mathrm{m}$ the $\mathrm{LC}$ alignment is along the direction imposed by the texture. Nevertheless, the behavior is qualitatively the same. It should be stressed that approximations had to be done in order to solve analytically the equations in the theoretical model, which can cause the simulated case to depart from the experimental conditions. For example, $K 1 / K 3$ was assumed to be 1.0 in the model, but for the $5 \mathrm{CB}$ LC it is 0.7 .

\section{CONCLUSIONS}

The in-plane orientational transition predicted in the model presented here could be confirmed experimentally, at least qualitatively. The experiments also suggested an out-ofplane transition for patterned substrates with periods below $1.0 \mu \mathrm{m}$. These results agree with those of Kim et al. [2], where transitions were observed, in the same range of periodicity, for textures produced with an atomic force microscope tip on polyimide. We conclude that these orientational transitions depend not only on the architecture of the texture, but also on the competition between the distortions imposed to the LC director, periodicity of the textures, and the elastic energy of the LC medium. The advantage of the method presented here is the simplicity for obtaining the textured substrates. In addition, the photoinduced effects are reversible and the use of photopolymers allowed the manipulation of the anchoring energy by controlling the irradiation time and the azodye concentration [4].

SNOM measurements were proven efficient to characterize the optical and morphological properties of polymeric

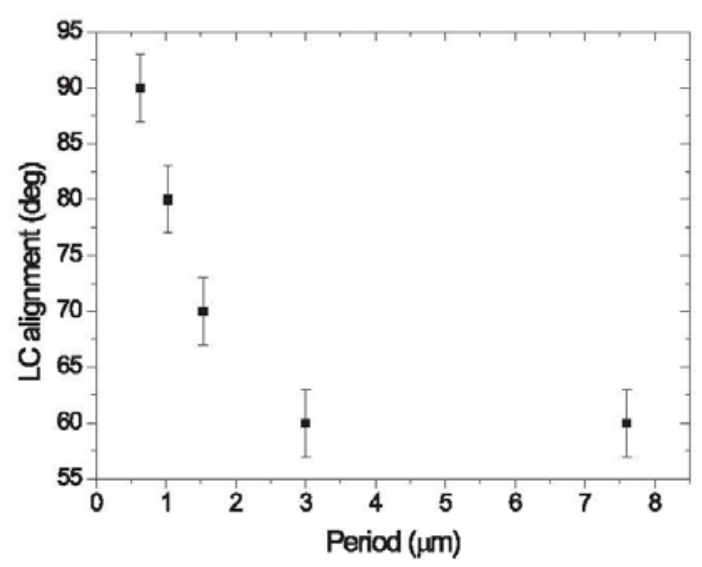

(a)

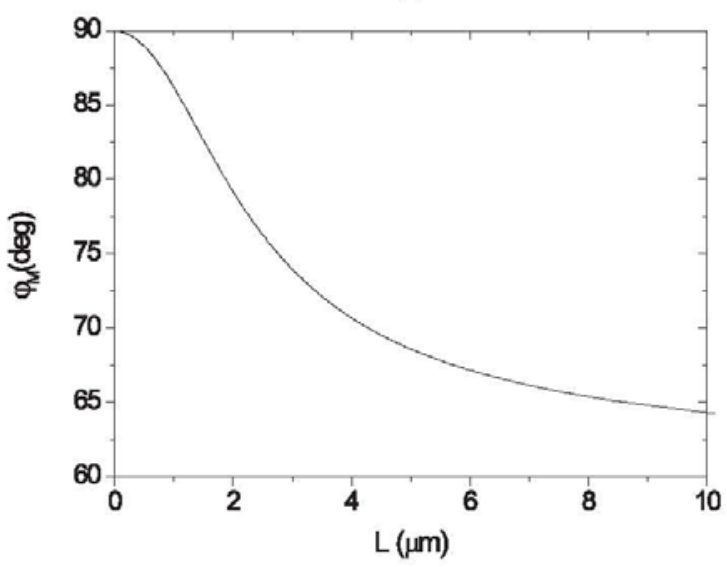

(b)

FIG. 9. (a) Experimental data for the LC alignment as a function of the pattem period; (b) simulated LC director mean angle $\varphi_{\mathrm{M}}$ as a function of the pattern period $L$.

substrates in the submicrometer scale. Therefore given that a linearly polarized $\mathrm{He}$ : $\mathrm{Cd}$ laser of $\lambda=442 \mathrm{~nm}$ could be injected into the fiber, the same equipment can be used to inscribe structures, where the lower dimensions are determined by the optical aperture of the tip. New experiments are underway to investigate the conditions for information inscription using lithographic techniques in the submicrometer scale, which can be used in data storage and specific LC alignment.

\section{ACKNOWLEDGMENTS}

The authors are grateful to Dr. Suhaila M. Shibli for the $\mathrm{Nd}: \mathrm{YVO}_{4}$ laser facilities. This work was supported by FAPESP, CNPq, and IMMP/MCT (Brazil). 
[1] A. J. Pidduck, S. D. Haslam, G. P. Bryan-Brown, R. Bannister, and I. D. Kitely, Appl. Phys. Lett. 71, 2907 (1997).

[2] J. H. Kim, M. Yoneya, J. Yamamoto, and H. Yokoyama, Appl. Phys. Lett. 78, 3055 (2001).

[3] B. Zhang, F. K. Lee, O. K. C. Tsui, and P. Sheng, Phys. Rev, Lett. 91, 215501 (2003).

[4] L. T. Thieghi, R. Barberi, J. J. Bonvent, E. A. Oliveira, J. A. Giacometti, and D. T. Balogh, Phys. Rev. E 67, 041701 (2003).

[5] C. J. Newsome, M. O'Neill, R. J. Farley, and G. P. BryanBrown, Appl. Phys. Lett. 72, 2078 (1998).

[6] M.-H. Kim, J.-D. Kim, T. Fukuda, and H. Matsuda, Liq. Cryst. 27, 1633 (2000).

[7] F. Batalioto, I. H. Bechtold, E. A. Oliveira, and L. R. Evangelista, Phys. Rev. E 72, 031710 (2005).
[8] A. Dhanabalan, C. R. Mendonça, D. T. Balogh, L. Misoguti, C. J. L. Constantino, J. A. Giacometti, S. C. Zilio, and O. N. Oliveira Jr., Macromolecules 32, 5277 (1999).

[9] N. K. Vismanathan, D. Y. Kim, S. Bian, J. M. Williams, W. Liu, L. Samuelson, J. Kumar, and S. K. Tripathy, J. Mater. Chem. 9, 1941 (1999).

[10] O. N. Oliveira Jr., L. Li, J. Kumar, and S. K. Tripathy, in Photoreactive Organic Thin Films, edited by Z. Sekkat and W. Knoll (Academic, San Diego, 2002), p. 429.

[11] J. Schoenmaker, M. S. Mancarotte, A. C. Seabra, Y. Souche, and A. D. Santos, J. Microsc. 214(1), 22 (2004).

[12] G. P. Bryan-Brown and I. C. Sage, Liq. Cryst. 20, 825 (1996).

[13] M. Schadt, K. Schmitt, V. Kozinkov, and V. G. Chigrinov, Jpn. J. Appl. Phys., Part 1 31, 2135 (1992). 


\section{Apêndice C - Modelo para a formação de SRGs em materiais azocorantes}

Nesta seção será feita a introdução ao modelo do gradiente de força, que explica o processo de formação de grades de relevo em fotopolímeros quando se incide dois feixes de luz linearmente polarizada na superfície do material. Inicialmente considera-se que o efeito de interferência ótica entre os dois feixes de luz incidente no material como sendo uma interação entre duas funções de onda, separadas por uma fase (cada função de onda correspondente a um feixe luminoso é interpretado como sendo um campo ótico) conforme mostra a figura C.1:

$$
E_{1}(r) e^{i\left(\omega t-k_{1} r\right)}, \quad E_{2}(r) e^{i\left(\omega t-k_{2} r\right)}
$$
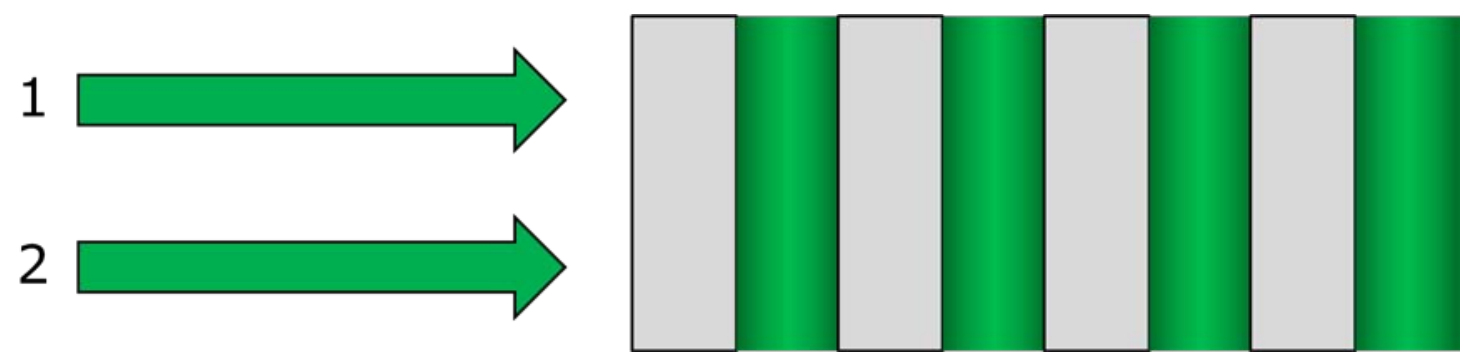

Figura C.1: Ilustração do efeito de interferência ótica obtida pela interferência de dois feixes incidentes.

A princípio a polarização induzida na superfície do polímero é essencialmente a mesma do campo elétrico $\mathbf{E}$ incidente. Como o perfil do feixe não é homogêneo, existe um gradiente de campo elétrico na área iluminada (que é máxima bem ao centro desta área, e vai diminuindo de intensidade conforme se aproxima da região não-iluminada). Deste modo, também existe uma diferença na probabilidade de absorção de um fóton por um grupo azocorante, que é maior conforme aumenta a intensidade luminosa na 
região iluminada. O efeito de formação de SRG ocorre com uma relação entre a direção de polarização do campo elétrico incidente e a direção de gravação dos canais (direção em que se dá a variação de energia luminosa). A força resultante, neste caso, pode ser expressa através da expressão:

$$
f=\operatorname{Re}[\vec{P}(r) \bullet \nabla] \vec{E}(r)=\operatorname{Re}\left(P_{x} \frac{\partial}{\partial x}+P_{y} \frac{\partial}{\partial y}+P_{z} \frac{\partial}{\partial z}\right) \vec{E}(r)
$$

onde $\vec{P}=\vec{P}_{0}+\vec{P}_{\text {induzido }} \quad$ é a polarização resultante, $\mathbf{P}_{\mathbf{0}}$ a polarização inicial e $\mathbf{P}_{\text {induzido a }}$ polarização induzida.

Escolhendo um sistema de coordenadas onde a gravação dos canais se dá na direção $\boldsymbol{x}$, o modelo de gradiente de força permite escrever a força resultante como:

$$
f=\operatorname{Re}\left(P_{x} \frac{\partial}{\partial x}+P_{y} \frac{\partial}{\partial y}+P_{z} \frac{\partial}{\partial z}\right) \vec{E}(r)
$$

No caso de ondas com polarização $\boldsymbol{s}$ (na direção $\boldsymbol{y}$ ) o modelo prevê um valor nulo de força, ou seja, não há formação de SRGs. Para qualquer outra direção de polarização haverá sempre uma componente do gradiente de força na direção $\boldsymbol{x}$. A figura C.2 mostra visualmente o modelo.

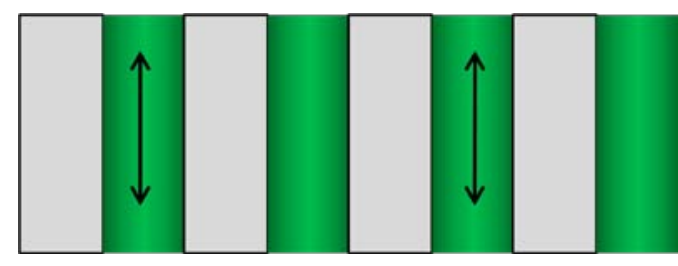

(a)
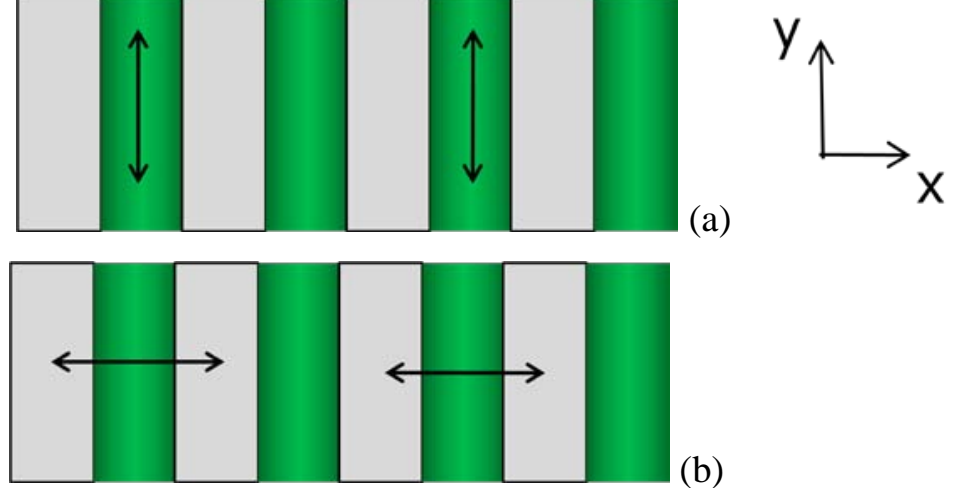

(b)

Figura C2: (a) polarizações do tipo s resultam em uma força resultante nula, enquanto (b) para qualquer outra configuração sempre há uma componente da força na direção $\boldsymbol{x}$; 
Esse modelo mostra que cadeias poliméricas que não são extremamente rígidas se comportam como um meio visco elástico, e podem ser deslocadas sob influência de forças oticamente induzidas. Além disso, a eficiência com que este deslocamento ocorre é proporcional à mobilidade das cadeias poliméricas. O modelo mostra também que a baixa magnitude de força não é capaz de realizar deformações no volume do material, embora seja bastante adequada para causar fluxo de massa nesses materiais fotossensíveis. 


\section{Apêndice D - Modelo de Berrreman}

Os termos da energia livre de Frank (Eq. 8) para o modelo de Berreman são:

- Termo de splay: $K_{11}(\nabla \bullet \hat{n})^{2}$;

$$
\begin{aligned}
& \vec{\nabla} \cdot \hat{n}=\cos \varphi \frac{\partial \varphi}{\partial x}-\sin \varphi \frac{\partial \varphi}{\partial z} \\
& (\vec{\nabla} \cdot \hat{n})^{2}=\cos ^{2} \varphi\left(\frac{\partial \varphi}{\partial x}\right)^{2}-2 \cos \varphi \sin \varphi \frac{\partial \varphi}{\partial x} \frac{\partial \varphi}{\partial z}+\sin ^{2} \varphi\left(\frac{\partial \varphi}{\partial z}\right)^{2}
\end{aligned}
$$

- $\underline{\text { Termo de twist : }} K_{22}[\hat{n} \bullet(\nabla \times \hat{n})]^{2}$;

$$
(\vec{\nabla} \times \hat{n})=\left|\begin{array}{ccc}
\frac{\partial}{\partial x} & \frac{\partial}{\partial y} & \frac{\partial}{\partial z} \\
\sin \varphi & 0 & \cos \varphi \\
i & j & k
\end{array}\right|=\left(\cos \varphi \frac{\partial \varphi}{\partial x}-\sin \varphi \frac{\partial \varphi}{\partial x}\right) j \rightarrow \nabla \bullet(\vec{\nabla} \times \hat{n})=0
$$

- Termo de Bend: $K_{33}[\nabla \times(\nabla \times \hat{n})]^{2}$;

$$
\begin{aligned}
& \vec{\nabla} \times \cdot(\vec{\nabla} \times \hat{n})=-\left[\cos \varphi \sin \varphi \frac{\partial \varphi}{\partial x}+\cos ^{2} \varphi \frac{\partial \varphi}{\partial z}\right] \hat{i}+\left[\sin ^{2} \varphi \frac{\partial \varphi}{\partial x}+\cos \varphi \sin \varphi \frac{\partial \varphi}{\partial z}\right] \hat{k} . \\
& {[\vec{\nabla} \times \cdot(\vec{\nabla} \times \hat{n})]^{2}=\sin ^{2} \varphi\left(\frac{\partial \varphi}{\partial x}\right)^{2}+2 \cos \varphi \sin \varphi \frac{\partial \varphi}{\partial z} \frac{\partial \varphi}{\partial z}+\cos ^{2} \varphi\left(\frac{\partial \varphi}{\partial z}\right)^{2}}
\end{aligned}
$$


Dessa forma, a densidade de energia livre é escrita como:

$$
\begin{aligned}
& f=\frac{K_{11}}{2}\left[\cos ^{2} \varphi\left(\frac{\partial \varphi}{\partial x}\right)^{2}-2 \cos \varphi \sin \varphi \frac{\partial \varphi}{\partial x} \frac{\partial \varphi}{\partial z}+\sin ^{2} \varphi\left(\frac{\partial \varphi}{\partial z}\right)^{2}\right]+ \\
& +\frac{K_{33}}{2}\left[\sin ^{2} \varphi\left(\frac{\partial \varphi}{\partial x}\right)^{2}+2 \cos \varphi \sin \varphi \frac{\partial \varphi}{\partial z} \frac{\partial \varphi}{\partial z}+\cos ^{2} \varphi\left(\frac{\partial \varphi}{\partial z}\right)^{2}\right]
\end{aligned}
$$

e portanto

$$
\begin{aligned}
& f=\frac{1}{2}\left(K_{11} \cos ^{2} \varphi+K_{33} \sin ^{2} \varphi\right)\left(\frac{\partial \varphi}{\partial x}\right)^{2}+\frac{1}{2}\left(K_{11} \sin ^{2} \varphi+K_{33} \cos ^{2} \varphi\right)\left(\frac{\partial \varphi}{\partial z}\right)^{2}- \\
& -\frac{1}{2}\left(K_{11}+K_{33}\right) \cos \varphi \sin \varphi \frac{\partial \varphi}{\partial z} \frac{\partial \varphi}{\partial z}
\end{aligned}
$$

Fazendo finalmente a aproximação de constante única $\boldsymbol{K}_{11}=\boldsymbol{K}_{33}=\boldsymbol{k}$, escreve- se finalmente a densidade de energia livre é escrita como

$$
f=\frac{1}{2} k\left[\left(\frac{\partial \varphi}{\partial x}\right)^{2}+\left(\frac{\partial \varphi}{\partial z}\right)^{2}\right] .
$$




\section{Apêndice E: Modos de operação de um microscópio de Força Atômica}

Será mostrada nesta seção uma pequena introdução aos conceitos básicos de operação de um microscópio de força atômica. Em especial, serão mostrados os conceitos relevantes para as técnicas de AFM de contato e contato intermitente.

\section{Introdução}

Foi no ano de 1986 que os físicos Gerd Binning e Heinrich Roher (juntamente como professor Ernst Ruska, tipo como o pai da microscopia eletrônica) receberam o Prêmio Nobel, por seus esforços que culminaram com o invento da Microscopia de Força Atômica (AFM) e conseqüentemente a Microscopia de Tunelamento (STM). Desde então, diversas técnicas vêm se aprimorando para melhorar e aperfeiçoar os domínios da AFM. Como o próprio nome sugere, a microscopia de força atômica mede, de alguma forma, a força trocada entre a ponta de prova (sonda) e a amostra utilizada, e esta força pode ser de origem repulsiva ou atrativa dependendo do caso. A monitoração da variação desta força num plano de varredura dará uma forma da topologia da superfície analisada.

Basicamente, um Microscópio de Força Atômica consiste de um sistema com um cantilever e uma sonda (ponta), que conforme se aproxima da superfície da amostra interagem com a mesma trocando forças. Através de um sistema de referência, composto por um feixe laser e um fotodiodo detector de posição, é possível a monitoração da deflexão do cantilever devido às forças entre a ponta e a amostra. A figura E.1 ilustra esta montagem: 


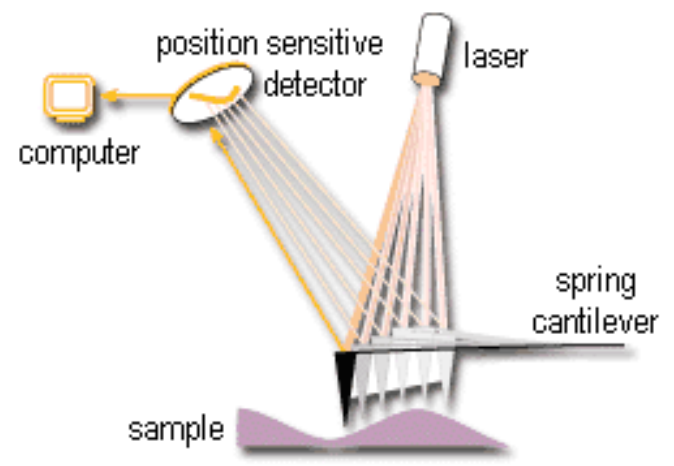

Figura E.1 - Esquema simplificado para a técnica de AFM.

Na verdade, o modo AFM se subdivide em 3 modos:

- $\quad$ AFM de contato

- $\quad$ AFM de contato intermitente (Tapping Mode)

- $\quad$ AFM de não-contato

Os três tipos de microscopia de força atômica podem ser usados para estudar amostras isolantes, semicondutoras ou condutoras.

A força que atua entre ponta e amostra no AFM é a de van der Waals. A dependência da força de van der Waals em termos da distância entre a ponta e a amostra é mostrada no gráfico da figura B.2: neste gráfico, os valores positivos de força correspondem à interação repulsiva, e os negativos correspondem à interação atrativa. Para grandes distâncias entre ponta e amostra esta força tende a zero, para pequenas distâncias ela é repulsiva e aumenta rapidamente com a diminuição da distância. Para valores intermediários ela é atrativa, possuindo um módulo máximo em uma dada distância.

No modo AFM de contato a ponta é mantida muito próxima da superfície da amostra e a força entre ponta e amostra é repulsiva, como mostra a figura B.2. No modo AFM de não contato a ponta é mantida a distâncias de dezenas ou centenas de angstroms da superfície da amostra e a força é atrativa. 
No modo AFM de contato intermitente o cantilever oscila mantendo distâncias entre ponta e amostra (figura E.2). Assim, a ponta oscila, tocando gentilmente a superfície da amostra a cada ciclo.

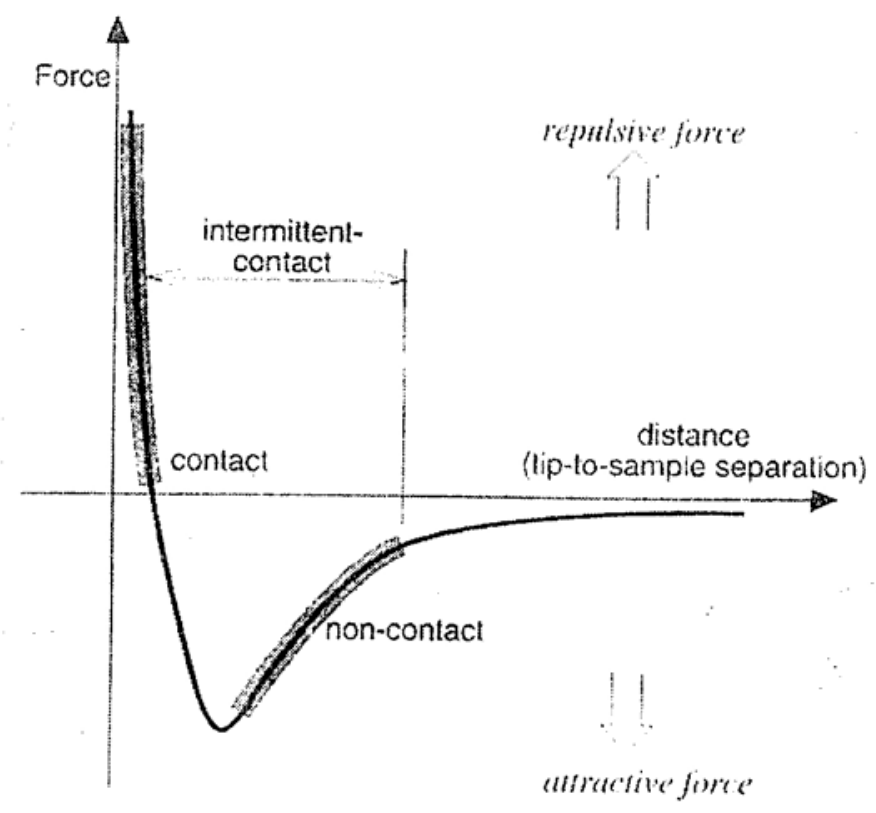

Figura E.2 - Forças entre ponta e amostra para as a técnicas distintas de AFM.

Note que a região no gráfico da figura B.2 em que a ponta oscila para o caso do modo AFM de não contato é diferente da região do modo AFM de contato intermitente. No primeiro caso a amostra não é tocada pela ponta, enquanto que no segundo caso ela é tocada suavemente a cada ciclo.

A ordem de grandeza da força total agente no modo AFM de contato é de $10^{-6} \mathrm{~N}$ ou $10^{-7} \mathrm{~N}$; para o modo de não contato é da ordem de $10^{-12} \mathrm{~N}$ e a de contato intermitente fica entre este dois valores. 


\section{$\underline{\text { Descrição do modo AFM de contato }}$}

Ponta e amostra são consideradas em contato quando a força de van der Waals se torna positiva, isto é, a força de interação é repulsiva. Como a inclinação da curva nessa região do gráfico é bastante acentuada, quando aumentamos a força entre ponta e amostra não temos uma aproximação maior entre elas, mas sim obteremos uma deformação do cantilever.

Além da força repulsiva de van der Waals, duas outras forças estão presentes na interação ponta/amostra: força exercida pelo cantilever, $\boldsymbol{F}=-\boldsymbol{k} \boldsymbol{x}$, e a força de capilaridade exercida pela fina camada de água freqüentemente presente na superfície da amostra. A força de capilaridade é atrativa $\left(\sim 10^{-8} \mathrm{~N}\right)$, ocorrendo devido à tensão superficial da água, presente na superfície da amostra, envolvendo a ponta. Enquanto a ponta estiver em contato com a amostra, a força de capilaridade deve ser constante, pois esta depende da distância ponta/amostra, que deve ser basicamente constante durante a varredura. Assim, a força variável no AFM de contato é a força exercida pelo cantilever.

Neste modo de operação o cantilever deve apresentar uma constante elástica $k$ menor que a constante elástica efetiva do acoplamento inter-atômico $k_{a t}$ do material de que a amostra é composta, pois na interação ponta/amostra o cantilever deve ser deformado, não a rede, para que imagens fidedignas sejam obtidas.

Assim a constante elástica da mola deve ser, portanto:

$$
k<k_{a t}=\omega_{a t}^{2} m_{a t} .
$$

Freqüências de vibração atômica típicas são da ordem de $\omega_{a t}=10^{13} \mathrm{~Hz}$ e massas atômicas podem ser tomadas da ordem de $10^{-25} \mathrm{~kg}$. Desta forma,

$$
k<\omega_{a t}^{2} m_{a t}=10 \mathrm{~N} / \mathrm{m} .
$$


Como já visto anteriormente, a formação da imagem se dá da quando a ponta varre a superfície da amostra e passa por pontos de diferentes alturas, gerando variação na deflexão do cantilever. Esta deflexão é medida através de um feixe de laser refletido na extremidade do cantilever, chegando até um fotodiodo. Através de uma corrente de retroalimentação (feedback) controlada através de um computador via software, a deflexão do cantilever é mantida constante durante a varredura, movendo o cantilever verticalmente, a cada ponto. A posição vertical do cantilever, juntamente com a posição cartesiana $(i, j)$ correspondente, é armazenada no computador formando a imagem topográfica da superfície da amostra. Esse sistema de medida ótica de variações de altura tem sensibilidade para detectar até fração de angstrom.

Outra possibilidade de obtenção de imagem em modo AFM de contato é manter constante a altura do cantilever e varrer a amostra registrando ponto a ponto a deflexão do cantilever. No modo onde se mantém a força constante, isto é, onde se faz correções na altura do cantilever para que sua deflexão seja mantida constante, a velocidade de obtenção das imagens é limitada pelo tempo de resposta do sistema de feedback, mas a força total exercida pela ponta sobre a amostra é bem controlada. O modo de força constante é geralmente o mais utilizado. O modo onde se mantém a altura do cantilever constante é freqüentemente utilizado para obtenção de imagens em resolução atômica, pois as variações na deflexão do cantilever são pequenas e, portanto, as variações na força da ponta sobre a amostra são também pequenas. Esse modo, de altura do cantilever constante, é especialmente interessante para registro de imagens em tempo real de superfícies em formação, pois nesse caso é desejável uma alta velocidade de varredura. 


\section{Descrição do AFM de contato intermitente (Tapping Mode)}

No modo de contato intermitente (Tapping Mode) a sonda consiste em uma ponta presa a um cantilever oscilante que, durante a varredura, toca a superfície da amostra no ponto de máxima amplitude de oscilação, conforme indicado na figura E.3.

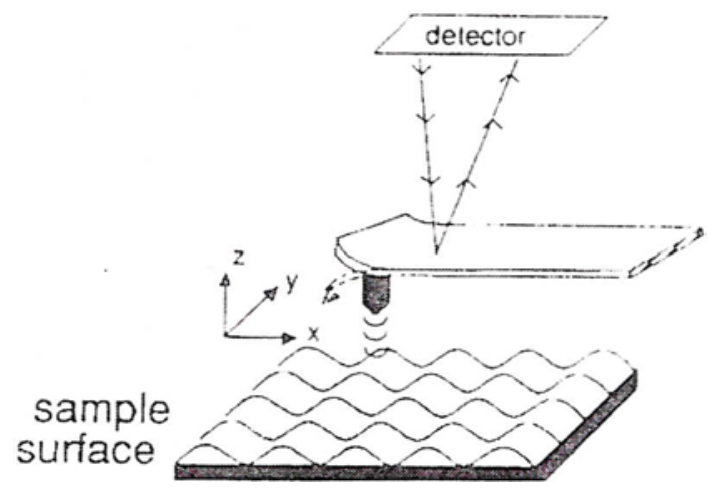

Figura E.3 - Esquema para a técnica de Tapping Mode.

O modo AFM de contato intermitente é similar ao de não contato, com a diferença em que a ponta oscila, tocando gentilmente a superfície da amostra a cada ciclo de sua oscilação. As distâncias entre ponta e amostra para o modo AFM de contato intermitente são indicadas na figura B.2.

É mais adequado analisar topograficamente algumas amostras através da modalidade de AFM de contato intermitente, quando comparamos esse modo com o de contato ou não contato. A razão para isso está no fato da modalidade de contato acarretar uma força de arrastamento entre a ponta e a amostra, inerente ao método, que pode causar dano na superfície da amostra. E, a modalidade de não contato, além de possuir resolução lateral inferior, também pode apresentar artefatos.

A amplitude de oscilação do cantilever é da ordem de $20 \mathrm{~nm}$ a $100 \mathrm{~nm}$ e a freqüência de oscilação pode variar entre 100 e $400 \mathrm{kHz}$. No caso específico da modalidade de contato intermitente, a amplitude é o parâmetro utilizado para ser mantido constante, pois o contato com a superfície impede a análise por freqüência. 
Assim, ao impormos que o rms da amplitude de oscilação seja constante equivale a manter uma altura média de ponta constante, através de correções em $\mathbf{z}$ ponto a ponto da varredura. Desta forma, ao final de uma varredura completa, tem-se uma imagem topográfica da superfície da amostra.

O setpoint para o modo Tapping tem um papel importante na interação ponta amostra. Para valores de setpoint próximos a um (1), teremos a oscilação da ponta quase como uma oscilação livre e, portanto, a interação ponta/amostra será fraca, causando menor dano para ambas. A desvantagem dessa interação fraca está na necessidade de um maior tempo para a correção na altura $z$ da amostra em cada ponto da varredura. No caso de valores de setpoint próximos a dois (2), teremos a ponta tocando a amostra em uma amplitude inferior à sua amplitude máxima de oscilação, o que gera uma interação ponta/amostra mais forte, causando maior dissipação de energia na superfície da amostra, mas exigindo menor tempo para a correção na altura $\mathbf{z}$ em cada ponto da varredura.

\section{Experimental}

Será mostrado um Scanning Probe Microscopy da Digital Instruments, empresa atualmente pertencente a Veeco [http://www.veeco.com/], denominado Nanoscope IIIA. Esse aparelho possui acessórios para a realização de AFM, STM e MFM e se encontra em operação no laboratório de Filmes Finos do IFUSP (auxílio FAPESP - Multiusuários - processo n ${ }^{\circ}$ 95/5651-0). A figura E.4 mostra o Nanoscope IIIA na modalidade de Força Atômica (AFM). 


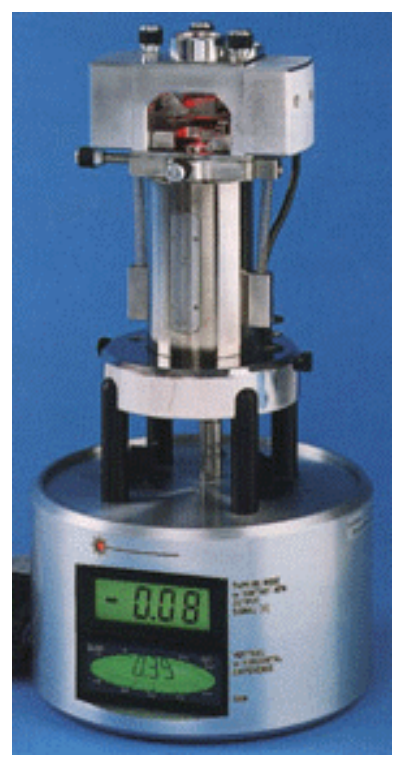

Figura E.4: Fotografia do equipamento de AFM Nanoscope III utilizado.

As pontas são as responsáveis pela interação do microscópio com o objeto em estudo, e é importante ressaltar algumas propriedades que esses elementos devem possuir. Primeiramente, é desejado que a ponta seja o mais fina possível, de modo que haja uma homogeneidade no processo de interação, ou seja, que a área da ponta que interage com o spécimen é constante. Existem vários tipos de pontas no mercado, de tamanhos e materiais distintos. Alguns modelos comerciais são apresentados com o cantilever embutido,e algumas marcas comercializam pontas fabricadas em uma única placa, porém embora o processo seja preciso é necessária a calibração da freqüência de ressonância individualmente para cada conjunto ponta/cantilever. Sondas individuais também podem ser adquiridas, obviamente com custo muito superior quando comparada ao tipo anteriormente citado. Foi possível observarmos esses elementos, porém a olho nu mal conseguimos distinguir o cantilever. Com o auxílio de uma lupa (lente de aumento) é possível observarmos o cantilever, mas não a sonda. Alguns modelos apresentam 4 cantilevers, posicionados 2 a 2 em lados opostos da célula primária. Na hora de se usar escolhe-se o mais adequado, descartando os outros (como o custo operacional é quase o mesmo, opta-se por fazer 4 de uma só vez). 
O porta-amostras funciona de tal forma que a ponta de prova é fixa numa posição, e a varredura é feita pelo próprio porta-amostras (neste caso, é chamado de scanner). Esse porta-amostras tem, portanto, movimento nos três eixos definidos no laboratório: $\boldsymbol{x}$, $y$ e z. O scanner em questão é composto por materiais piezelétricos, e conforme aplicamos tensão a ele é possível varrer a amostra num plano $x \boldsymbol{y}$. Monitorando a variação da corrente no filamento (STM) ou a deflexão do cantilever (AFM) é possível obter informações sobre o eixo $\mathbf{z}$ (altura) do objeto. Os scanners podem ser do tipo A, E e J. Suas diferenças principais se devem ao tamanho da área da amostra que vai ser varrida sob a sonda e a precisão de cada "passo" realizado na variação espacial (plano xy). O valor máximo da rugosidade (“altura” ou eixo z) do material analisado também é fixado pelo tipo de scanner utilizado.

O sistema de controle, aquisição, registro, gravação e edição dos resultados consiste de um microcomputador PC com sistema operacional MS-DOS. Uma curiosidade é a presença de dois monitores de vídeo independentes, sendo que um deles opera exclusivamente para exibir as imagens obtidas. O software utilizado é da própria empresa que comercializa o microscópio, e o código do programa é fechado, ou seja, não é possível adaptar o programa para nenhuma situação diferente da original (nem mesmo se pode corrigir algum problema existente). O menu principal dá acesso ao tipo de microscopia a ser utilizada (contato, tapping mode, tunelamento) e para cada opção surge um menu de parâmetros que variam conforme a opção escolhida. Para a técnica de SFM, alguns dos controles disponíveis são:

- freqüência de ressonância do cantilever.

- tensão elétrica aplicada ao cantilever (deflexão ou força inicial).

- quantidade de linhas medidas (resolução).

- tamanho da área selecionada para a varredura.

- posição de offset (centralizar a região desejada sob a sonda). 
As imagens obtidas podem ser salvas em formato de imagem digital (.tif) ou em uma seqüência binária (.dat). O software possui ainda uma serie de funções interessantes, como por exemplo filtros para eliminar ruídos (um em especial trata de identificar e realçar redes existentes), efeitos para melhor visualização (por exemplo adicionar "sombra" na imagem para que a topologia se torne mais evidente), zoom, entre vários outros que serão utilizados nas próximas aulas práticas. As figuras obtidas também podem ser visualizadas no padrão de “corrente”, ou seja, teremos uma imagem com contraste de cor que indica a variação da corrente na sonda, dando novamente uma idéia da organização dos átomos no material estudado. 


\section{Apêndice F: Nanolitografia em azopolímeros}

Nesta seção, será apresentado um pequeno ensaio realizado durante a realização do estudo proposto, e se refere à tentativa de gravação de SRGs através da técnica de AFM, usando a própria sonda do microscópio para realizar essa nanolitografia.

$\underline{\text { Introdução }}$

Encontra-se na literatura vários trabalhos relativos à gravação de SGRs usando técnicas de SPM, de forma a usar a própria sonda para se realizar uma litografia na superfície numa escala nanométrica. Foi feita então uma tentativa de se gravar sulcos (nanolitografia com a técnica de AFM no modo de contato) periódicos e com profundidade controlada num polímero fotossensível. O efeito de gravação das SRGs é feito pela própria sonda durante a varredura, e desta forma o problema experimental se refere a acertar os parâmetros acessíveis para que isto ocorra. De fato, deseja-se que a sonda realize uma pressão no substrato, fazendo literalmente ranhuras periódicas e com igual profundidade. Para a realização do projeto, foi utilizada uma amostra do polímero PS119 diluído em água na proporção $1 \mathrm{~g}$ para cada $100 \mathrm{ml}$ de água destilada. Foram cortadas pequenas lâminas de vidro (lâminas simples, de microscópio com espessura de $\sim 2 \mathrm{~mm}$ ) de forma a serem compatíveis com as dimensões do porta amostra do microscópio. Os filmes de polímero foram produzidos pela técnica conhecida como casting, simplesmente pipetando a solução na lâmina e deixando secar a temperatura ambiente.

Como referência, encontramos os valores de uma força normal à superfície de $F \approx$ $1,25 \mu N$ para a obtenção de ranhuras com profundidade de $5 \mathrm{~nm}$ [A. Rastegar et al., 2001]. Obviamente, o período pode ser estimado calculando-se a quantidade de linhas 
por área varrida, e é proporcional à resolução do aparelho (128, 256 ou 512 linhas). Adicionalmente, também foram feitas medidas auxiliares (tapping mode) para análise da topologia gerada.

Resultados e análise

Para a realização da nanolitografia, foi utilizado um Scanning Probe Microscopy da Digital Instruments, empresa atualmente pertencente a Veeco, denominado Nanoscope IIIA. Esse trabalho foi realizado como um projeto final para o curso de pósgraduação do IFUSP (FAP 5753) ministrado pela $\operatorname{Prof}^{a} \operatorname{Dr}^{a}$ Maria Cecília B. S. Salvadori, do grupo de Filmes Finos do IFUSP-SP (auxílio FAPESP - Multiusuários processo no $95 / 5651-0$ ).

No Nanoscope III, foi utilizada uma ponta de silício para a gravação do polímero. A princípio, foram feitas medidas numa área de $30 \mu \mathrm{m}$ com uma resolução de 128 linhas. Isto nos dá um espaçamento entra as linhas de $234,4 \mathrm{~nm}$. O processo decisivo pra a formação das ranhuras foi determinar qual a força necessária para o efeito ocorrer. Foi feito então um ajuste na calibração do aparelho (figura F1). Foi feito um ajuste de setpoint tal que a deflexão do cantilever seja correspondente força necessária para a gravação dos canais. 


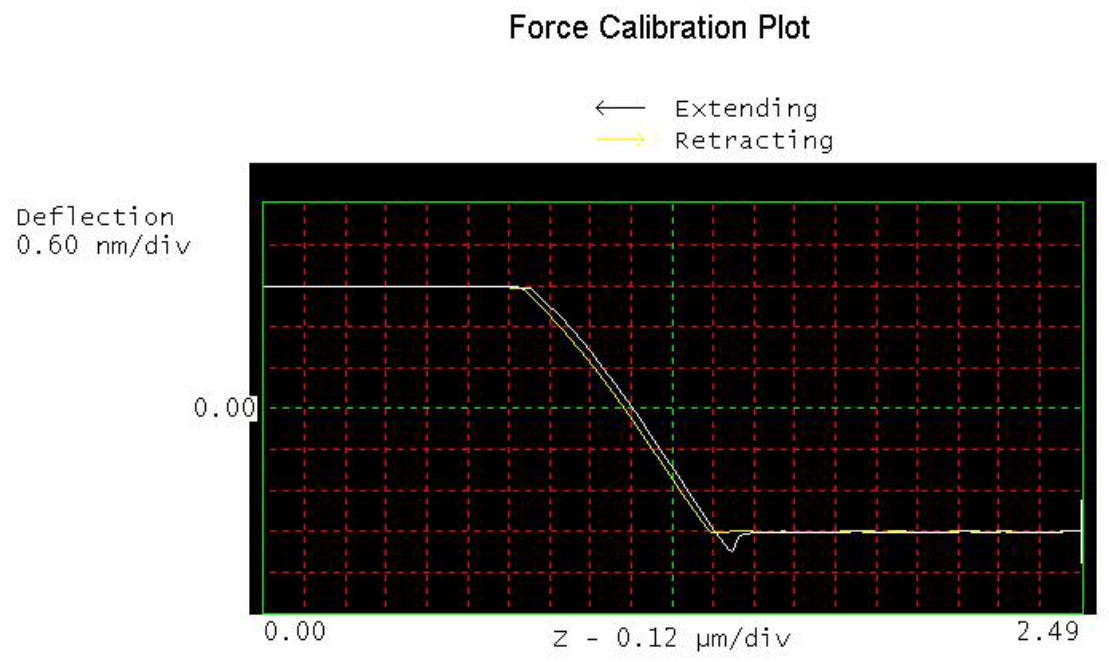

$\begin{array}{lr}\text { Digital Instruments Nanoscope } \\ \text { Z scan size } & 2.490 \mu \mathrm{m} \\ \text { Scan rate } & 4.883 \mathrm{~Hz} \\ \text { Range } & 6.000 \mathrm{~nm}\end{array}$

06221050.001

Figura F.1 - Calibração da força necessária para a gravação de canais no polímero.

A força pode ser obtida facilmente das relações:

$$
\begin{aligned}
& v^{2}=\frac{1,03 t^{2} E}{(2 \pi)^{3} l^{4} \rho}, \\
& k=\frac{0,25 E w t^{3}}{l^{3}}
\end{aligned}
$$

onde $E_{S i}=162 \mathrm{GPa}, \rho_{S i}=2,33 \mathrm{~g} / \mathrm{cm}^{3}, v=336 \mathrm{kHz}$ e $\mathrm{k}$ é a constante do sistema ponta/cantilever. Os valores de $l$ e $w$ são valores da geometria da ponta, e são $w=$ $0,42 \mathrm{~mm}$ e $l=1,30 \mathrm{~mm}$. Desta forma, encontramos $k=9,13 \mathrm{~N} / \mathrm{m}$ e finalmente obtêm-se a força da ponta sobre a amostra, conforme a segunda lei de Newton: 


$$
F=-k \Delta z
$$

onde da figura C1 se pode notar que a deflexão corresponde a três divisões na escala, de forma que $F=3,3(8) \mu N$.

A seguir será mostrada uma imagem obtida no modo de contato intermitente (figura F.2) mostrando claramente os canais gravados. A medida foi realizada com um ângulo de $45^{\circ}$ em relação à varredura feita por contato, principalmente para se ter a certeza de que a imagem observada não contenha artefatos.

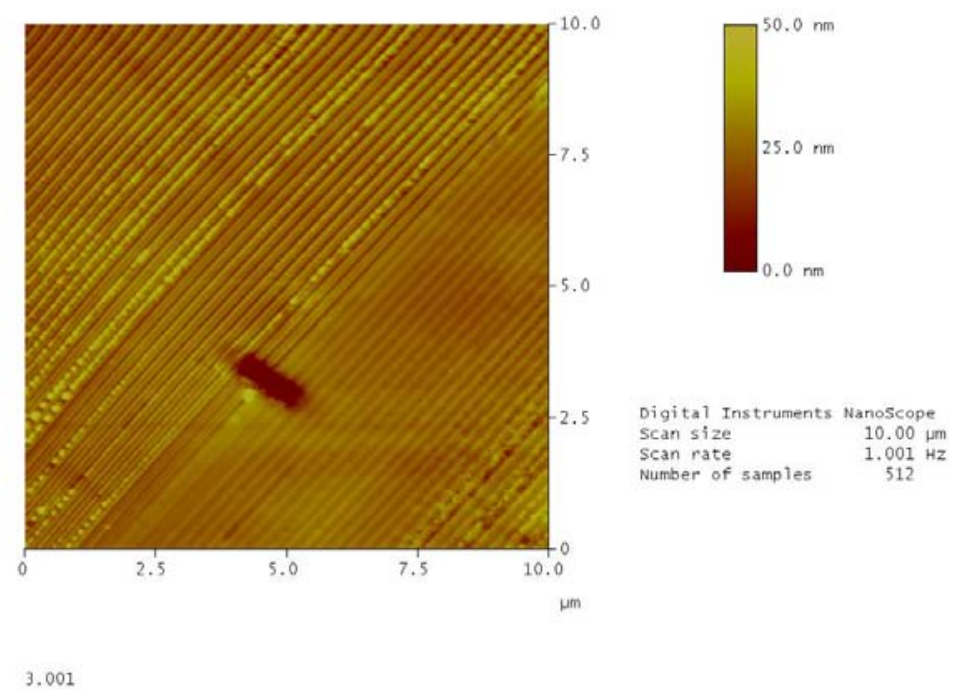

Figura F.2: Imagem por contato intermitente a $45^{\circ}$ da varredura de gravação dos canais mostrando o efeito de nanolitografia.

A imagem mostrada na figura E2 mostra claramente que os objetivos iniciais foram atingidos. Pelo menos à primeira vista, as ranhuras parecem ser periódicas e bem espaçadas. As figuras F.3 e F.4 mostram em detalhes as medidas das distâncias entre as linhas e a altura dos canais através da análise da vista lateral da imagem obtida. 


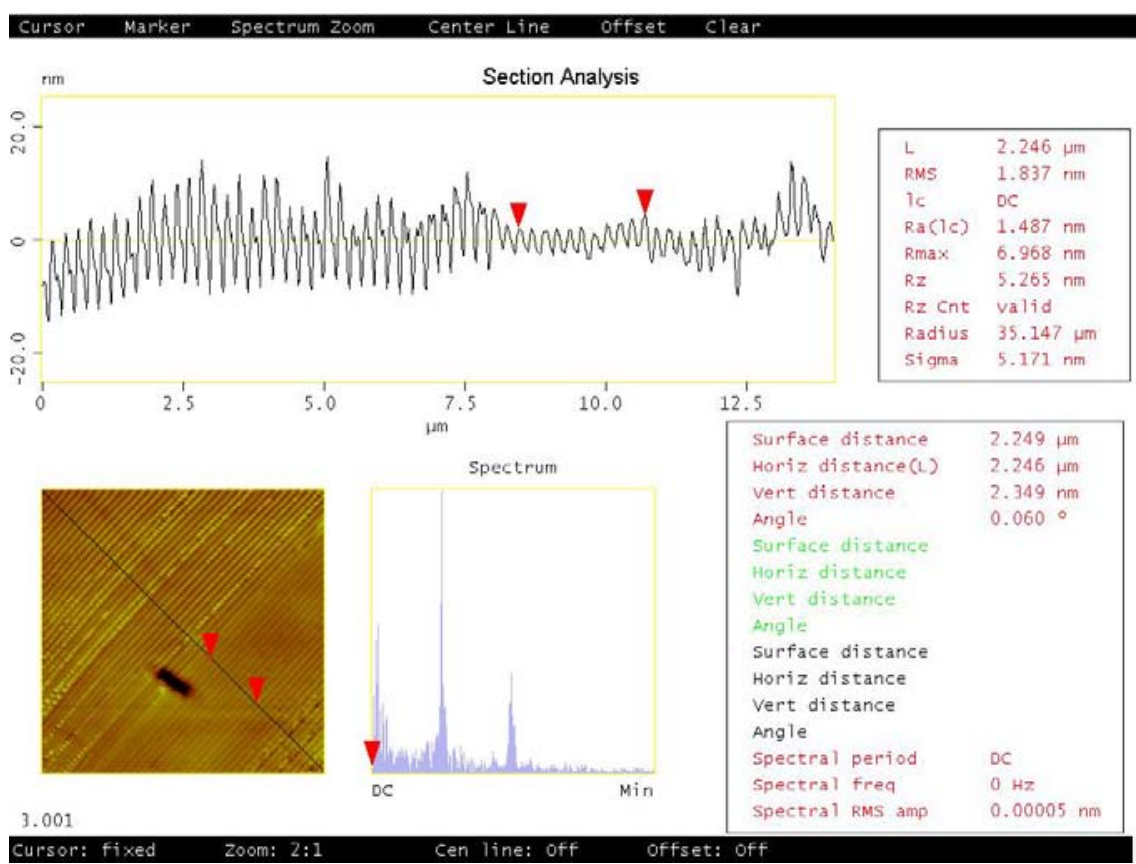

Figura F.3: Medida da distância para dez períodos fornece o valor médio de 224,6nm para um período.

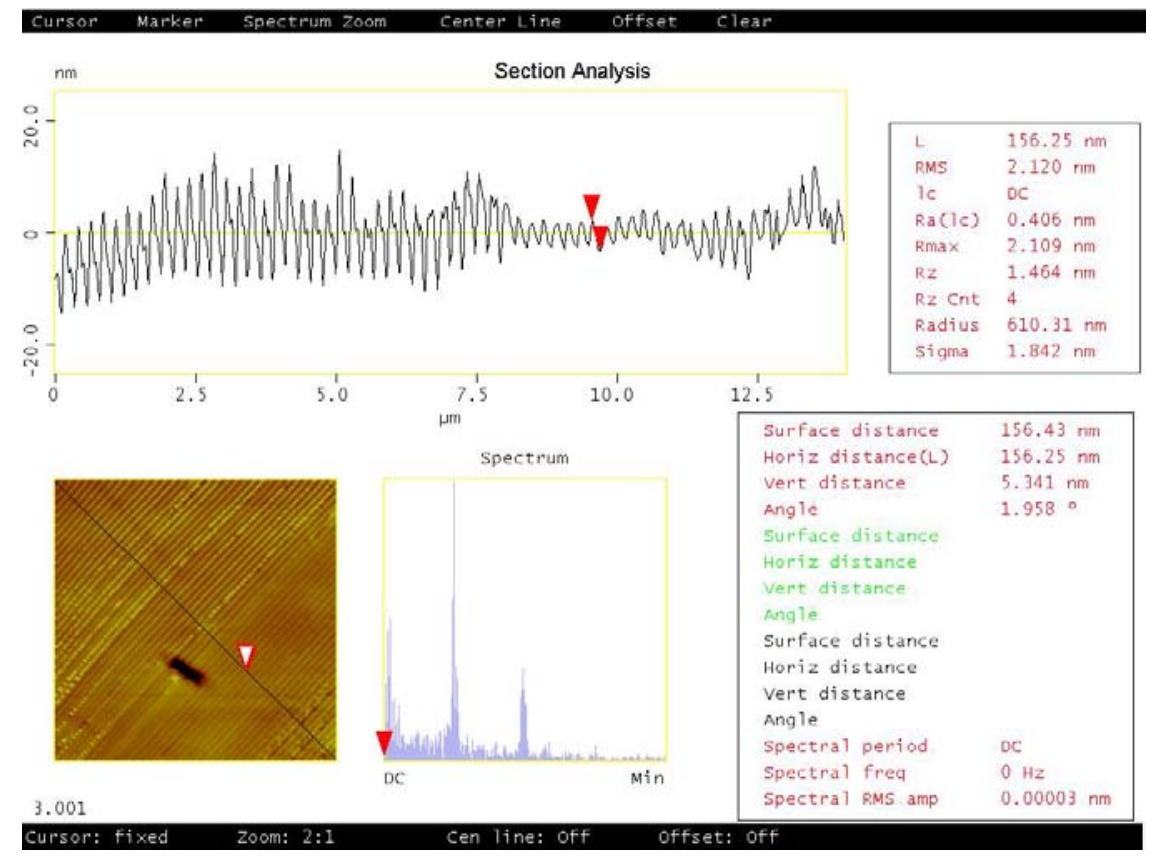

Figura F4: Distância vertical (altura) dos canais gravados. 


\section{$\underline{\text { Conclusões }}$}

Os resultados obtidos podem ser considerados excelentes para uma primeira tentativa de realização de nanolitografia em fotopolímeros. Em primeiro lugar, o valor da força encontrado $F=3,3$ (8) $\mu N$ é muito próximo do valor entrado na literatura (1,25 $\mu N$ ), sem considerar as incertezas envolvidas (estimada em cerca de 25\%) de uma forma mais sistemática. O valor médio do período encontrado foi $224,6 \mathrm{~nm}$ que é muito próximo do da estimativa feita anteriormente $(234,4 \mathrm{~nm})$ levando em conta o número de varreduras na área escolhida. A altura dos canais $(\sim 5 \mathrm{~nm})$ também atendem à necessidade, pois produzem uma energia de ancoramento compatível com o intuito de comparação com os canais gravados por fotoalinhamento. Adicionalmente, realizadas algumas gravuras adicionais seriam de extrema valia, pois deste modo poder-se variar o período de gravação dos canais mantendo fixa a profundidade, e desta forma controlar a intensidade de ancoramento de relevo por nanolitografia. 


\section{Referências}

A. A. Sonin, "The Surface Physics of Liquid Crystals", Gordon and Breach Pub., Luxemburg (1995);

A. Natansohn, P. Rochon, Chem. Rev. 102, 4139-4175(2002);

A. Natansohn, S. Xie, P. Rochon, Macromolecules 25, 5531 (1992);

A. P. Guwot-Sionnest, H. Hsiung and Y. R. Shen, Phys. Rev. Lett. 57, 2963 (1986);

A. Rastegar et. al, J. App. Phys. 89 (2), 960-964 (2001);

A. R. Blyte, "Electrical propertiees of polymers", Cambridge University Press, New York (1971);

A. Rapini and M. Papoular, J. Phys. (Paris), Colloq. 30, C4-54 (1969);

B. Lee, N. A. Clark, Science 291, 2576 (2001);

B. Zhang, F.K. Lee, O.K.C. Tsui, and P. Sheng, Phys. Rev. Lett. 91, 215501 (2003);

D.W. Berreman, Phys. Rev. Lett. 28, 1683 (1972). 
F. Batalioto, I.H. Bechtold, E.A. Oliveira and L. R. Evangelista, Phys. Rev. E 72, 031710 (2005);

F. M. Shimizu, D. Volpati, J. A. Giacometti, J. Sworakowski, K. Janus, E. Luboch, Journal of Applied Polymer Science 105, 130 (2007);

G. Arfken, Mathematical Methods for Physicists, 3rd ed. Academic Press, Orlando, FL: (1985);

G. S. Hartley, Nature 140, 281 (1937);

G. S. Hartley, J. Chem. Soc., p. 663 (1938);

I. D. Olenik, M. W. Kim, A. Rastegar and T. Rasing, Phys. Rev E 61, R3310 (2006);

I.H. Bechtold, M.P. de Santo, J.J. Bonvent, E.A. Oliveira, R. Barberi and T. Rasing, Liq. Cryst. 30, 591 (2003);

Ivan H. Bechtold, tese de doutorado, IFUSP (2006);

J. A. Castellano, Mol. Cryst. Liq. Cryst., 94, 33, (1983);

J. Cognard, Mol. Cryst. Liq. Cryst. 78, 1 (1982);

J. Israelachvili, ”Intermolecular and Surface Forces”, Academic Press, London (1991);

J. Kumar, L. Li, X. L. Jiang, D. Y. Kim, T. S. Lee, and S. K. Tripathy, Appl. Phys. Lett. 72, 2096 (1998); 
Jong-Hyun Kim, Makoto Yoneya, and Hiroshi Yokoyama, Nature 420, 159 (2002);

L. M. Blinov, A. Yu. Kabayenkov and A. A. Sonin, liquid Cristals 5, n 2, 645- (1989);

L. T. Thiegui, tese de doutorado, IFUSP (2004);

L.T. Thiegui, F. Batalioto, I.H. Bechtold, V. Zucolotto, D.T. Balogh, O.N. Oliveira Jr., L.R. Evangelista and E.A. Oliveira, Phys. Rev. E 74, 011802 (2006);

M. Schönhoff, M. Mertesdorf and M. Lösche, J. Phys. Chem. 100, 7558(1996);

M. Sheik-bahae, A. A, Said and E. W. van Stryland, IEEE J. Quant. Eletr. QE-27, 1296 (1991);

M. W. Gibbons, P. J. Shannon, S. T. Sun, B. J. Swetlin, Nature 351, 49 (1991);

M. W. Gibbons, T. Kosa, P. Palffy-Muhoray, P. J. Shannon \& S. T. Sun, Nature 477, 43 (1995);

N. Inoue, M. Nozue, O. Yamane, and S. Umegaki, J. Appl. Phys. 104, 023106 (2008)

O. K. C. Tsui et al, Phys. Rev Lett. 91(21), (2003);

P. G. de Gennes and J. Proust, "The Physics of Liquid Crystals”, Clarendon Press, Oxford (1993);

P. J. Collings and M.Hird, "Introduction to Liquid Crystals: Chemistry and Physics", Taylor and Francis, 1997; 
Peter Zijlstra, James W. M. Chon \& Min Gu, Nature 459, 410-413 (2009);

R. deSalvo, M. Sheik-Bahae, A. A. Said, D, J. Hagan and E. W. Van Stryland, Optical Letters 18(3), 194 (1993);

R. K. Meyer, R. E. Benner, Z. V. Vardeny, X. Wei, J. B. Lin and T. Barton, Mol. Cryst. Liq. Cryst, 256, 605 (1994);

S. G. Grubb, M. W. Kim, Th. Rasing and Y. R. Shen, Langmuir 4, 452 (1988);

S. Bian, L. Li, J Kumar, D. Y. Kim, J. Willians and S. K, Tripathy, Appl. Phys Lett 73(13), 1817 (1998);

T. Ushida, M. Ohgarawa, M. Wada, Jpn. J. Appl, Phys 19, 2127 (1980);

V. P. Vorflusev, H. S. Kitzerow and V. C. Chigrinov, Jpn. J. Appl. Phys. 34, part 2, 9A, L1137 (1995);

W. Chen, M. B. Feller and Y. R. Shen, Phys. Rev. Lett. 63, 2665 (1989);

X. L. Jiang, L. Li, J Kumar, . Y. Kim, and S. K, Tripathy, Appl. Phys Lett 72(20), 1817 (1998);

Z. Sekkat, J. Wood and W. Knoll, J. Phys. Chem. 99, 17226(1995); 